\author{
A Thesis \\ Presented to \\ The Faculty of California Polytechnic State University, \\ San Luis Obispo
}

\author{
In Partial Fulfilment \\ Of the Requirements for the Degree \\ Master of Science in Engineering, \\ With Specialization in Biomedical Engineering
}

By

Folorunso Ashaolu

December 2009 
(C) 2009

Folorunso Ashaolu

ALL RIGHT RESERVED

COMMITTEE MEMBERSHIP 
TITLE:

AUTHOR:

DATE SUBMITTED:

COMMITTEE CHAIR:

COMMITTEE MEMBER:

COMMITTEE MEMBER:
Measuring The Nanoindentation Properties Of

Alendronate-Time Treated Canine Cortical

Folorunso Ashaolu

October 2009

Lanny V. Griffin, PhD

Scott J. Hazelwood, PhD

Daniel W. Walsh, PhD 


\section{ABSTRACT \\ MEASURING THE NANOINDENTATION PROPERTIES OF ALENDRONATE-TIME TREATED CANINE CORTICAL}

Folorunso Ashaolu

This study examines the nanoindentation (energy inclusive) properties of $0.2 \mathrm{mg} / \mathrm{kg}$ alendronate treated ribs at one and three years against a vehicle treated control in a fresh-frozen, non-coldmounted, condition. This was to verify if the tissue-level properties for 0.2 ALN treated beagles would increase because of an increased level of mineralization despite a microdamage increase.

A total of twelve (12) skeletally mature (1-2 years old) female beagle dogs were treated daily for three years and one year with oral doses of vehicle (VEH, $1 \mathrm{~mL} / \mathrm{kg}$ saline) or alendronate (ALN, 0.2 Merck, Rahway, NJ). The $0.2 \mathrm{mg}$ dose corresponds, on a milligram per kilogram basis, to those used for treatment of postmenopausal osteoporosis. Transversely cut samples were ground and polished to $0.3 \mu \mathrm{m}$, and were then mounted while nanoindentation was performed. The data obtained were analyzed using two modes of diamond area functions: ideal function and general function. The statistical analysis for the data were carried out using a repeated measured ANOVA (SAS V 9.1, Cary NC.) with the measured and calculated mechanical property (elastic modulus or hardness) or energy property (elastic work or plastic work) as the dependent variable and treatment (control, 1 year or 3 years) modeled as the subject. Either Turkey-Kramer or Bonferroni method was used to compute the pair-wise difference. The results indicate that when compared to one year, the three years of alendronate medication for postmenopausal osteoporosis did not have any effect on the strength of the canine cortical bone, whereas this had effect on the hardness of the subjects. This increase in the medication time resulted in an increase in the elastic work but a decrease in the plastic work. The two methods (modes) of diamond area function analysed showed different mechanical properties (elastic modulus and hardness).

Keywords: alendronate, elastic modulus, hardness, elastic work, plastic work 


\section{ACKNOWLEDGEMENT}

I am using this opportunity to express my heartfelt appreciation for the effort and mentorship of Dr Lanny Griffin who had made the project an interesting and resourceful study for me. I find it hard to get out of my memory his thoughtful guidance which put me back on the right track during the laboratory work as well as the data and statistical analysis periods. Dr Griffin made the study environment conducive for me knowing that I needed such to succeed as a foreigner who was studying for the first time in this country. Million of thanks are continually echoed from me to you for making my coming to the University a meaningful one - acquiring such a great knowledge and skill. You shall always be remembered for your good works in my life.

Thanks to Dr. Hazelwood for his resourceful contributions during my literature collections. Those literatures and peer-reviewed papers came to me when I needed them most.

To my precious one - my wife - I cannot forget your strong support and encouragement during the study which enabled me to stay away from my four children leaving them in the care of such a reliable, virtuous, amiable and intelligent woman like you. I say without mincing words that you are wonderful, peculiar and indeed precious to my life! You are far more precious than jewels and your value is far above rubies or pearls (Prov. 31:10). Assuredly, you shall be dearly and forever compensated.

To my God and Lord, Jesus Christ, forever be all the glory and pride that may come from completing this study and for all that ha been of help to me in one way or the other.

Thanks to my brothers especially 'Dele Ashaolu and his wife for their encouragement. 


\section{TABLE OF CONTENTS}

$\begin{array}{lr} & \text { Page } \\ \text { LIST OF TABLES } & \text { ix } \\ \text { LIST OF FIGURES } & \mathrm{x} \\ \text { CHAPTER } & \\ \text { LIST OF FIGURES ........................................................................................... ix }\end{array}$

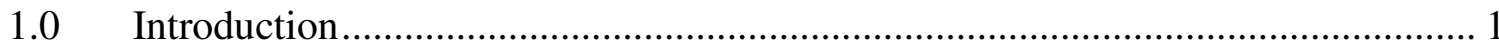

1.1 Bone Composition and Structure ................................................... 1

1.2 Bone Mechanical Properties and Fracture .................................... 4

1.3 Osteoporosis and Bone Fracture …................................................. 6

1.4 Bone Micro and Nanoindentation Techniques .................................. 7

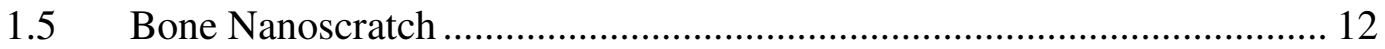

1.7 Bone Nanoindentation: Wet (mounted) and Dry Conditions ............ 16

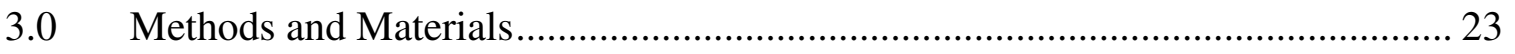

3.1 Nanoindentation Equipment: Functions (Wet/Dry) ........................ 24

3.2 The Nanoindentation System Descriptions \& Operation........................ 26

3.3 Sample Preparation and Microscopy …............................................... 28

3.4 Normal Nanoindentation Calibration.................................................. 32

3.5 Stub Modification and Sample Mounting ............................................ 35

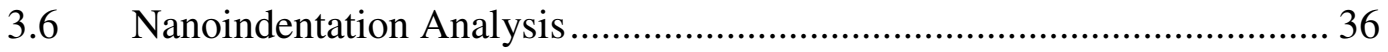


3.7 Nanoindentation Tests (Measurements) …........................................ 38

3.8 Indentation Parameter Selection ....................................................... 38

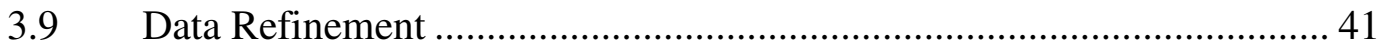

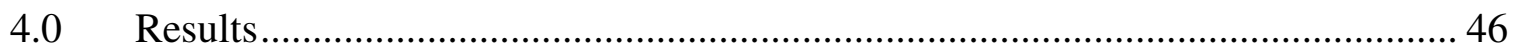

4.1 Data Analysis Definition: General and Ideal Functions................... 46

4.2 Optical Microscopic Evaluation .................................................. 48

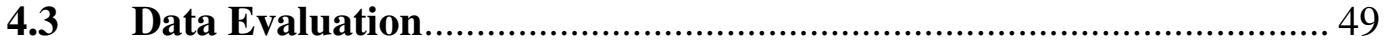

4.5 Ideal Function Elastic Modulus ................................................. 50

4.6 General-Function Elastic Modulus ............................................. 53

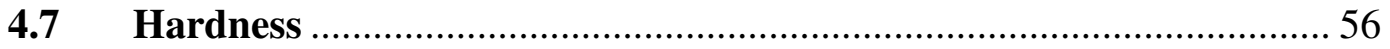

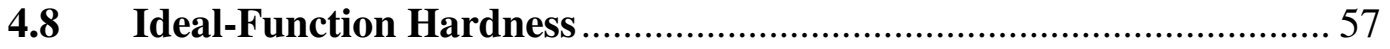

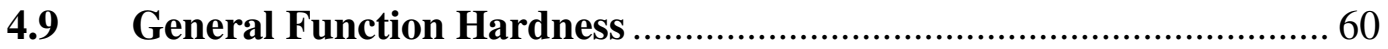

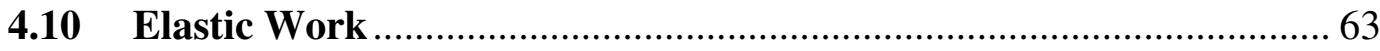

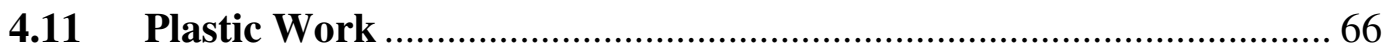

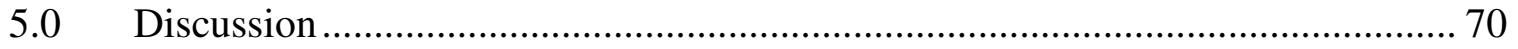

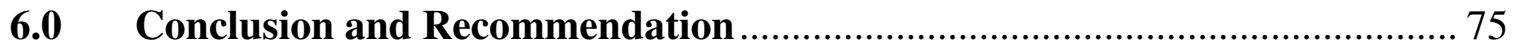

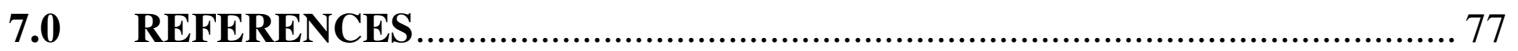

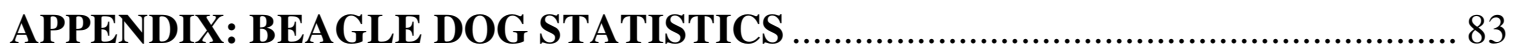




\section{LIST OF TABLES}

Table

3.1 Overview of Calibration Procedures for the NanoTest ${ }^{\mathrm{TM}}$ Indentation System

Error! Bookmark not defined.32

3.2 Properties and Parameter of the Indenter Used for Test

\section{.Error! Bookmark not defined.33}

3.3 Indentation schedule for Diamond Area

Function.............................Error! Bookmark not defined. 35

3.4 A typical effect of Load-Depth Termination Control on Indentation Results ..... 39

3.5 System Parameter and Specifications of Indentation Schedule/Definition .....

\section{Error! Bookmark not defined.40}

4.1 Typical effect of Thermal drift mode on the indentation results ...............44

4.2 Analysis definition for the indentation experiment pyramidal analysis .........47

4.3 General and ideal function values and parameter for the data analysis ..........47 


\section{LIST OF FIGURES}

Figure

Page

1.1 Sketch of a typical long bone showing key features [2]..... Error! Bookmark not defined.5

1.2 Load-deformation showing mechanical behavior of a femur shaft in compression load [2] Error! Bookmark not defined.7

1.3 Typical one-cycle indentation load-displacement curve showing loading and unloading, peak load $\left(\mathrm{P}_{\max }\right)$, maximum displacement $\left(\mathrm{h}_{\max }\right)$ and stiffness $(\mathrm{S})$.

Error! Bookmark not defined.11

1.4 A Schematic Drawing of a micro- and nanoindentation machine, showing microindenter head (1) and nanoindenter head (2). [25] .... Error! Bookmark not defined.15

1.5 Schematic Diagram of nanoscratch using a cube corner tip [26]. Error!

Bookmark not defined.17

1.6 Schematic Diagram of nanoscratch using Brinnel (ball) indenter [27]...... .....Error! Bookmark not defined.17

1.7 Force-displacement curves for treated and untreated bone fragility [4]....... Error! Bookmark not defined.22

3.1 NanoTestTM 1200 machine used for the nanoindentation tests. Error! Bookmark not defined. 27 
3.2 NanoTest control shelf for manual control boxes and mounted NTX Controller Error! Bookmark not defined.29

3.3 A typical sample before (a), and after (b) filling marrow spaces with wax... Error!

\section{Bookmark not defined.31}

3.4 Fabricated head raiser for Olympus TH3 microscope used. Error! Bookmark not defined. 32

3.5 Microscopic (topographical) view of a sample before (a) and after (b) 3 micron polishing . ......................................Error! Bookmark not defined. 33

3.6 Relationship between measure (total) compliance $(\mathrm{Ct})$, contact compliance $(\mathrm{C})$ and frame machine (Cf) compliance.........................Error! Bookmark not defined.36

3.7 The modified sample mounting technique adopted for the experiment ......... Error!

\section{Bookmark not defined.38}

3.8 Nanoindentation bridge box knobs used for the adjustment of the rectified output voltage Error! Bookmark not defined.37

$\begin{array}{lll}\text { Figure Page } & \text { Par }\end{array}$

3.9 Typical rejected indents due to: a) landing on Haversian canal b) landing on an artifact, c) technical problem and d) landing in wax-filled marrow canal.

Error! Bookmark not defined.42

3.10 A typical load-displacement graph of a rejected data showing: (a) too much lag on the displacement axis (the reason for rejection), (b) maximum load dwell (creep evidence) and (c) the thermal drift correction......Error! Bookmark not defined. 43

4.1 Microscopic view of typical accepted indents on a specimen showing the indenter tip impression and geometry 48 
4.2 Analysis Effect on elastic modulus in beagle dog ribs ....... Error! Bookmark not defined.50

4.3 1-year treatment effect on ideal-function elastic modulus in beagle dog ribs Error! Bookmark not defined.51

4.4 3-year treatment effect on ideal-function elastic modulus in beagle dog ribs Error! Bookmark not defined.54

4.5 Treatment Time effect on elastic modulus in beagle dog using ideal function analysis Error! Bookmark not defined.53

4.6 1-year treatment effect on general-function elastic modulus in beagle dogs. Error! Bookmark not defined.54

4.7 3-year treatment effect on general-function elastic modulus in beagle dog ribs Error! Bookmark not defined.55

4.8 Treatment Time effect on elastic modulus in beagle dog using general function analysis Error! Bookmark not defined.56

4.9 Analysis Effect on hardness in Beagle dog ribs.Error! Bookmark not defined.57

4.10 3-year treatment effect on ideal-function hardness in beagle dog ribs................ 58

4.11 1-year treatment effect on ideal-function hardness in beagle dog ribs................59

4.12 Treatment Time on hardness in beagle dog using ideal function analysis ..... Error! Bookmark not defined.60

4.13 3-year treatment effect on general-function hardness in beagle dog ribs....... Error!

\section{Bookmark not defined.61}


4.14 1-year treatment effect on general-function hardness in beagle dog ribs....... Error! Bookmark not defined.62

4.15 Treatment Time effect on hardness in beagle dog using general function analysis............................................................

4.16 1-year treatment effect on elastic work in beagle dog ribs... Error! Bookmark not defined.64

4.17 3-year treatment effect on elastic work in beagle dog ribs... Error! Bookmark not defined. 65

4.18 Treatment Time effect on elastic work in beagle dog........... Error! Bookmark not defined.66

4.19 1-year treatment effect on plastic work in beagle dog ribs... Error! Bookmark not defined.67

4.20 3-year treatment effect on plastic work in beagle dog ribs.................................. 68

4.21 Treatment Time effect on plastic work in beagle dog.......................................... 69 


\subsection{Introduction}

\subsection{Bone Composition and Structure}

Bone is a mineralized tissue with a primary structural function; its basic constituents are collagen fibers, mineral crystals and water. According to J.B. Park and R.S. Lakes, normal wet cortical bone is composed of $22 \%$ organic matrix [1]. The mineral constituents of bone are made up of nanoscale crystals of an apatite of calcium and phosphate that resembles hydroxyapatite in its crystal structure $-\left(\mathrm{Ca}_{10}\left(\mathrm{PO}_{4}\right)_{6}(\mathrm{OH})_{2}\right)[1]$. Hydroxyapatite crystals have been proven to be very stiff and brittle. However, a blend of this stiffness with the toughness and flexibility of collagen fiber produces the very strong and resilient mechanical properties in bone [2]. There are other mineral ions such as

citrate $\left(\mathrm{C}_{6} \mathrm{H}_{5} \mathrm{O}_{7}^{-4}\right)$, carbonate $\left(\mathrm{CO}_{3}^{-2}\right)$, fluorides $(\mathrm{F})$, and hydroxyl $\left(\mathrm{OH}^{-}\right)$which may yield some other subtle differences in microstructural features of the bone [1-3]. The collagen fibrils contain mineral arranged into lamellar sheets of 3-7 microns thickness that generally run helically with respect to the long axis of osteon - a cylindrical collagen fibril also called Haversian systems. The osteon is made up of 4-20 sheets wound concentrically around the Haversian canal and is typically 150-250 microns in diameter. The cement line clearly separates one osteon from the other. 


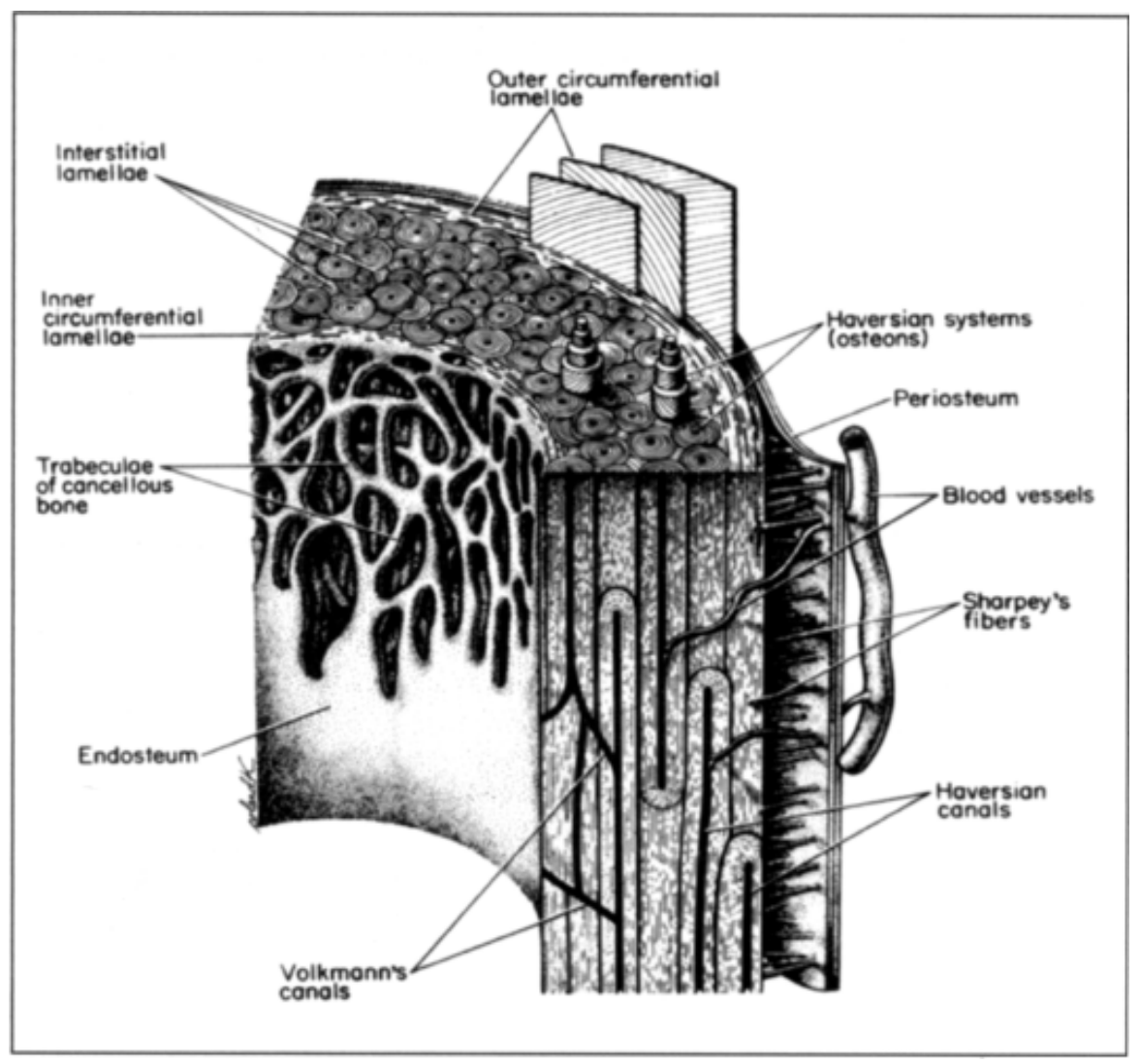

Figure 1.1: Sketch of a typical long bone showing key features [2].

Bone constituents, degree of organization, porosity and age are basic factors for the classification of bone tissue. Cortical bone has $5-10 \%$ porosity while trabecular, also known as spongy or cancellous bone, has $75-95 \%$ porosity [2]. Figure 1.1 shows some key physical features of a typical long bone [2]. The pore spaces help get metabolic substances transported through the communication pore systems called canaliculi, lacunae and Volkmann canals which connect with the marrow cavity and the Haversian canals $[1,2]$. The cortical bone is located in the cortices of long bone and is also known as compact and Haversian bone. Cortical bone is the major form present in the diaphysis of a long bone, while more spongy bone is found in the epiphysis of long bone and 
vertebrae[1]. Periosteum and endosteum refer to the external and the internal surface of the bone respectively, with both having ostoegenic properties [1].

The degree of organization of the microstructural tissue of a bone will determine whether it can be termed a lamellar or a woven bone. A lamellar bone is a highly organized but slowly arranged bone layer of a plywood-like structure that is comprised of mineral crystals and collagen fibers [2]. The woven bone, on the other hand, forms rapidly and is less organized; its rapid formation results in the poorer overall mechanical strength, though this is advantageous in fracture stabilization. The woven bone increases in cross sectional area and mineralization to compensate for mechanical inadequacy by increasing the stiffness, though overall it is still weaker than lamellar bone [2]. Fine-fibered bone tissue, as found in small animals like rats and mice, do not have a well pronounced structural difference. The tissue appears more organized than bigger animal woven bone because their smaller collagen fibers are closely packed [2].

Primary and secondary bones are terms used to classify cortical bone based on the state of remodeling. A primary bone is the originally existing bone tissue formed on the surface of periosteum at the growing (juvenile) stage as the bone responds to blood vessel and nerves organization, during modeling. Adults do not have much primary bone due to frequent bone turnover [2]. Secondary bone, also known as mature bone, is formed from the primary bone that has undergone remodeling. This remodeling can occur in both compact and trabecular bone. This forms secondary osteon lamellae wound around a Haversian canal while a cement line marks concentric boundary lamellae of the osteon. 


\subsection{Bone Mechanical Properties and Fracture}

Over the years, engineers have developed load-deformation tests to determine how structural members, such as a beam in a bridge or the femur shaft, will behave or respond when subjected to a controlled load. Many mechanical properties of any structure can be deduced from a graph generated from the load-deformation test result.

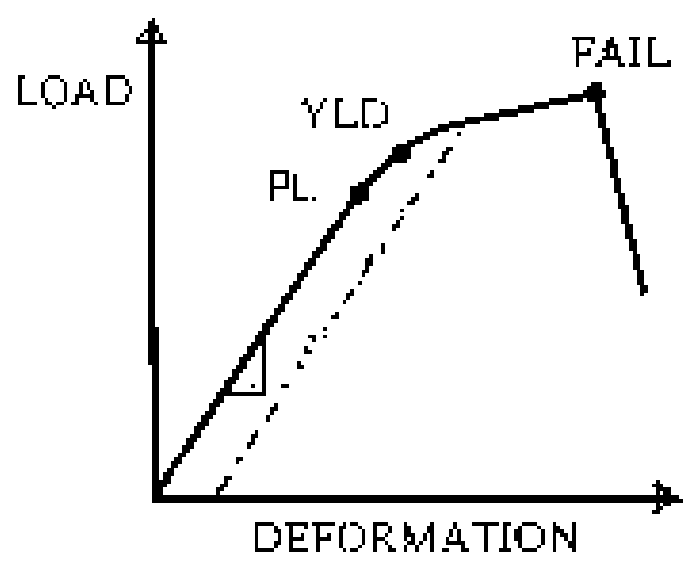

Figure 1.2: Load-deformation showing mechanical behavior of a femur shaft in compression load [2]

Figure 1.2 shows a test result for a femur shaft loaded in compression. From this figure, the relationship between the load and deformation is linear for some time (elastic period) until a limit is reached, called elastic limit or limit of proportionality, PL where the straight line begins to bend. After this point the curve slope is reduced such that even after unloading the structure, it is already permanently deformed. This point at which the bone begins to deform plastically is known as yield point, YLD. Before the yield point, if the bone is unloaded, it will return back to its original shape, meaning that the deformation is elastic. There may be failure (or fracture) whenever a loading of a material (bone inclusive) reaches its ultimate strength. This point is the failure or fracture point. Cortical bone unlike some ductile metals, has the same ultimate and failure 
strength [2]. Bone strength, a mechanical property, may be defined as the load at the yield, failure, or ultimate load, depending on the prevalent situation.

Bone could be termed rigid or stiff depending on whether it deforms under a specified or given amount of load. So, stiffness or rigidity of bone can be determined from the slope of the load-deformation curve measured within the proportionality range, where it is constant. Compliance is the inverse of stiffness and explains the ease with which a bone could be deformed. The highest load obtained before fracture corresponds to the ultimate strength while the area under the curve represents the energy absorbed, otherwise known as toughness. Thus, these ideas help to understand the reason for any bone failure both from macro to submicron level. They also assist in the selection of appropriate bone implant materials and prostheses design. The mechanical behavior of bone is a function of such factors as moisture content (dry or wet), age, mineralization, type of load (compressive or tensile), loading rate and the direction of the applied load with respect to the orientation of the microstructure [1,2]. For example, an increased rate of loading will result in corresponding increase in the elastic modulus, ultimate compressive and yield strength. There is no critical rate of loading for human cortical bone [1]. Some mechanisms help to reduce bone fragility and these include: increase bone mass: larger bone carry more load, distribute bone mass effectively, put bone tissue where mechanical needs are greatest and improve the material properties of bone tissue such that the bone is stronger at a tissue level $[2,4]$. A well mineralized bone has the best combination of stiffness and brittleness while a poorly mineralized bone is brittle and hypermineralized bone is more fragile [4]. Work-to-failure (toughness) appears to reduce as the bone 
becomes more highly mineralized [5]. Turner, 1993, measured mechanical strength of bone in different part of the skeleton, subjecting them to different forms of load: vertebral body or proximal tibia - compression; long bones such as tibia, femur or humerus - three- or four-point bending test; and femoral neck - shear test [6]. Bone type and orientation are primary factors that determine the bone elastic modulus and hardness. Bone indented in the load-bearing direction has a greater elastic modulus than same bone in the circumferential or transverse direction [7]. Thick lamellae have a higher elastic modulus at low indentation depths and a decrease in the indentation modulus as the depth increases [8]. Nanoindentation has been developed to identify mechanical behavior of hard thin films, small volumes and small microstructural features, such as bone lamellar [9]

\subsection{Osteoporosis and Bone Fracture}

Osteoporosis is the most common of all bones diseases found in adults, especially the aged and particularly in postmenopausal women $[3,10]$. It is characterized by bone loss and alteration of the micro-architecture which results in increased bone fragility. Some of the common causes of osteoporosis are: lack of physical stress on the bone because of inactivity; malnutrition to the extent that sufficient protein matrix cannot be formed and lack of calcium and protein, which is necessary for the formation of osteoid by the osteoblast; abnormalities of vitamin D and calcitonin metabolism $[3,10]$. Others causes are: postmenopausal lack of estrogen secretion due to smoking; old age in which the growth hormone and other growth factors have diminished greatly and Cushing's disease which ultimately depresses osteoblastic activity [3]. Burge et al, predicted the population 
and costs of incident osteoporotic-related fractures in the US by 2025 as over 3 million and $\$ 25$ billion respectively [11]. Osteoporosis has been associated with high morbidity and increased mortality and considered worldwide to be a major health problem [12]. Li and Aspden found 17\% loss of cancellous bone volume in osteoporotic human femoral heads [13]. Another study shows that an osteoporotic subchondral bone has elastic modulus and hardness of $9.66 \pm 0.78 \mathrm{GPa}$ and $45.2 \pm 4.9 \mathrm{VHN}$ respectively [14]. Other problems that cause bone fracture are: falls, due to loss of balance, inappropriate protective responses, or muscle weakness [15]. This suggests that any of these problems could complicate osteoporotic-related fracture.

\subsection{Bone Micro and Nanoindentation Techniques}

Microindentation is over the decades used to describe the hardness of bone tissue. Further steps have been advanced through nanoindentation techniques which measure indentation load at such a low resolution as $0.3 \mu \mathrm{N}$ and displacement at $0.16 \mathrm{~nm}$, which are lower scale (more finite) compared to microindentation [16]. The most distinguishing difference between microindentation technique and nanoindentation technique is that nanoindentation (by depth sensing) indirectly measures the area of contact between the indenter and specimen whereas, in microindentation, the area of contact is directly calculated from the optical measurements of the dimensions (areas) of the residual impression left in the specimen upon removal of the load. Hence, in nanoindentation, the measured depth penetration of the indenter and known indenter geometry data help to calculate the required contact area [17]. In their study, Oliver and Pharr [16] used a Berkovich tip tool and arrived at the relationship between contact stiffness which is the 
slope of the upper portion of the unloading curve $(\mathrm{dP} / \mathrm{dh})$ and elastic properties of the material sample.

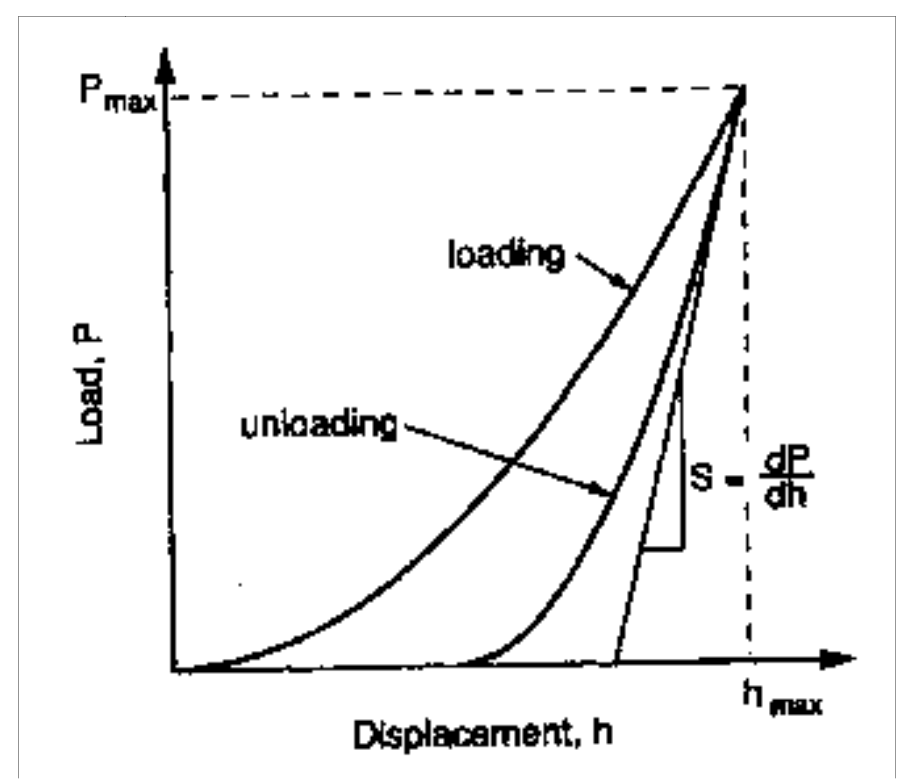

Figure 1.3: Typical one-cycle indentation load-displacement curve showing loading and unloading, peak load $\left(\mathrm{P}_{\max }\right)$, maximum displacement $\left(\mathrm{h}_{\max }\right)$ and stiffness $(\mathrm{S})$.

Equation 1.1 shows this elastic relationship between the material and the tool tip during indentation as depicted in the force-displacement curve in Figure 1.3. Rearranging Equation 1.1, this gives Equation 1.2 which is generally used today for calculating the indentation (reduced) modulus of any material:

$$
S=\frac{d P}{d \boldsymbol{h}}=\beta \frac{\mathbf{2}}{\sqrt{\pi}} \sqrt{A} E_{r},
$$

Making $E_{\mathrm{r}}$ the subject of the equation yields, 
$E_{p}=\left(\frac{\sqrt{\pi}}{2 \beta}\right)\left(\frac{S}{\sqrt{A_{\sigma}}}\right)$

where:

$\mathrm{S}=$ contact stiffness - measure at the early stage of unloading- $(\mathrm{mN} / \mu \mathrm{m})$

$P=$ applied load $(\mathrm{mN}$ or $\mu \mathrm{N})$

$h=$ elastic displacement $(\mu \mathrm{m}$ or $\mathrm{nm})$,

$\beta=$ empirical indenter correction factor, $(=1.034$ for Berkovich $)$,

$E_{\mathrm{r}}=$ reduced modulus, $(\mathrm{GPa})$

$A_{c}=$ diamond contact area at $\mathrm{h}_{\max },\left(\mathrm{nm}^{2}\right)$ determined by Oliver and Pharr-derived

procedure [16].

The sample compliance, which is the reciprocal of stiffness, can also be related to reduced modulus (indentation modulus) and the diamond tool contact area as seen in

Equation 1.3.

$C_{s}=\frac{\sqrt{\pi}}{2 E \sqrt{A_{g}}}$

where $C_{s}=$ the contact compliance

Equation 1.4 shows that knowing Poisson ratio and reduced modulus of a material, as well as knowing both the modulus of elasticity and the Poisson ratio of tool tip will help to determine the Young's modulus of the material 


$$
\frac{1}{E_{r}}=\frac{\left(1-v_{s}^{2}\right)}{E_{s}}+\frac{\left(1-v_{i}^{2}\right)}{E_{i}}
$$

Rearranging Equation 1.4 yields Equation 1.5:

$$
E_{S}=\frac{\left(1-v_{s}^{2}\right)}{\frac{1}{E_{r}}-\left(\frac{1-v_{i}^{2}}{E_{i}}\right)}
$$

where:

$E=$ Elastic modulus, $\left(E_{\text {Diamond tip }}=1140 \mathrm{GPa}\right)$

$v=$ known Poisson ratio, $\left(0.3 \leq v_{\text {Bone }} \leq 0.4[8,18]\right.$, and $\left.v_{\text {Diamond }}=0.07\right)$

The subscripts $i$ and $s$ refer to the indenter tip and sample respectively.

Indentation hardness is another mechanical property of material which is defined as the mean pressure a material will support when it is subjected to load [16]. It measures the resistance of the probed material to plastic (permanent) deformation which is caused by impact of an infinitely hard material (commonly diamond). This is mathematically expressed in Equation 1.6

$H=\frac{P_{\max }}{A_{\sigma}}$,

$\mathrm{H}=$ hardness $(\mathrm{MPa}$ or $\mathrm{GPa}$ or $\mathrm{VHN})$;

$P_{\max }=$ maximum load (force) applied $(\mathrm{mN}$ or $\mu \mathrm{N})$;

$A_{c}=$ contact area of indenter with sample surface at maximum load $\left(\mathrm{nm}^{2}\right.$ or $\left.\mu \mathrm{m}^{2}\right)$.

Several factors may affect the results obtained from indentation and these include:

environmental condition, indenter shape, surface roughness, specimen preparation, and offsets in depth measurements. Nanoindentation experiment sometimes exhibits creeps 
and thermal drift behaviors which are significant in result analysis. Creep is exhibited when there is an observed change in the depth at a constant load, while thermal drift involves change in the depth at a constant load as a result of material thermal expansion and contraction [17]. Thus, load-displacement sensing indentation instrument can be used to determine the intrinsic mechanical behavior of bone from macro to sub micron level [19]. Bone, a biological tissue, is such a complex material that varies in mechanical property when load varies between low and high [19]. The use of nanoindentation technique allows bone measurement to approach a collagen-hydroxyapatite compound scale, and eliminate the defect effect on the measured properties [19]. Nanoindentation probe is also useful in characterizing the elastic properties of bone fracture callus [20].

Average Young's modulus of normal bone under low load (nanoindentation) and high load (microindentation) are 17.5 GPa and 12.2 GPa respectively [21]. The stiffness of trabecular bone measured by microindentation is approximately four times less than that measured by a nanoindentation [19]. The indentation moduli of compact bone and trabecular bone are 18.0 $\pm 1.7 \mathrm{GPa}$ and $22.5 \pm 3.1 \mathrm{GPa}$ respectively [22] while an earlier

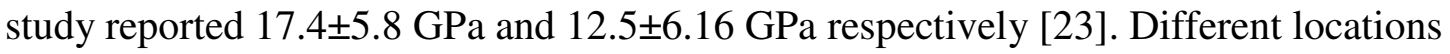
within same bone type (cortical or trabecular) may have different elastic modulus and hardness because of the difference in mineral content at those locations [22]. Recently, Franzoso and Zysset developed a method to estimate the orthotropic stiffness tensors of human cortical bone osteons. They used nanoindentation measurements to quantify the elastic properties of various osteons from human femoral shaft, and compared it to those of compact bone at macro-level. The anisotropy ratios (Lateral modulus to longitudinal 
modulus) of the tested secondary osteons vary within the same bone [24]. Equipment has been developed to incorporate both micro and nanoindentation features which enable researchers make a choice between the two techniques as shown in Figure 1.4 [25]

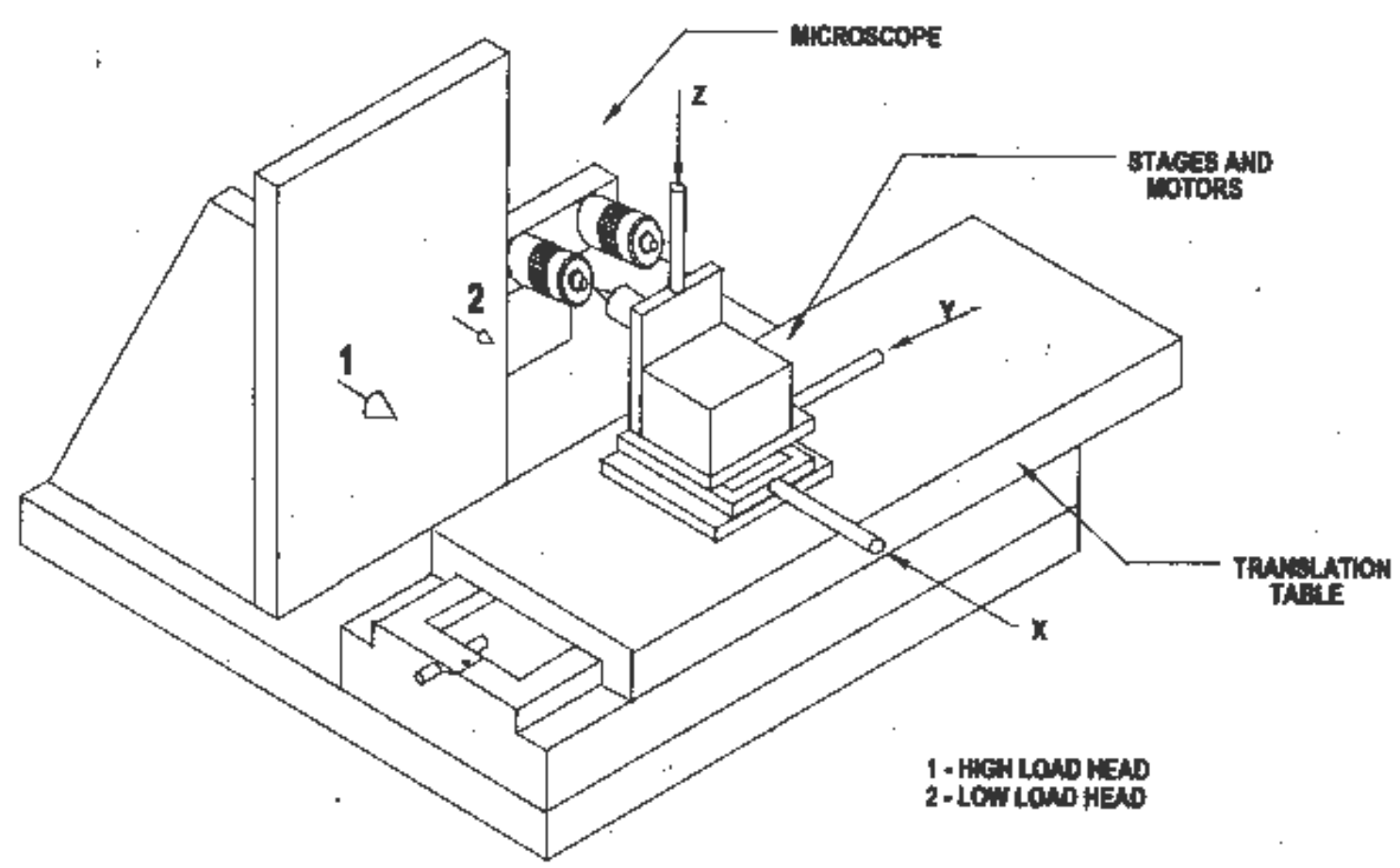

Figure 1.4: A Schematic Drawing of a micro- and nanoindentation machine, showing microindenter head (1) and nanoindenter head (2). [25]

Strict adherence to the instruction manual as outlined by the manufacturer has been strongly recommended so that the machine can produce reasonable result.

\subsection{Bone Nanoscratch}

A scratch test is characterized by a combination of indentation and cutting processes simultaneously. Scratch groove is generated partially by tissue removal while the toughness of the bone could be estimated by removal energy consumed during the scratch 
test [27]. Recent progress in nanotechnology has made possible a nanoscratch technique to comparatively assess the toughness of bone at submicron level [26]. Bone as a quasibrittle material may be removed by scratching upon failure. So, the energy required to form the scratch groove can be calculated from Equation 1.7:

$W=\int_{-n}^{L_{z}} F_{f} d x$

where:

$W=$ the work done to form to form scratch groove $\mathrm{mJ}$

$F_{f}=$ lateral scratch force $\mathrm{mN}$;

$L_{s}=$ scratch length $\mu \mathrm{m}$

Then the total energy density for scratch groove formation or scratch toughness $\left(U_{\mathrm{s}}\right)$ could be estimated from Equation 1.8:

$$
U_{s}=\frac{W}{V_{s}}
$$

where:

$U_{s}=$ scratch toughness;

$V_{\mathrm{s}}=$ groove volume estimated from the cross sectional area $A_{s}$ and $L_{s}$ of the scratch groove $\left(\mathrm{nm}^{3}\right)$;

Wang and Ji investigated the local tissue toughness of secondary osteons in human cortical bone and reported that aging had a significant effect on the local scratch toughness $\left(U_{\mathrm{s}}\right)$, scratch resistance and scratch groove geometry of the osteons and that 
the scratch orientation has little effect on the scratch properties [26]. Figures 1.5 and 1.6 show schematic diagrams of two different scratch grooves produced by a cube corner tip and Brinnel (ball) indenter geometries respectively [26, 27].

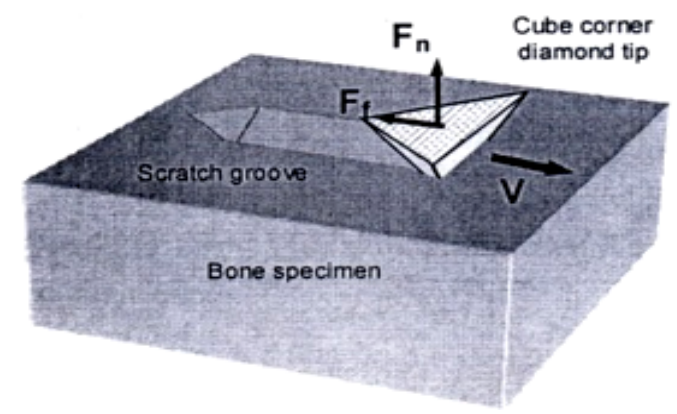

Figure 1.5: Schematic Diagram of nanoscratch using a cube corner tip [26].

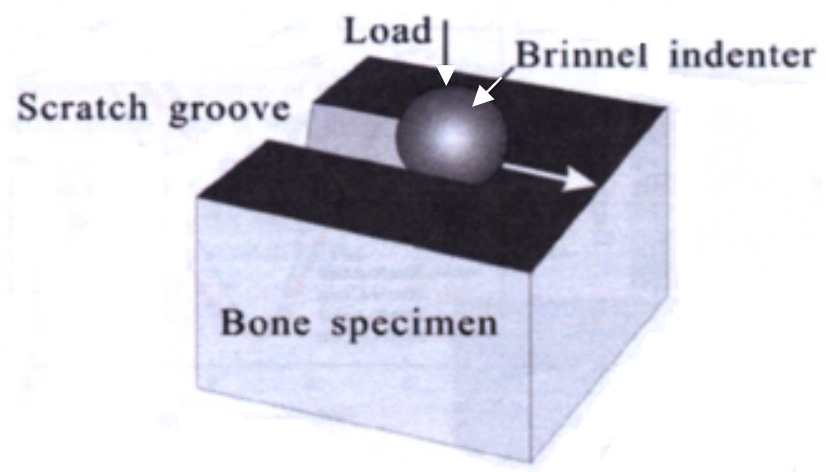

Figure 1.6: Schematic Diagram of nanoscratch using Brinnel (ball) indenter [27].

Age-related differences in the nanoscratch behavior of secondary osteons diminish upon dehydration [26]. A scraping technique based on atomic force microscopy (AFM) nanoindentation was recently developed that can dislocate parts of the outer layer of a specimen. Gao, et al. used nanoscratch test to study wear resistance of mandible cortical bone in three directions. They reported a better wear resistance in axial (parallel with osteon and perpendicular to osteon) section than that of cross section due to lamellae 
arrangement [27]. As the applied scratch load increases, the wear mechanisms of cortical bone becomes more complicated [27].

\subsection{Atomic Force Microscopy (AFM)}

The coefficient of friction (COF) which is the ratio of the tangential force to normal force, is a function of bone surface roughness achieved during the surface polishing [27]. The surface roughness of bone lamellae has a significant effect on the indentation modulus of its extra cellular matrix [8].

Atomic force microscopy and nanoindentation characterize surface topography, microstructure, and micromechanical properties of human bone matrix [8, 27]. Two methods of lamellar bone surface preparation were experimented by $\mathrm{Xu}$, et al.: microtome sectioning and mechanical polishing [28]. Mechanical polishing of bone lamellae surfaces resulted in approximately 200nm depression on thin lamellar, whereas the surfaces prepared by microtome sectioning were flat [28]. Bone surface topography measured on nanoscale affect the elastic modulus of osteoblastic cell and may be used with the bone chemistry to alter the response of cells to external mechanical stimuli [29]. Turner et al. used nanoindentation and acoustic microscopy techniques to measure Young's moduli of cortical bone. They compare their results and reported that cortical bone determined by nanoindentation has mean average anisotropy ratio (Lateral modulus to longitudinal modulus) similar to that determined by the acoustic microscope.[30]

AFM tip manipulation has been used to nanodissect individual collagen fibrils to expose them and analyze their internal structure without causing much structural damage [31]. 


\subsection{Bone Nanoindentation: Wet (mounted) and Dry Conditions}

Both micro and nanoindentation probes have revealed that mechanical behavior of bone changes under different moisture content [32-36]. A foam-hydrated soft tissue sample maintained its mass over 8 hours while the mass of the sample that was not hydrated decreased by $80 \%$. A bone hardness property is a function of several environmental conditions during storage preparation and testing [32]. Therefore efforts should be made as much as possible to maintain the integrity of bone as harvested. Rewetted dried bone has mechanical properties close to that of physiological condition $[33,36]$. Both hardness and the elastic modulus of dry bone are higher in magnitude compared to wet bone $[8,34$, 35]. Rho et al studied and reported that, in both dry and wet conditions, the elastic moduli and hardness of interstitial lamellae are significantly higher than those of osteons[23, 34].

Some authors have earlier used nanoindentation probes to examine bone properties and studied the effect of such bone factors as age, microstructure, lamellae orientation, drying anatomical location and compared compact to trabecular bone. Reilly and Burstein reported a Young's modulus of $17.9 \mathrm{GPa}$ for large wet femoral cortical specimens in the longitudinal direction and $10.1 \mathrm{GPa}$ in the transverse direction [37]. A study on buckling of single lamellae, reported an increase in the elastic modulus due to $24 \%$ drying and general change in the specimen deformation mode (ductile-wet to brittle-dry) [35]. 


\subsection{Nanoindentation and Biphosphonate (Alendronate) Therapy}

Investigation started in the 1960s into the medical use of Biphosphonates for correction of bone metabolism disorder [38, 39]. In the 1990s, studies began to demonstrate the actual mechanism of action of this drug [38]. There are two classes of Biphosphonate and they adopt different mechanisms in killing the osteoclast cells: the nitrogenous and non-nitrogenous biphosphonates. Alendronate and risedronate - two examples of $\mathrm{N}$ containing biphosphonates - are the most popular first-line drugs for treating and preventing high osteoporosis in postmenopausal women; treating glucocorticoid-induced osteoporosis in men and women; and treating Paget's diseases of bone [40]. Biphosphonates are well known for treating adult bone fragility and bone diseases such as osteoporosis which is the characteristic of bone loss. Biphosphonates bind to the bone surfaces and inhibit osteoclast action, thereby preventing the breakdown of bone [41]. The drugs achieve the repair by acting as antiresorptive agents, and increasing the bone mineral content and bone mechanical strength [42]. Ammann and Rizzoli in their study recommended the use of nanoindentation to probe into the quality of bone in order to have a better understanding of the mechanism by which osteoporosis treatments could improve bone strength [12]. Wang et al. researched into biphosphonate therapy effect on the elastic modulus and hardness of a cancellous bone and reported no significant difference between alendronate and risedronate [43]. Bovin et al. used microradiography on alendronate-treated osteoporotic women bone to determine the mean degree of mineralization of bone and bone mineral densities which are important factors in determining strength and quality of bone. They reported that in post menopausal 
osteoporotic bone, the mean degree of mineralization of bone tissue will increase due to alendronate therapy [44].

Several studies showed the effects of biphosphonate and dosages on the structure of bone under different operating conditions. Alendronate, depending on dosage, significantly reduces the bone turnover rate without complete suppression, though at any dose [45]. Suppression of bone resorption by alendronate drug could lead to cumulative effect over time [46]. Odvina et al. reported that prolonged alendronate treatment can potentially cause severely suppressed bone turnover and result to poor-to-heal nonspinal fractures [46]. Continuously administered biphosphonate drug even at a possibly clinical dose could delay callus remodeling and may further delay reconstruction of bone structure [47]. Although biphosphonate is generally known as a drug that improves structural properties of bone, it however reduces the elastic modulus of developing bone by deteriorating the bone quality and bone microstructure [48]. Li et al. used a three-point bending test to determine the effect of incadronate on the fracture healing of a rat limbs [47]. They reported that, biphosphonate treatment at clinical dose will not disturb the fracture healing process in non-aged bone if the treatment is stopped when fracture occurs [48].

There are several available options for biphosphonate dosing and these include: daily, weekly, twice monthly or once monthly [40]. Wang et al. studied the effect of alendronate treatment on the material properties of cancellous bone of beagle dogs that were treated daily for one year. [43] They compared the material properties obtained 
through three methods: Oliver-Pharr, Continuous Stiffness Measurement, and the MohrCoulomb FE model (their newly developed one). They concluded that nanoindentation modulus and hardness determined by Oliver-Pharr method can be associated with a modulus and a set of Mohr-Coulomb material parameters that are useful in finite element analysis [43]. The finite element analysis showed that biphosphonate drug increases bone hardness by increasing the tissue modulus and cohesion - a Mohr-Coulomb material parameter [43]. The nanoindentation test however adopted displacement controlled procedure with as low as 500nm maximum termination depth. Amanat et al. administered $0.1 \mathrm{mg} / \mathrm{kg}$ dose of zoledronic acid to fracture femoral diaphsis of a rat at selected time point and reported little variation in the elastic modulus and hardness of the three tested regions of the bone [49]. Figure 4 shows that when bone fragility, osteoporosis or any bone disease is treated with ideal biphosphonate dosage, the bone strength (the force at failure) would increase while the brittleness decreases by increasing the displacement [4].

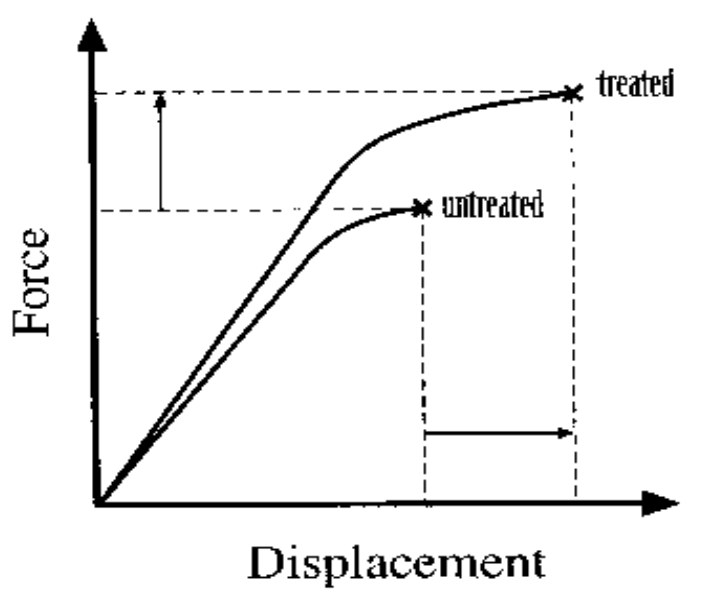

Figure 1.7: Force-displacement curves for treated and untreated bone fragility [4]. 


\begin{abstract}
Almost all the previous indentation studies were carried out with a considerably very low number of indents on each sample, the results of which appear not to represent the actual properties of the tested sample due to low size of indents.
\end{abstract}




\subsection{Research Objectives and Hypothesis}

\section{Objectives}

This research project is aimed at using nanoindentation to determine how alendronate therapy affects the elastic modulus and hardness of beagle dog ribs using the two different modes of data analysis found in the instrument software. Clear understanding of the structural performance of alendronate-treated ribs under different dosage and techniques of analysis could help predict the right dosage administration for osteoporotic patients, and also arrive at a better analysis method for testing for the mechanical properties of bone.

As earlier discussed in 1.1, nanoindentation technique has been used to probe into intrinsic mechanical properties of different bone classes, and some authors have further researched into the effect of alendronate medication on the bone strength. The shortness of the duration of medication suggests that the adequacy of the data and results obtained in previous studies might demand a second thought. Hence the results reported may not be sufficient enough to better represent how a bone would react mechanically to loading when treated with alendronate long term. Some other reviewed literatures have shown studies done on mechanical effects of various dosages of biphosphonate (alendronate) in treating bone loss and fracture appear not to represent ideal performance of treated bone because of the small sample size experimented. At best, the few authors with larger sample sizes adopted only one single data analysis method and, that with restricted 
indentation parameters such as termination depth and/or load. The nanoindentation of alendronate-treated bone using two different analysis modes of the diamond area function hopes to better elucidate how a long term biphosphonate (alendronate) treatment and relatively larger termination depth could affect the mechanical strength of osteoporotic bone.

\section{Hypothesis}

The research hypotheses for this study are stated as follows:

1. The strength and stiffness of alendronate-treated beagle dog increases due to an increase in mineralization.

2. Long-term biphosphonate treatment in osteoporosis healing may not adversely affect the intrinsic mechanical properties of canine cortical bone.

3. The use of ideal (default) function of an instrument diamond area mode for data analysis may produce lower strength and stiffness values of bone over the general function method of analysis. 


\subsection{Methods and Materials}

The machine used for the nanoindentation experiments was a Nanotest manufactured by Micromaterials Limited UK. This equipment is a fully flexible, multi-task nanomechanical property measurement system that has three separate modules (indentation, scanning and impact) which can be used in conjunction with the low load head (0.1-500 $\mathrm{mN})$ or the high load "Micro Test" head (0.1-20 N)[50]. After necessary calibration, it is capable of making as many indents as possible on material (bone inclusive) samples following the preset schedule. Features, accessories and various calibrations of this machine are discussed in detail below. The sample stub was modified to hold the sample on a plate rather than direct gluing to the plate.

The twelve fresh $10^{\text {th }}$ and $11^{\text {th }}$ left ribs of a beagle dog were obtained from Indianapolis University, Purdue University Indiana. All procedures were approved by the Indiana University School of Medicine Animal Care and Use Committee. Female beagles (1-2 years old, $n=12$ ) were confirmed to be skeletally mature (closed proximal tibia and lumbar vertebral growth plates on X-ray) prior to the start of the study. Animals were treated daily for 3 years with oral doses of vehicle (VEH, $1 \mathrm{~mL} / \mathrm{kg}$ saline) or alendronate (ALN, 0.2 Merck, Rahway, NJ). The $0.2 \mathrm{mg}$ dose corresponds, on a milligram per kilogram basis, to those used for treatment of postmenopausal osteoporosis.

These samples were labeled as follows: 59210, 59230, 59234, 59256, 59257 and 59258 for the 10th ribs; and 3919340, 3929370, 3936881, 3961630, 3962253 and 3976441 for the $11^{\text {th }}$ ribs. The age and treatment (dosage) of these beagle dogs were blinded with code 
throughout the experimentation and data refining. The code was later broken during the statistical analysis of the system-generated data. Except when in use, the samples always remained wrapped in $0.09 \%$ saline solution-soaked gauze and at a time stored at room temperature for 24 hours, and at most time in a laboratory sub-zero chest freezer at -20 ${ }^{\circ} \mathrm{C}$.

The detailed processes and procedures involved in the preparation and nanoindentation of the sample are described below. These processes include: cleaning, cutting, marrow filling, grinding with sandpaper, polishing and microscopic evaluation. After cutting, the samples were microscopically evaluated to determine if the marrow spaces were large and many enough to require wax-filling. This precaution was taken to prevent the indenter tip from running into holes during indentation which could lead to the indenter and/or machine damage.

\subsection{Nanoindentation Equipment: Functions (Wet/Dry)}

Figure 3.1 is the NanoTest ${ }^{\mathrm{TM}}$ machine (inside cabinet) which when fitted with appropriate tool, is capable of offering a complete range of nanomechanical and nanotribological tests, including microindentation (MT) nanoindentation (NT), nanoscratch and wear, nanoimpact and fatigue, elevated temperature nanoindentation 


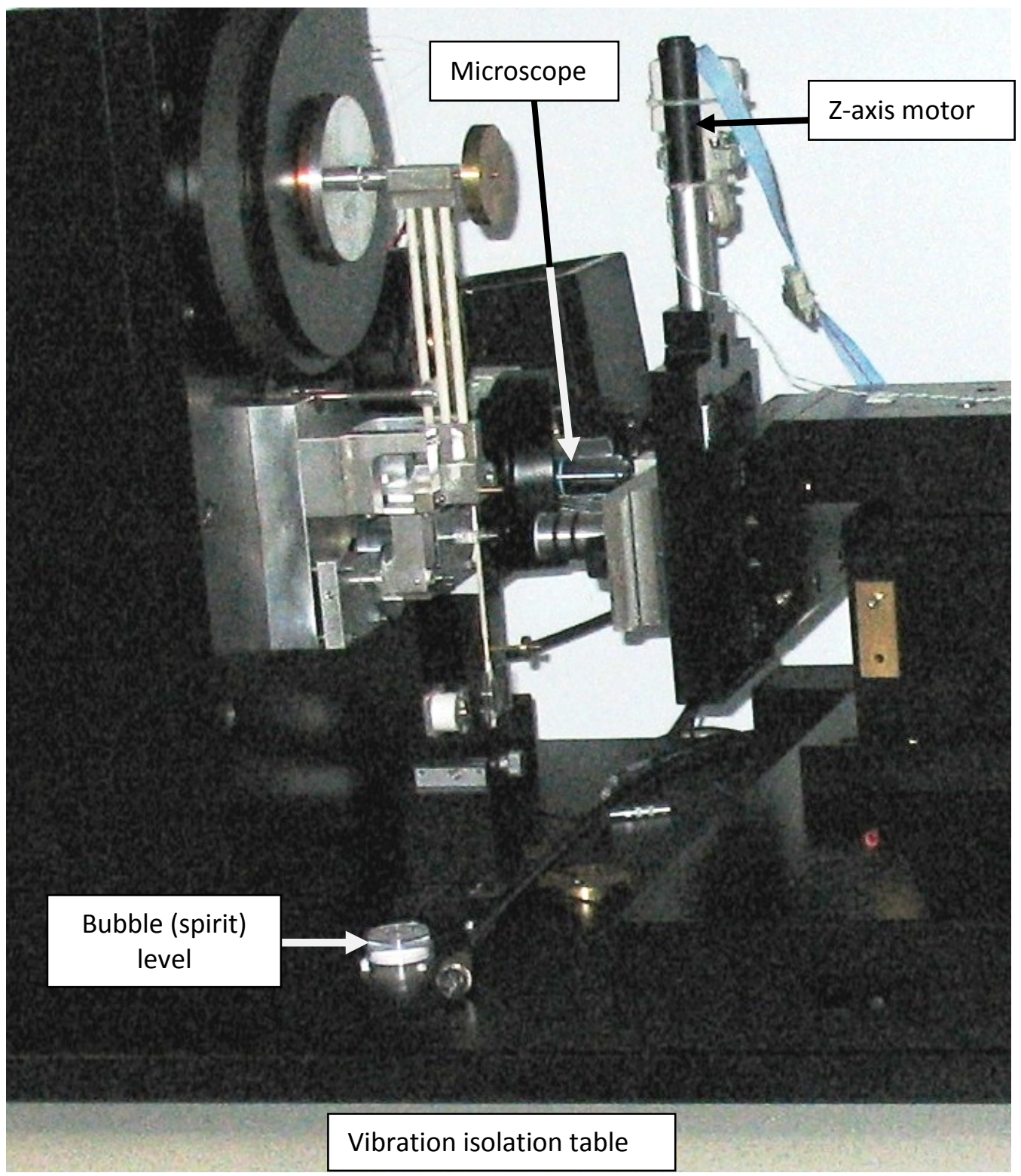

Figure 3.1: NanoTest ${ }^{\mathrm{TM}} 1200$ machine used for the nanoindentation tests.

and indentation in fluids. Amongst other parameters, the NanoTest ${ }^{\mathrm{TM}}$ is capable of measuring hardness, modulus, toughness, adhesion and many other properties of thin films and other surfaces or solids such as bone and soft tissues [50]. The system has testing methods which allow a sample to be tested in an environment which can be adjusted to closely replicate conditions as these materials actually appear in everyday use. 
These include testing of a bone sample fully immersed in extracellular fluid which allows the reproduction of physiological (in-vivo) condition. The NanoTest system is equipped with a wide range of options including continuous compliance measurement, 2D leveling stage, high resolution microscopes $(4 \mathrm{x}, 10 \mathrm{x}, 20 \mathrm{x}$ and 40x), humidity control, and acoustic emission system amongst others. It allows the testing of samples at temperatures up to as high as $750^{\circ} \mathrm{C}$.

The instrument is enclosed in an environmental cabinet that helps to reduce air turbulence that may upset NanoTest pendulum, providing a thermally controlled environment and providing sound-proofing to reduce acoustic disturbance. The acoustic emission system in vibration-isolation table detects the emission and minimizes the effect of the ambient vibration so the machine could produce reproducible noise-free results. The $2 \mathrm{D}$ leveling control ensures the machine operates on a leveled stage while this is monitored on the bubble level. The temperature control assists in minimizing electronic drift of the capacitance bridge unit and thermal drift due to expansion. Two small heaters are placed in front of the cabinet away from the machine's base while temperature controller's probe (and sensor) is placed towards the center of the machine at the height of the measurement in order to give an average value for the cabinet temperature.

\subsection{The Nanoindentation System Descriptions \& Operation}

The entire system hardware summarily consists of a pendulum with a coil mounted on top. When current is present, the coil is attracted towards a permanent magnet, producing 
motion of the diamond towards the sample and into the sample surface. The movement of the diamond results in its displacement which is measured by means of a parallel plate capacitor, one of which is attached to the diamond holder. This movement caused a change in the capacitance, measured by means of a capacitance bridge. The three direct current (DC) motors manipulate the sample movement as desired by driving the micrometer stages in an XYZ directions.

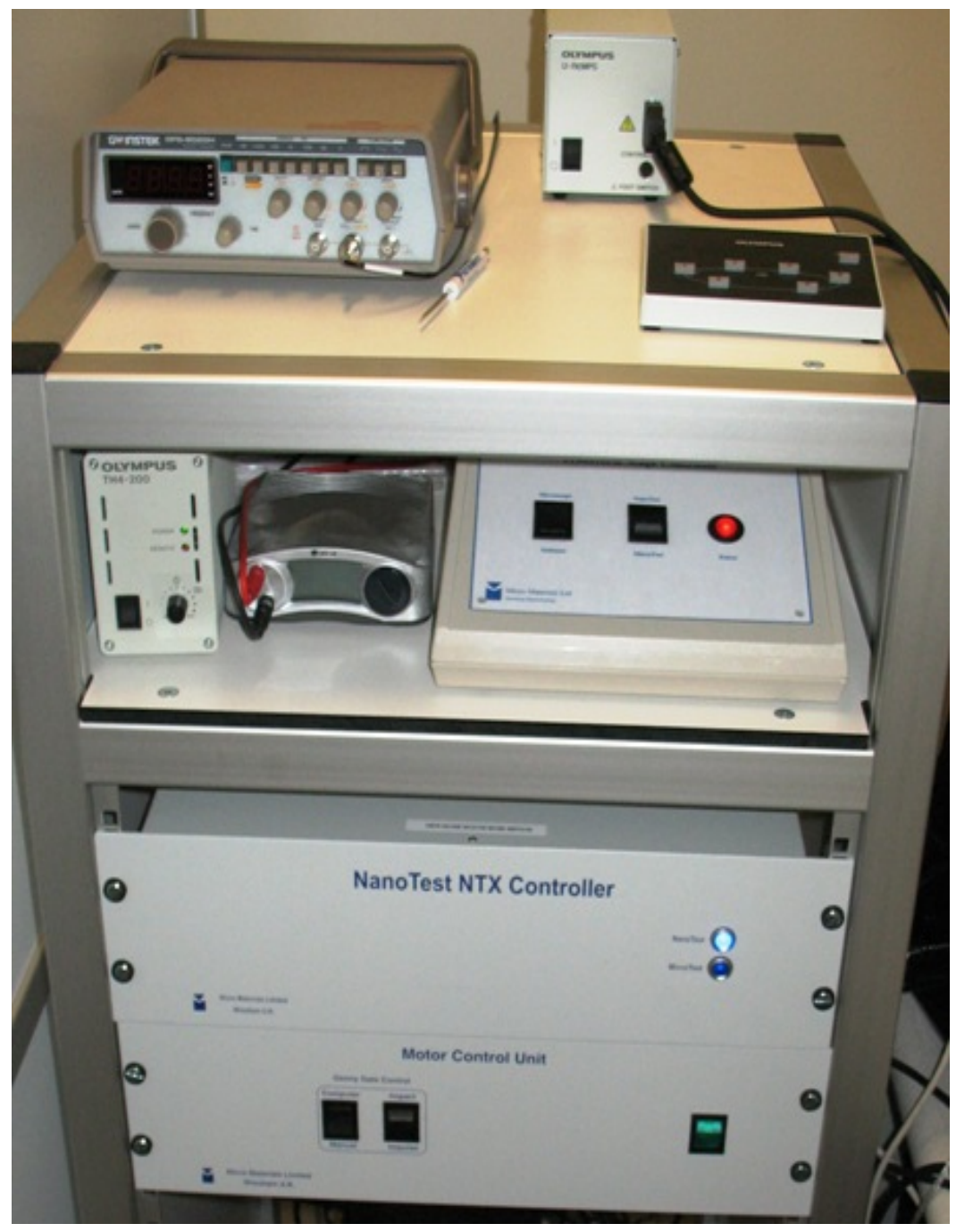

Figure 3.2: NanoTest control shelf for manual control boxes and mounted NTX Controller 
The limit stop defines the maximum outward movement of the diamond, and also the operating orientation of the pendulum, when a load is applied. With zero load current, the equilibrium position of the pendulum is adjusted with balance weights which are movable along both the horizontal and vertical axes. The NanoTest system has a separate shelf for mounting NTX Controller - DC motor control unit - and any other device. Figure 3.2 shows this shelf holding boxes for manual control of microscope resolution, microscope power and for indenter-microscope transverse stage. The computer system has two monitors so that one was used for microscopic evaluation of the sample - before or after indentation experiment - and the other one for running the Material Testing Platform Two. The platform enables such operations like, stage control, indentation scheduling (defining), machine calibration, data analysis and system maintenance (tests). The system software is capable of carrying out all the above operations as scheduled.

\subsection{Sample Preparation and Microscopy}

The 12 frozen 10th and $11^{\text {th }}$ left ribs of beagle dogs were first cleaned of flesh using forceps, knife and razor. From each of the canine ribs, two bone discs of 2.5-3mm thickness were cut transversely and perpendicular to the long axis, using a low-speed precision cut-off saw having a diamond-tipped wafering blade (ISOMET 1000, Buehler $^{\mathrm{TM}}$, Lake Bluff, IL.). The thickness of the cut was such to allow for enough bone for indentation after surface preparation. One end of the bone sample's transverse surfaces was pressed against the 3x (cold to cool water) wax (Sex Wax Inc, Carpinteria, CA) to displace the marrow. This forced all the marrow out through the other (opened) 
end until the wax came out completely replacing the marrow - filling the pores. This pore filling would possibly eliminate all traces of pore which might be exposed during the size reduction during polishing with sandpaper and on the polishing table. The filling of the hollows spaces with wax was to allow the indenter find a contact surface (in case the indenter runs into bone marrow space during indentation) so that the wax would comply when the indenter comes in contact with it. Figure 3.3 shows a sample before and after wax-filling the marrow space.

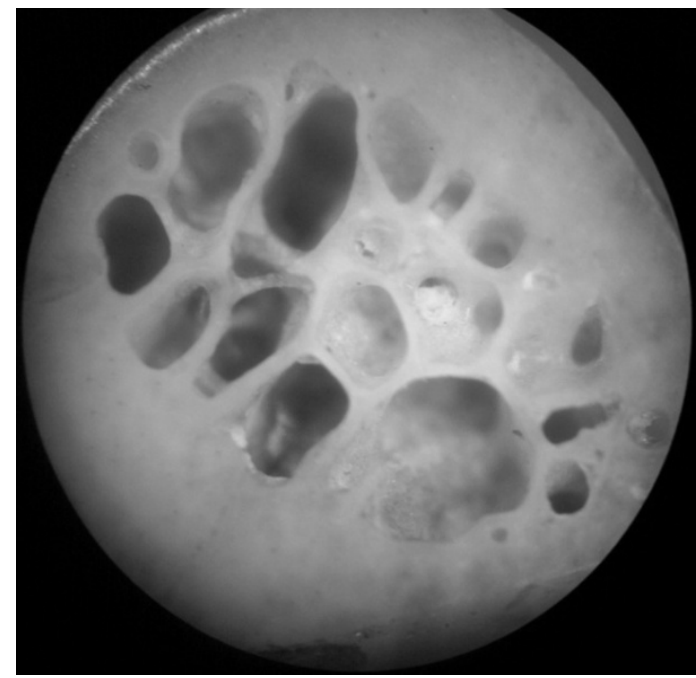

a)

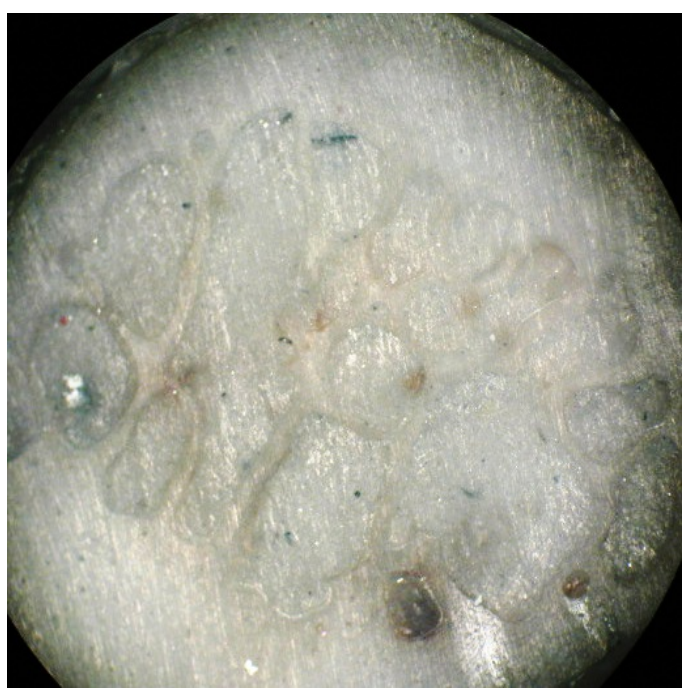

b)

Figure 3.3: A typical sample before (a), and after (b) filling marrow spaces with wax.

These bone surfaces were ground with sandpaper successively with 600, 1200, 1500 and 2,000 grit of silicon carbide abrasive paper constantly wetted and thereafter cleaned with $0.09 \%$ saline. The sample was rotated 90 degrees relative to previous sanding line direction and firmly run unidirectional across the next grit paper to between 8-12 strokes, while maintaining a relatively uniform contact pressure and level. During grinding with sandpaper, it was always ensured that traces of immediate previous grit lines were 
completely removed by the present grit before proceeding to the next. The sample surface was regularly evaluated microscopically before proceeding to using the next sanding grit and finally to polishing, and the sample was ready for indentation.

Olympus TH3 microscope used for the observation was firstly modified to allow the sample and its stand fit under the microscope lens.

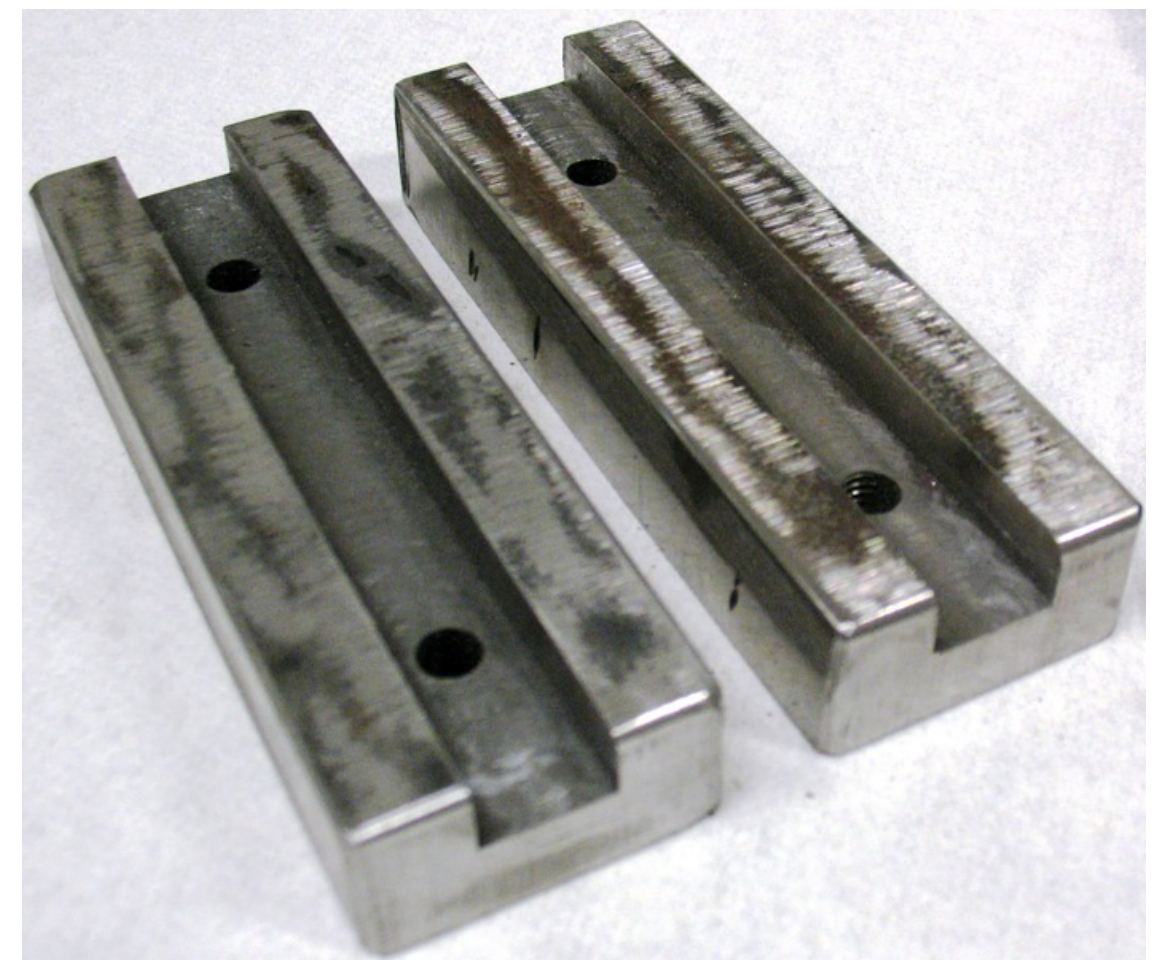

Figure 3.4: Fabricated head raiser for Olympus TH3 microscope used

Figure 3.4 shows the two head raisers fabricated to raise the microscope head. Each was machined from a $19.1 \times 38.1 \times 101.6 \mathrm{~mm}$ mild steel blocks to have a slot $11 \mathrm{~mm}$ wide and $10 \mathrm{~mm}$ deep each into which each leg $(10 \mathrm{~mm}$ thick and $80 \mathrm{~mm}$ long $)$ of the microscope head fitted. Two holes were drilled on each of the blocks through which they (the blocks) 
were connected and fastened to both the base and the legs. The $4 \mathrm{x}$ and 10x lenses of the microscope were used to observe the surface of the samples and check for good grinding before proceeding to polishing. After ensuring that the last line on the sample surface was that of 2000 grit, the surface was then ready for polishing. The samples were then polished to 3 microns under a continuously wetted polishing clothes and 3 micron suspension. The Buehler polishing machine used an 8-inch diameter base plate and was operated at low speed. The polishing was done to smooth the sample surface to approximately 3 microns. This polishing allowed the sample osteons to clearly show when observed under the microscope. Figure 3.5 shows two topographical views of a sample, which is before and after polishing. The 2,000 grit lines which is conspicuous after hand grinding with sandpaper was seen removed after polishing.

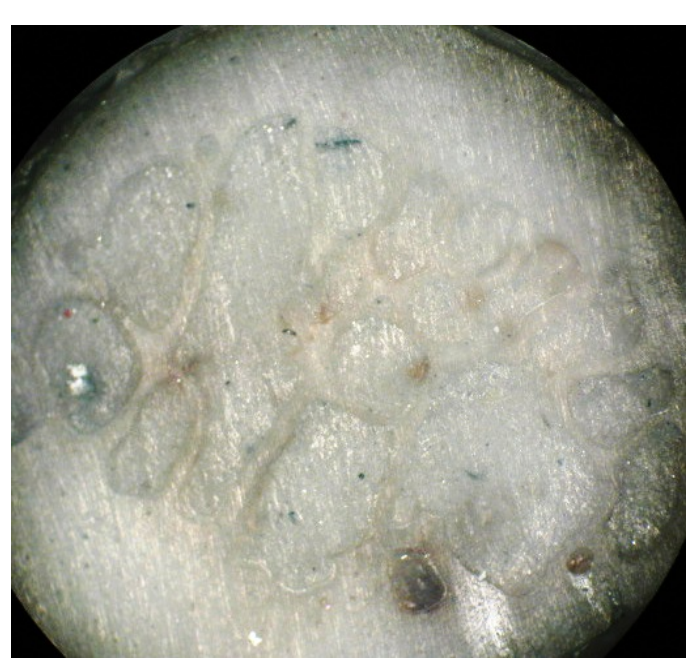

a)

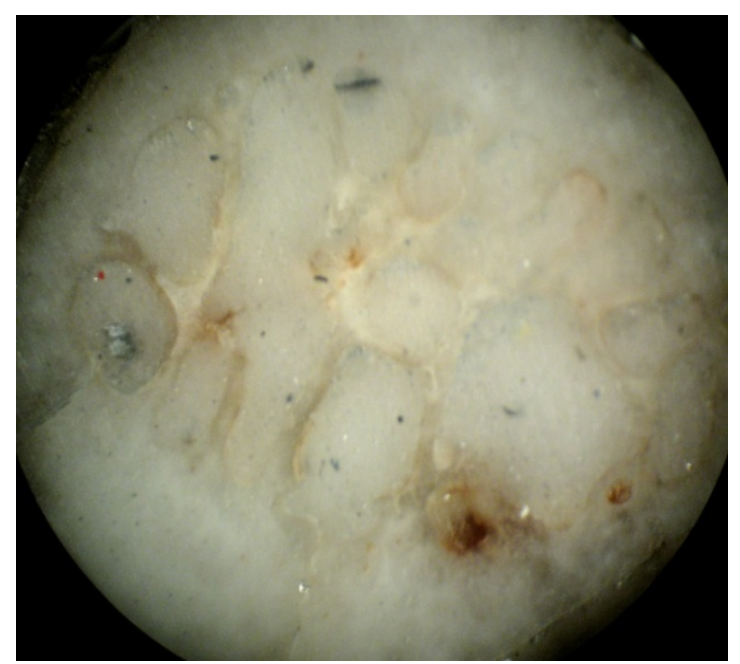

b)

Figure 3.5: Microscopic (topographical) view of a sample before (a) and after (b) 3 micron polishing .

After storage for couple of days, a slight depression was noticed in wax in the bone 
marrow area during use. This depression was refilled with wax to the cortical surface level and thereafter polished again before sample was mounted for the nanoindentation tests. The samples were never at anytime outside the freezer for more than 24 hours. The nanoindentation testing was performed on four groups of beagle dog ribs: 1-year control, 1-year treated, 3-year control and 3-year treated.

\subsection{Normal Nanoindentation Calibration}

The normal nanoindentation calibration is required for a dry or non-physiologically conditioned testing of bone sample. Once the instrument has been certified to be working properly, a series of calibrations were performed before using machine for indentation of both normal and wet mounted of prepared sample. Table 3.1 shows the overview of the manufacturer-recommended calibrations and tests, frequency and purpose of the test.

Table 3.1: Overview of Calibration Procedures for the NanoTest ${ }^{\mathrm{TM}}$ Indentation System

\begin{tabular}{|c|c|c|}
\hline Calibration & Frequency (Recommended) & Purpose \\
\hline Pendulum Test & Each morning & $\begin{array}{c}\text { Measure mobility and } \\
\text { sensitivity to displacement }\end{array}$ \\
\hline Zero Load & $\begin{array}{l}\text { Three before each schedule (set of } \\
\text { recorded indentation) }\end{array}$ & $\begin{array}{l}\text { Determine minimum voltage } \\
\text { to hold pendulum to limit- } \\
\text { stop }\end{array}$ \\
\hline Load & Every three months & $\begin{array}{l}\text { Check for damaged pivot } \\
\text { spring }\end{array}$ \\
\hline Depth & $\begin{array}{c}\text { Weekly or whenever indenter was } \\
\text { changed }\end{array}$ & $\begin{array}{l}\text { Relate change in capa- } \\
\text { citance to a known distance }\end{array}$ \\
\hline $\begin{array}{c}\text { Machine } \\
\text { Compliance } \\
\end{array}$ & $\begin{array}{l}\text { Every three months or whenever stage } \\
\text { components were dismantled }\end{array}$ & $\begin{array}{l}\text { Correct of errors in sample } \\
\text { compliance }\end{array}$ \\
\hline $\begin{array}{l}\text { Diamond Area } \\
\text { Function }\end{array}$ & $\begin{array}{c}\text { Every three months or whenever the } \\
\text { indenter was changed }\end{array}$ & $\begin{array}{l}\text { Find function to use for a } \\
\text { general, non-ideal contact. }\end{array}$ \\
\hline $\begin{array}{l}\text { Microscope } \\
\text { screen }\end{array}$ & $\begin{array}{l}\text { After every completion of an indent- } \\
\text { ation schedule or set of schedules }\end{array}$ & $\begin{array}{l}\text { Accurately position the } \\
\text { sample for indentation }\end{array}$ \\
\hline
\end{tabular}


The detailed procedure of the calibrations done for the experiment is discussed below. Generally, before using the instrument, the diamond area function of the indenter was determined and the results saved as default for analysis of indentation data. Table 3.2 is the summary of the indenter properties and parameters were used for the test and indentation data analysis.

Table 3.2: Properties and Parameter of the Indenter Used for Test

\begin{tabular}{|l|l|}
\hline \multicolumn{1}{|c|}{ Indenter Property } & \multicolumn{1}{c|}{ Parameter } \\
\hline Type & Berkovich \\
\hline Geometry/Shape & Triangular Pyramid \\
\hline Material & Diamond \\
\hline Elastic Modulus $(\mathrm{GPa})$ & 1140 \\
\hline Poisson Ratio & 0.07 \\
\hline
\end{tabular}

To obtain an accurate diamond area function, the load, depth and machine compliance calibrations were earlier performed. The machine frame compliance was determined using an indirect method which required a Berkovich indenter and a reference sample of known modulus (in this case a fused silica - 69.9 MPa). The Berkovich indenter used was a normal type which had a sharp tip 3-sided pyramid geometry with the three faces symmetrically placed around the axis $120^{\circ}$ apart. Figure 3.6 depicts the relationship between the compliance before and after correction, and the frame compliance. The following mathematical expressions describe the relationship between contact, sample and the indenter compliances: Contact compliance $(\mathrm{Ct})$ equals the sum of the contact compliance and the machine compliance. Therefore, from Figure 3.5 total (measured) compliance, $\mathrm{Ct}$ equals the sum of the contact compliance, $\mathrm{C}$ and the machine compliance, Cf. 


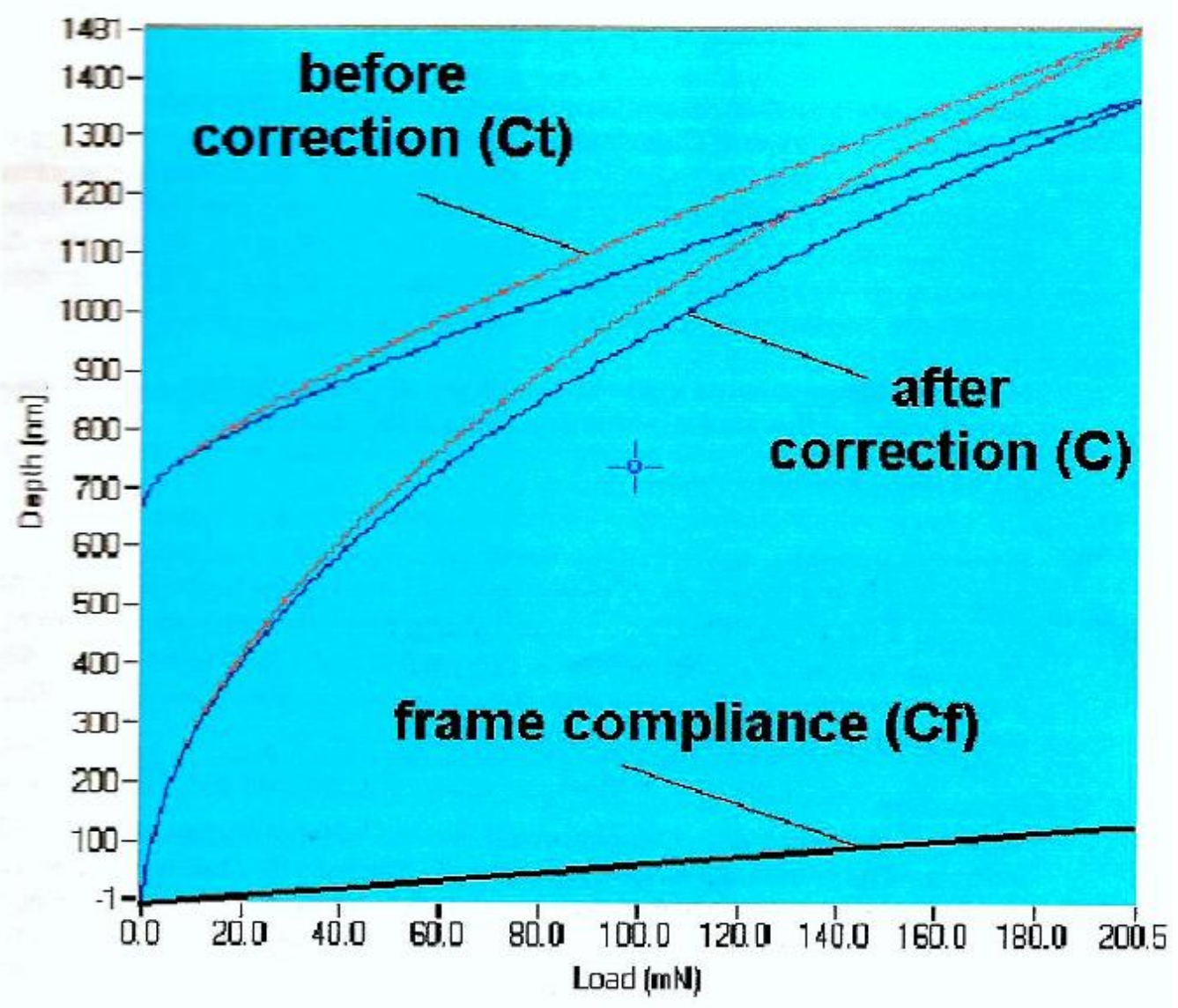

Figure 3.6: Relationship between measure (total) compliance $(\mathrm{Ct})$, contact compliance (C) and frame machine (Cf) compliance.

The instructions from the system were followed, and after exiting the file was analyzed and added to the calibration-machine compliance menu of the system. The instrument was scheduled, as shown in Table 3.3, to run five indentation experiments using load vs. depth hysteresis. The schedule covers the range of plastic depths for the diamond area function. The value obtained was saved in a text file for future reference. 
Table 3.3: Indentation schedule for Diamond Area Function

\begin{tabular}{|c|c|c|c|c|}
\hline Test & $\begin{array}{c}\text { Maximum } \\
\text { Load }(\mathbf{m N})\end{array}$ & $\begin{array}{c}\text { Minimum } \\
\text { Load }(\mathbf{m N})\end{array}$ & $\begin{array}{c}\text { Initial Load } \\
(\mathbf{m N})\end{array}$ & $\begin{array}{c}\text { Loading Rate } \\
(\mathbf{m N} / \mathbf{s})\end{array}$ \\
\hline 1 & 200 & 150 & 0.05 & 4 \\
\hline 2 & 140 & 40 & 0.05 & 1.8 \\
\hline 3 & 30 & 5 & 0.03 & 0.45 \\
\hline 4 & 4 & 2 & 0.03 & 0.06 \\
\hline 5 & 2 & 0.5 & 0.03 & 0.02 \\
\hline
\end{tabular}

According to the manufacturer's specification, a total of 8 indents were made for each test while the dwell time at maximum load was 5 seconds. Each indentation thermal drift was corrected for duration of 60 seconds.

\subsection{Stub Modification and Sample Mounting}

The bone samples for this experiment were glued to the scanning electron microscope (SEM) plates which fitted into the stub. The wet mounted stub was modified to accommodate the SEM (sample) plate by tapping the longitudinal surface to size $3 \times 0.5$ $\mathrm{mm}$ through to the center hole and at $5 \mathrm{~mm}$ beyond the holed end of the stub. A set screw of size $3 \times 0.5 \mathrm{~mm}$ was used to set the plate stem in place in the stub. The use of this modified stub and SEM plate allowed for easy and quick changing of the sample, and also prevented direct gluing of the sample to the original sample stub which was difficult and time-consuming to remove when practiced earlier. Figure 3.7 shows the assembly of the modified sample mounting technique adopted for the experiment. 


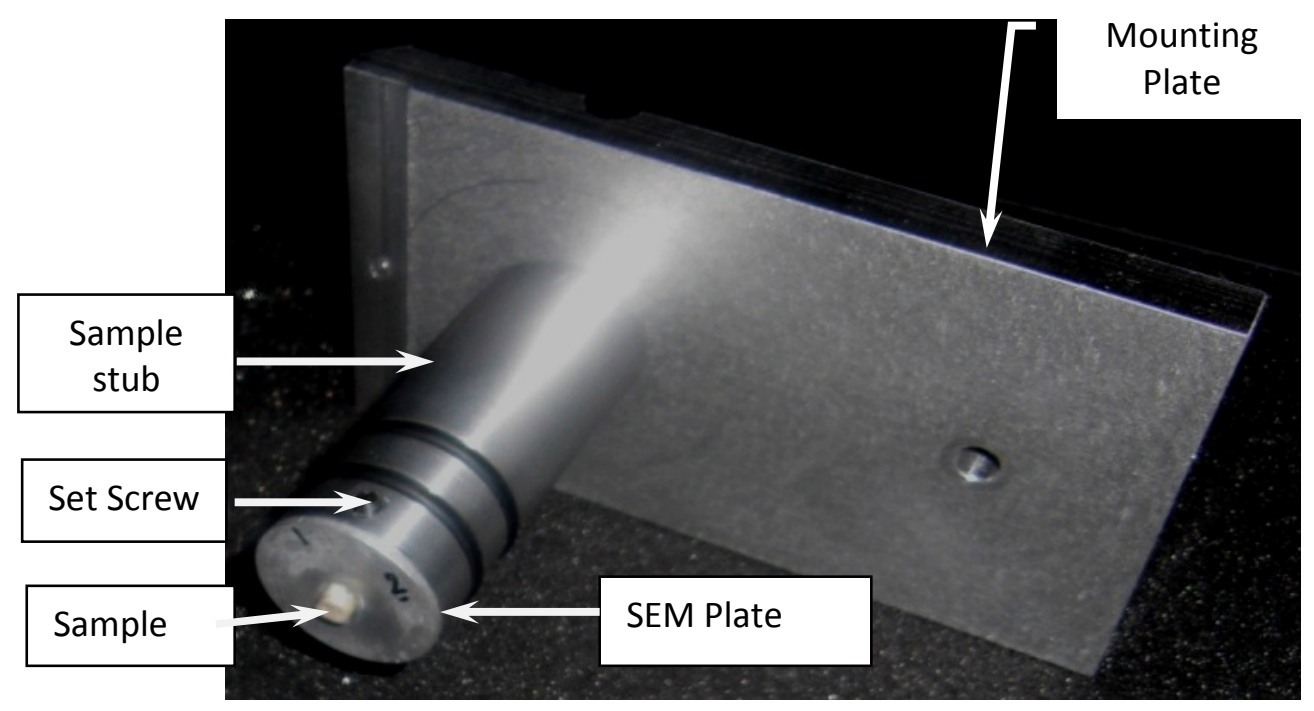

Figure 3.7: The modified sample mounting technique adopted for the experiment

\subsection{Nanoindentation Analysis}

For the experiment, the wet mounted indenter was replaced with normal indenter (no extension arm) and the following instructions on the system screen were followed to get the instrument ready for the test. A Berkovich diamond tip indenter was fitted directly to the nanoindentation pendulum (head) of the machine.

The pendulum test was performed by adjusting the bridge box in order to establish a rectified output voltage of 7.9-8.0 Volts (V) prior to the nanoindentation scheduling. Figure 3.8 shows the picture of the three knobs used for the adjustment of the rectified output voltage with the coarse and ultra-fine (two lower) as the most used. These knobs were in combination used to adjust the rectified output so as to bring the minimum voltage to a stable value of less than $0.1 \mathrm{~V}$ while only the coarse knobs was always and finally used to set the reference limit stop value of approximately $7.9 \mathrm{~V}$ recommended for nanoindentation. The fine tune (topmost) knob was occasionally used after the coarse 
knob to slowly bring the voltage to desired high precision value. The machine manual was used frequently to troubleshoot in case of doubt the need arose. The machine automatically performed the pendulum test after getting a 'Good Limit Stop Value' and 'Good Minimum Value'. Whenever the pendulum test failed to yield an acceptable result the computer indicated and this process was repeated. Every one of the experiment schedule yielded a satisfactorily and steady state (limit stop) value of $7.95 \pm 0.045 \mathrm{~V}$.

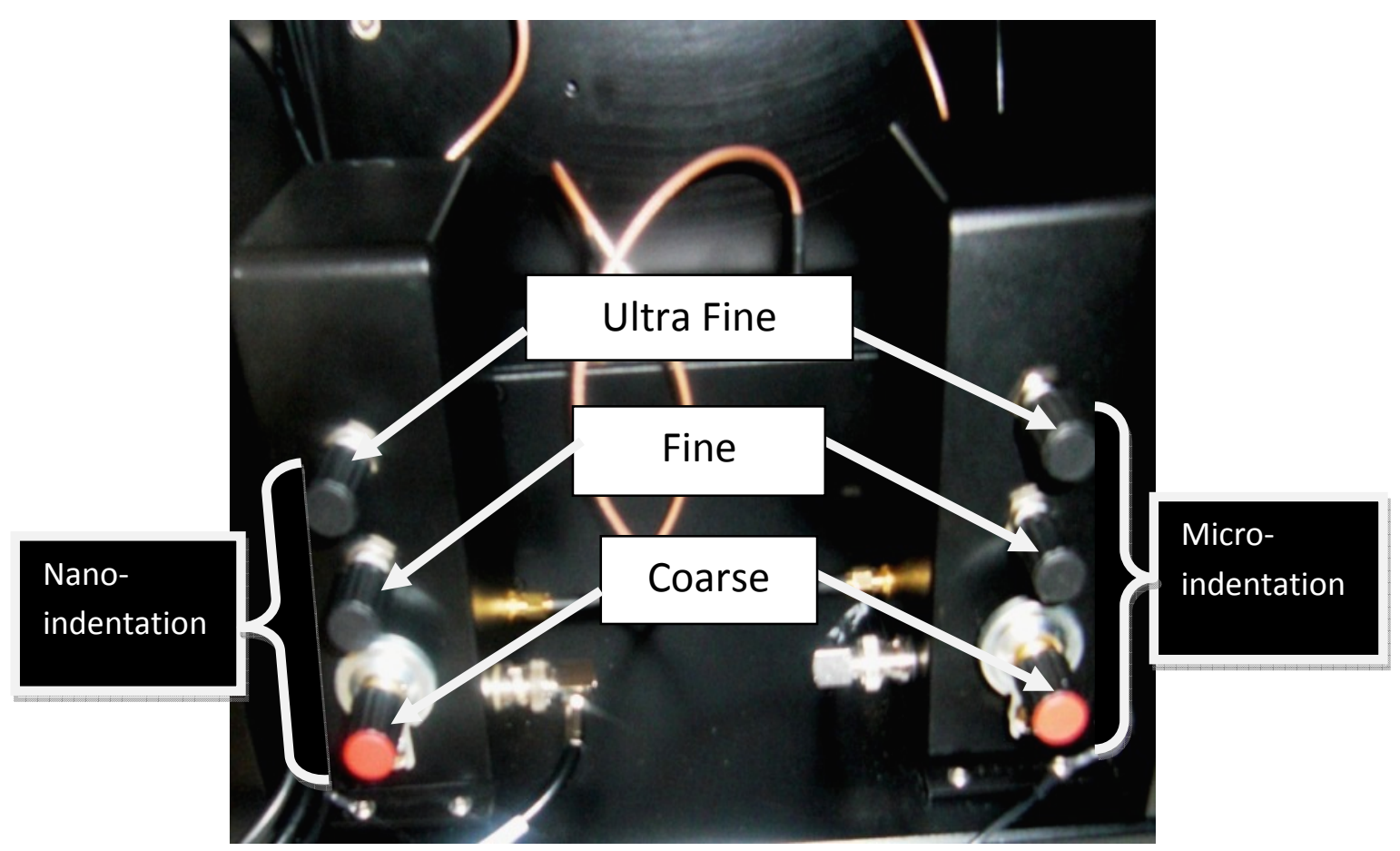

Figure 3.8: Nanoindentation bridge box knobs used for the adjustment of the rectified output voltage 


\subsection{Nanoindentation Tests (Measurements)}

Using the 40x lens of the instrument microscope, a range of indentation spots around the transverse surface of the prepared specimens was selected for the experiment scheduling depending on the integrity of the location. During this pre-indentation microscopic evaluation, spots and regions of poor integrity were avoided as much as possible; these include trabecular, Harvesian canal, wax-filled marrow space, sandpaper lines, crack lines and others that can give false data. Every experiment was scheduled so that the indenter would possibly indent only the cortical area of the bone. Once a defined position was in focus in front of 40x lens (the highest resolution), the experiment wasadded to the schedule queue and the next location was defined if more than one experiment was desired for the specimen. Each experiment was saved with a file name (sample code number used) for data/results saving and tracking. The system automatically ran all the schedules on queue as defined. The samples at the prompts from the system were moved to the front of the indenter using the transverse stage control. Because the high resolution microscope was already calibrated, the system automatically moved the indenter from the focal to measurement plane at the beginning of each schedule.

\subsection{Indentation Parameter Selection}

In order to better understand the effect of depth and load controls on the reduced modulus and the hardness properties of the bone, the indentation depth and load values were varied for various trials. When the maximum indentation termination depths were set (at different time) to $2500 \mathrm{~nm}$ and $3,000 \mathrm{~nm}$, with a $200 \mathrm{mN}$ maximum termination load (whichever condition is first attained), the indents when observed under microscope 
appear too shallow while the reduced modulus and hardness data seem to be significantly lower compared to those values obtained with uncontrolled depth. It was also observed that the indentation termination depth 2,500 - 3000nm was less or just about the 3 microns to which the sample was polished. This means that the indentation terminated at a depth not large enough to produce reasonable mechanical properties of a sample. A typical effect of load-depth termination on the mechanical properties of specimens is shown in the data in Table 3.4 below. In this table the results of maximum load-depth termination (whichever condition comes first) and only load termination controls of one of the samples using same condition and function (general) analysis are shown.

The spacing between the indentation positions was $25-30 \mu \mathrm{m}$. This was to correct overlapping of indents that was observed with $20 \mu \mathrm{m}$ spacing. The indenter retraction distance ranged from $30-50 \mu \mathrm{m}$, the higher value was chosen for schedules having experiments in a relatively distant region to the starting point. This will prevent the indenter from scratching the bone surface in case the next location to indent is of higher elevation - a problem peculiar to samples with non-uniform thickness. This allowed the indenter to completely retract from the bone sample before moving to the next indentation position.

Table 3.4: A typical effect of Load-Depth Termination Control on Indentation Results

\begin{tabular}{|c|c|c|}
\hline Termination & Hardness (GPa) & Reduced Modulus (GPa) \\
\hline $\begin{array}{c}\text { Max/Min Load: } 200 \mathrm{~N} \text { and } \\
\text { Max/Min Depth: 2,500nm }\end{array}$ & 0.63361 & 15.06652 \\
\hline $\begin{array}{c}\text { Max/Min Load: } 200 \mathrm{~N} \text { only } \\
\text { (unrestricted depth) }\end{array}$ & 0.89403 & 20.21784 \\
\hline
\end{tabular}


All data generated from many indentation trials were analyzed by the Oliver-Pharr method using various techniques: ideal DAF with one and two parameters and a general DAF with one and two parameters. The results were compared within samples, which helped arrive at reasonable indentation schedules that were used for this report, as shown in Table 3.5. The schedule used for each sample and test varied, depending on such factors as slope of the sample surface and available good area on the sample surface for the indentation. These factors helped minimize the number of rejected indentation results.

Table 3.5: System Parameter and Specifications of Indentation Schedule/Definition

\begin{tabular}{|l|c|}
\hline SYSTEM PARAMETER & SPECIFICATION \\
\hline Type of Experiment & Depth versus Load Hysteresis \\
\hline Number of Zero Load Calibrations & 3 \\
\hline Indentation Start Delay $(\mathrm{s})$ & 10 \\
\hline Number of indents per test & $25-100$ \\
\hline Maximum Termination Load $(\mathrm{mN})$ & 200 \\
\hline Minimum Termination Load $(\mathrm{mN})$ & 200 \\
\hline Termination Depth $(\mathrm{nm})$ & N o n - c o n t r o l l e d \\
\hline Loading \& Unloading Rate $(\mathrm{mN} / \mathrm{s})$ & 2.00 \\
\hline Thermal Drift Correction Method & Collect Data Post indentation \\
\hline Indentation Pattern & $25-30$ \\
\hline Indentation Spacing $(\mu \mathrm{m})$ & 60 \\
\hline Thermal Drift Correction Time $(\mathrm{s})$ & $\mathrm{S} \mathrm{t} \mathrm{a} \mathrm{n} \mathrm{d} \mathrm{a} \mathrm{r} \mathrm{d}$ \\
\hline Load Ramp Control Method & $30-50$ \\
\hline Retraction Distance $(\mu \mathrm{m})$ & 0.05 \\
\hline Ramp Initial Load $(\mathrm{mN})$ & 0.3 \\
\hline Ramp Limit Stop Load & 5 \\
\hline Dwell Period at Max. Load $(\mathrm{s})$ & 0.30 \\
\hline Indenter Contact Velocity $(\mu \mathrm{m} / \mathrm{s})$ & \\
\hline
\end{tabular}




\subsection{Data Refinement}

Some indentation files were rejected and removed for such reasons as improper calibration of the machine prior to testing. The data refinement was performed for each test whose files were accepted after observing the indents in the microscope and checking the analyzed results (both graphically and numerically), and then comparing and relating the results of these two. The results of observations were finally compared and related to previously published mechanical properties of bone. Those files and data found incorrect were rejected based on either one or a combination of the following: technical problems; indenter running into wax filled holes/canals (marrow or Haversian) canal; comparatively too high or too low maximum termination depth; pendulum test not performed (incorrect rectified output); initial rectified output too high for safe contact (as prompted on screen). Others reasons were: indenter landing on artifact, trabeculae or crack lines; non- or poor preparation of sample surface, poor indents (impression) and too much lag on the displacement axis of the load-displacement graph.

Out of the total of 2,358 indentations (tests) performed on all the samples, 1,230 indents were accepted after data refinement, while files containing 1,025 indents were completely rejected. The accepted data amounts to approximately $44 \%$ of the total indentation test data. As earlier discussed in section 3.10, most of the 20 files - containing 1,025 indents - were rejected due to error in parameter selection which resulted in unrealistic results. Figure 3.9 shows some typical indents, the data of which were rejected during the indentation data review and refinement. To fix one of the technical problems, the instrument software was re-installed. Following the software reinstallation, the machine 
depth was calibrated and the experiment rescheduled because the data obtained before the technical problem was lost.

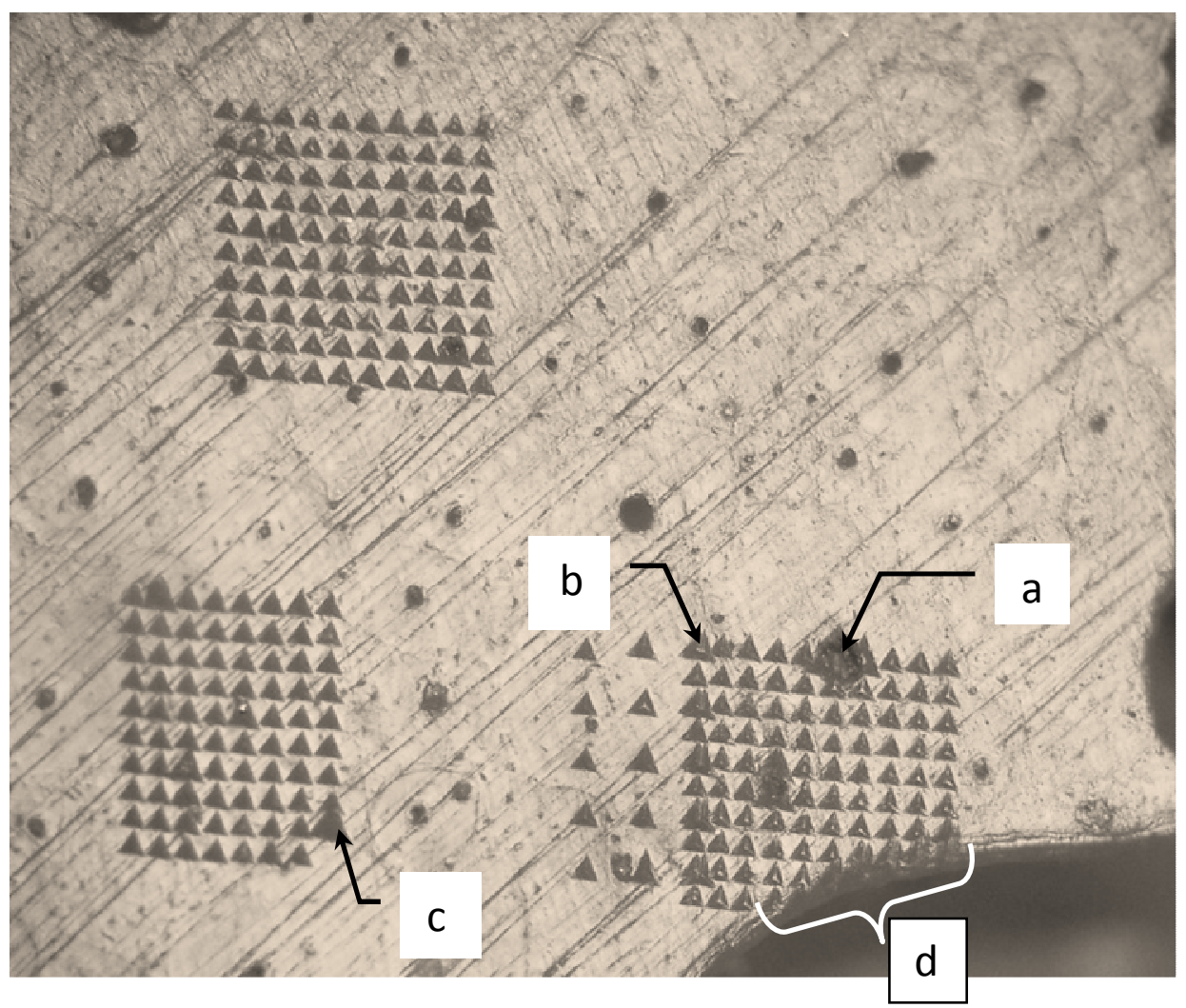

Figure 3.9: Typical rejected indents due to: a) landing on Haversian canal b) landing on an artifact, c) technical problem and d) landing in wax-filled marrow canal.

Figure 3.10 is a graph of one of the rejected tests which reveals too much lag on the on the displacement axis (the reason for rejection) and how the instrument responded to the thermal drift correction and dwell duration setting. 


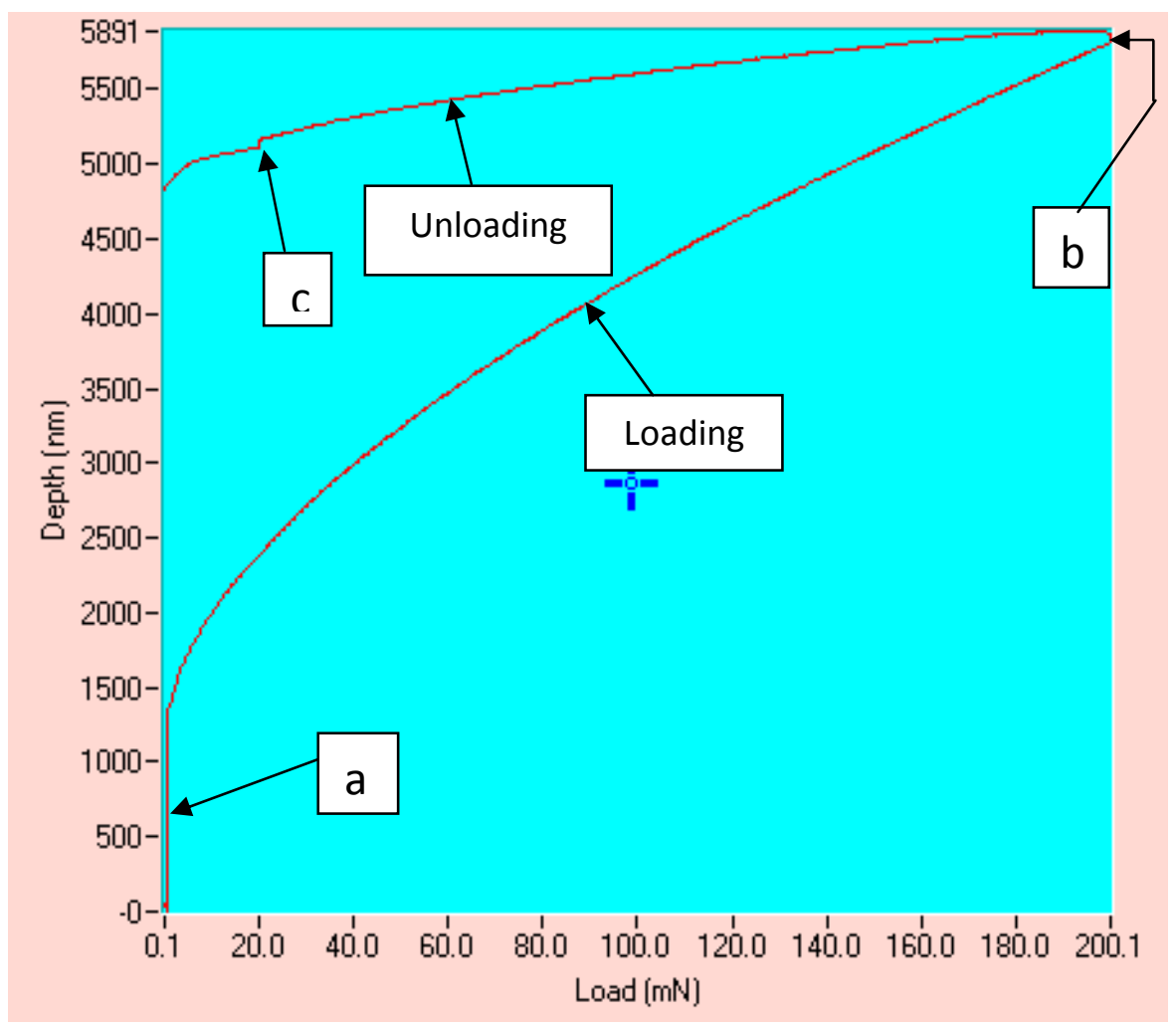

Figure 3.10: A typical load-displacement graph of a rejected data showing: (a) too much lag on the displacement axis (the reason for rejection), (b) maximum load dwell (creep evidence) and (c) the thermal drift correction.

\subsection{Statistical Analysis}

The instrument software collected all the indentation data includes the hardness, reduced modulus, maximum depth and plastic depth, maximum load, elastic recovery parameter, contact compliance, elastic work, plastic work, and fitting mean square error. The two different modes of determining diamond area (as defined by from the instrument software) were adopted for the indentation data analysis: ideal and general functions. The energy data (elastic work and plastic work) analysis did not require diamond area function for analysis and hence no machine frame compliance since the contact area is 
not needed to determine the energy required to indent samples instead the elastic and plastic depths.

The statistical analysis software SAS V 9.1 Cary, NC was thereafter used to analyze all the statistical data from the study. Using this software, a repeated measures analysis of variance (ANOVA) of the mechanical properties was performed, probing into the effect of the alendronate treatments ( 1 Yr and $3 \mathrm{Yr}$ ) on both the elastic modulus and hardness. Further analysis was performed to determine the energy required (elastic work and plastic work done) to indent the beagle dog ribs. In the analysis, the desired mechanical property was specified as the dependent (continuous) variable, while the treatment (1) (1 year and 3 years) and control (0) as the group to be modeled. In the combined 1 year and 3 years analysis, the treatment was crossed with the treatment time as model to determine significant difference $(\mathrm{P} \leq 0.05)$ between the treated groups $(1$ year and 3 years alendronate) and between the control groups of the crossed model.

The second study attempted to differentiate between ideal and general function methods of analysis. The data for all the four groups of treatment were combined for the analysis. Microsoft Office Excel 2007 was used to perform paired t-test of means for the hardness and elastic modulus in order to assess the significant difference in both methods (ideal and general). Significant difference was accepted for $\mathrm{p}$-value $\leq 0.05$ (see the later part of the Appendix). 
Several selections and combinations (of variables) were tried for the repeated measure analysis before arriving at a reasonable and acceptable model that best fit the set data. The model chosen would describe $95 \%$ of the data in order to determine the significance for each effect treatment ( 1 year and 3 year alendronate treatment) and the control. The probability $(\mathrm{P})$ value $\leq 0.05$ means that the treatments had effect on the particular mechanical property. Pairwise difference (means) between a particular year treatment and the group control were tested for significance and adjusted using Tukey-Cramer and Bonferroni methods. With adjusted P-value (Adj. P) of $\leq 0.05$ the compared treatments (control and alendronate treated) show a significant difference. Additional repeated measures ANOVA was also performed by combining both the 1-year and 3-year treatment to test for the significant difference and was adjusted using Bonferroni method with $\mathrm{P} \leq 0.05$ as evidence of significance in the difference (if any). The average means of the data obtained from SAS analyses were graphically represented (using Microsoft Excel 2007) by bar charts with appropriate standard error bars. 


\subsection{Results}

For the twelve samples, 1,225 indentation data, which is $44 \%$ of the total indentation tests performed, were accepted and analyzed. So, approximately 103 indents' data per sample were analyzed, and each sample data set was statistically analyzed for discussion. The minimum and maximum numbers of indents analyzed per sample were approximately 74 and 140 respectively. Many parameters were tried with various combinations before finally arriving at a reasonable and acceptable combination. Table 4.1 below is an example of results (hardness and elastic modulus) obtained from an ideal function mode data analysis of a sample due to change in the thermal drift mode from off to on:

Table 4.1: Typical effect of Thermal drift mode on the indentation results

\begin{tabular}{|c|c|c|}
\hline Parameter $\downarrow /$ File $\longrightarrow$ & 3919340A & 3919340B \\
\hline Thermal drift & Off & On \\
\hline Hardness & $0.51311 \pm 0.063$ & $0.47803 \pm 0.053$ \\
\hline Reduced Modulus & $15.05092 \pm 0.966$ & $16.47292 \pm 0.883$ \\
\hline
\end{tabular}

\subsection{Data Analysis Definition: General and Ideal Functions}

Table 4.2 shows the data analysis parameter used for the analysis of the indentation tests while Table 4.3 shows diamond area function definition (values and parameter) for both the general and the ideal functions modes that were used for the data analysis. 
Table 4.2: Analysis definition for the indentation experiment pyramidal analysis

\begin{tabular}{|l|l|}
\hline \multicolumn{1}{|c|}{ Parameter } & \multicolumn{1}{c|}{ Method/Specification } \\
\hline Analysis method & Power Law fit \\
\hline Start fitting @ & $100 \%$ of maximum load \\
\hline Stop fitting @ & $20 \%$ of maximum load \\
\hline Epsilon Constant & 0.75 \\
\hline Frame Compliance & 0.30607 \\
\hline Thermal drift correction & Collect data post indentation \\
\hline
\end{tabular}

Table 4.3: General and ideal function values and parameter for the data analysis

\begin{tabular}{|l|l|l|}
\hline \multicolumn{1}{|c|}{ Parameter (Berkovich) } & \multicolumn{1}{|c|}{ General } & \multicolumn{1}{c|}{ Ideal } \\
\hline Indenter tip Area & N/A & 24.50 \\
\hline Function & Fitted APd $+\mathrm{BPd}^{\wedge} 2$ & N/A \\
\hline Beta Factor & 1.03400 & 1.03400 \\
\hline Selected file & C:/ Calpoly/TRAINING.DAF.daf & N/A \\
\hline Curve fitting @ & \multicolumn{2}{|c|}{$40 \%$ of the total data collection time } \\
\hline
\end{tabular}

Using general function (with an earlier saved diamond area function file) the instrument software analyzed the data and the following result was obtained: hardness range, 0.5098 - 1.0646 GPa and reduced modulus range, 13.99 - 30.40 GPa. The ideal function type of the analysis when performed yielded hardness and reduced modulus values range of $0.335-0.522 \mathrm{GPa}$ and $11.33-21.91 \mathrm{GPa}$ respectively. All the accepted data were subjected to statistical analyses of repeated measures ANOVA (SAS V. 9.1, Cary, NC) and the results shown in the Appendix are discussed later in the report. 


\subsection{Optical Microscopic Evaluation}

The indents were also evaluated visually using the instrument-equipped high resolution microscope (40x). The accepted indents were approximately 550 micron sided equilateral triangles arranged in the range of 5 by 5 to 10 by 10 grid form and spaced $25-30$ microns between centers. The indents' impressions showed three-lines geometry from the indenter pyramidal edges and tip, converging at the center of the triangular shaped indents. Figure 4.1 shows the result sample of the microscopic views of typical indent (without overlap) that was accepted for statistical analysis and evaluation.

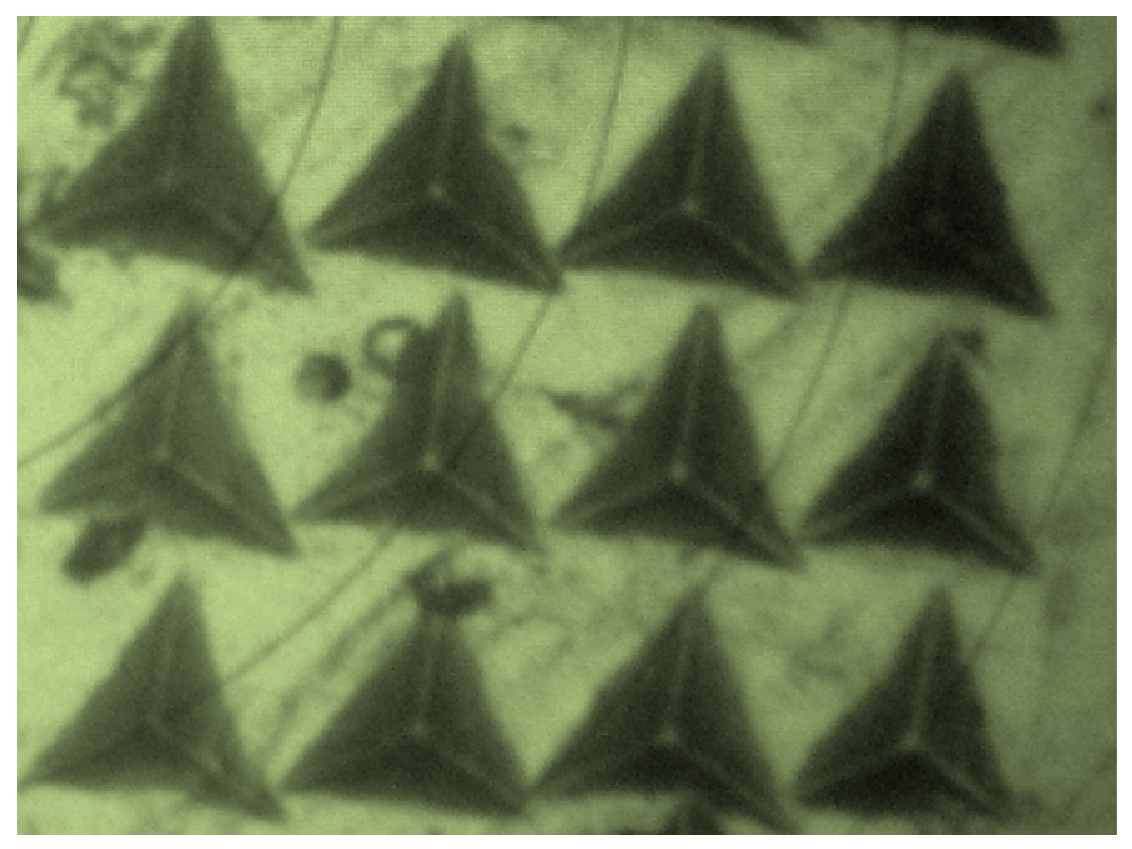

Figure 4.1: Microscopic view of typical accepted indents on a specimen showing the indenter tip impression and geometry. 


\subsection{Data Evaluation}

When the bone specimen was subjected to constant load during the loading-unloading transition period, being a visco-elastic material, creep occurred at this maximum loading dwell period. The specimen deformed elastically and caused an increase in the displacement at the constant loading. The instrument software - using equation 1.2 derived by Oliver-Pharr - generated the reduced modulus from the slope of the unloading curve obtained after the dwell period. The elastic modulus was computed from the instrument-generated reduced modulus using equation 1.5 . The hardness was directly determined by the instrument software using equation 1.6: a function of the maximum load applied (approx. $200 \mathrm{mN}$ ) and the contact area of the indenter with sample surface under the maximum load.

\subsection{Elastic Modulus}

The elastic modulus was input in the repeated measures ANOVA ( SAS V. 9.1, Cary, $\mathrm{NC}$ ) as the dependent variable, and the treatment (VEH (0) and $0.2 \mathrm{ALN}(1)$ ) as both the subject and effects in model to determine if there were significant differences between the three subjects in each of the two treatments - that is, within control and then within medicated. The differences in treatments were tested for significance in their effects on the elastic modulus and p-value adjusted using Tukey-Cramer. A paired two sample ttest was performed (irrespective of the medication treatment) to further determine if there was any difference in the elastic modulus of the samples using the two methods of analysis: Ideal and General function. The result indicates that the elastic modulus obtained from the sample due to ideal analysis (14.506 SD 3.268 GPa) was significantly 
lower than that obtained from general method (17.803 SD 3.998GPa). Figure 4.2 depicts mean elastic moduli obtained using the two analysis methods and also reflects the difference. See Appendix A for paired two samples t-test Analysis of the statistical data.

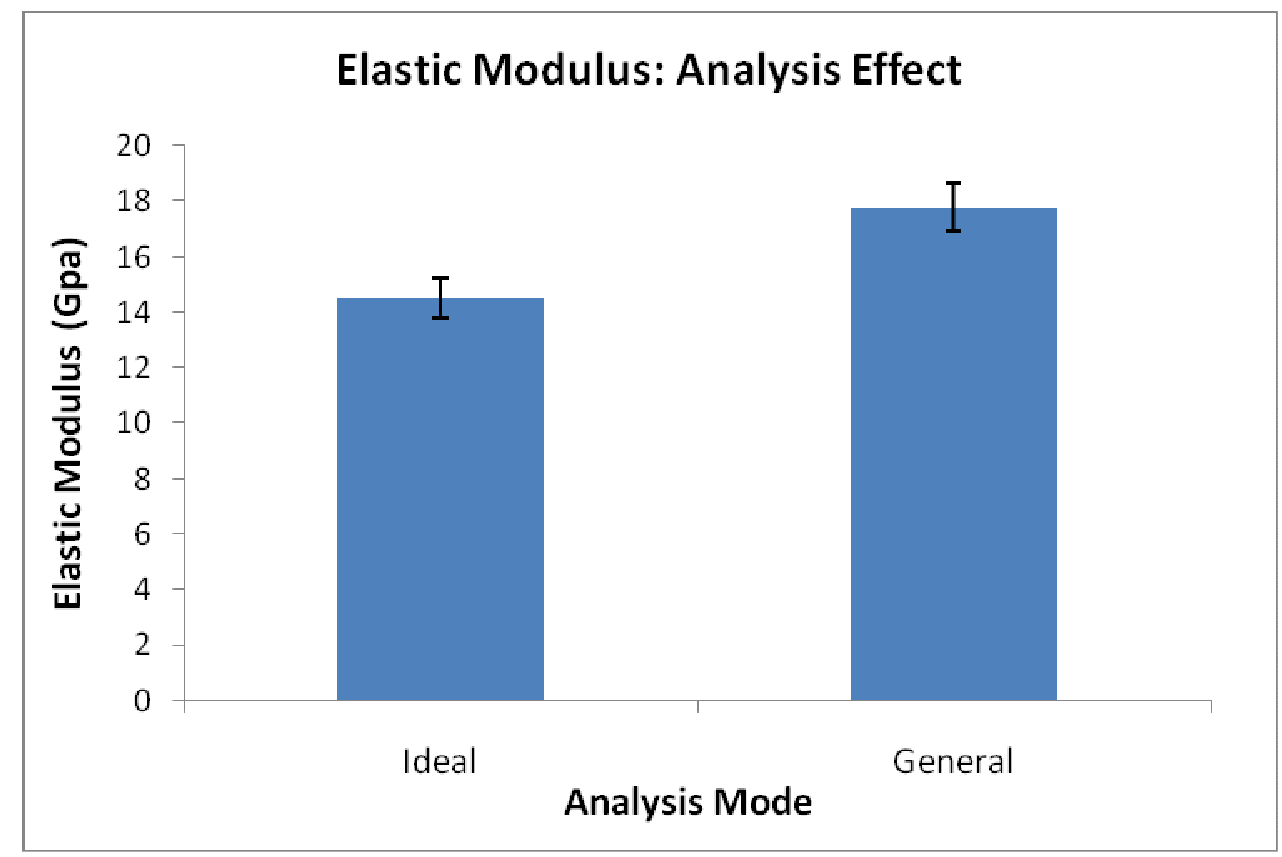

Figure 4.2: Analysis Effect on elastic modulus in beagle dog ribs

\subsection{Ideal Function Elastic Modulus}

When the data was analyzed using ideal mode of the instrument, there were significant differences for the elastic modulus in the interaction between the control (0) and alendronate treatment (1) whether 1 year or three years treatment. Thus, the elastic modulus of the treated (medicated) subjects after 1 year alendronate medication (13.720 
$\pm 0.142 \mathrm{GPa})$ was significantly greater than that of the control subject $(12.382 \pm 0.143$ GPa) - Figure 4.3.

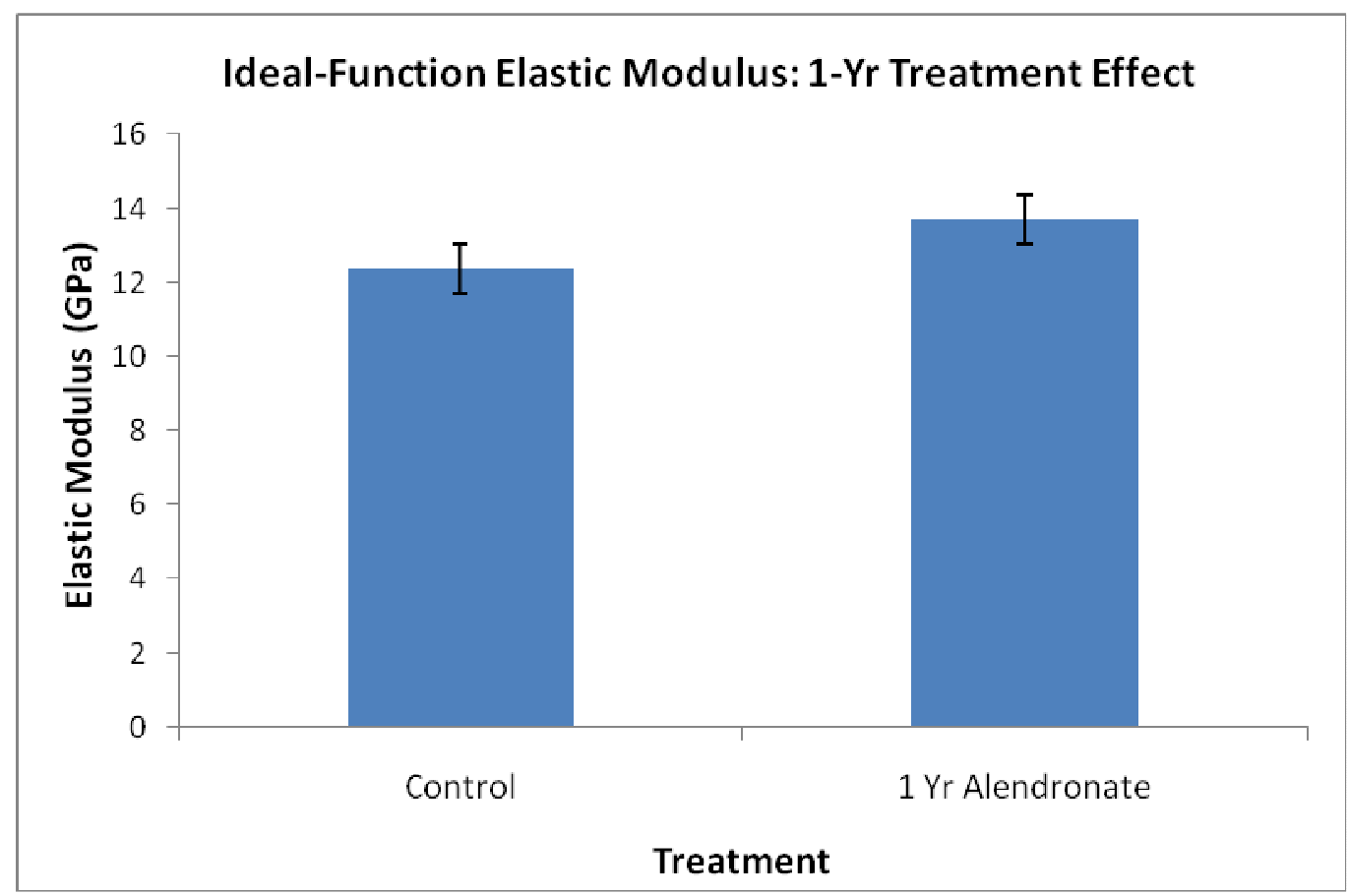

Figure 4.3: 1-year treatment effect on ideal-function elastic modulus in beagle dog ribs

In the Figure 4.4, the 3 year alendronate treatment study showed that the elastic modulus of control subjects $(18.481 \pm 0.126 \mathrm{GPa})$ was significantly greater than that of the medicated $(13.434 \pm 0.131 \mathrm{GPa})$ with $<0.0001 \mathrm{p}$-value. The elastic moduli of subjects within each group were also significantly different with same p-value of $<0.0001$. 


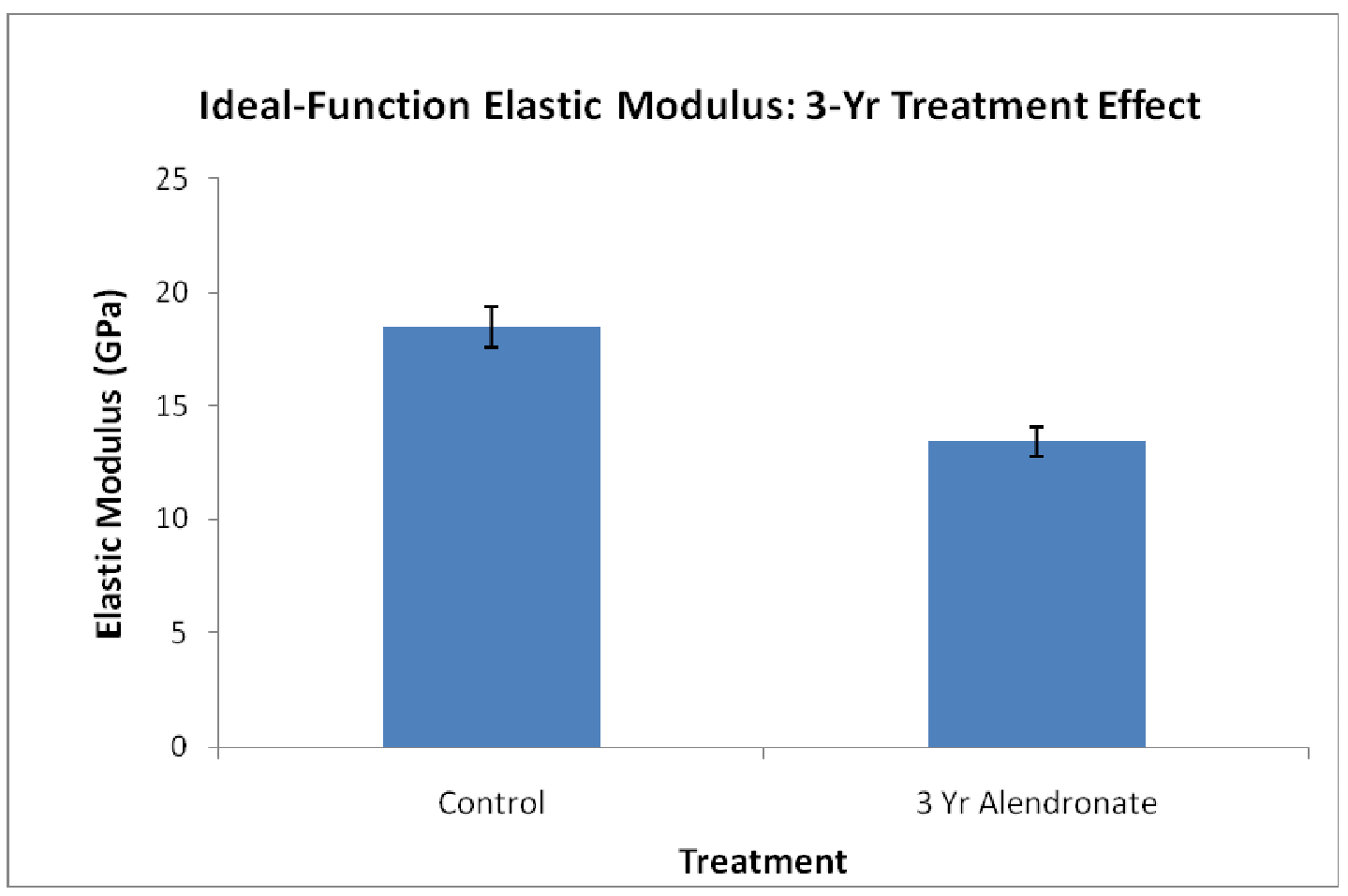

Figure 4.4: 3-year treatment effect on ideal-function elastic modulus in beagle dog ribs

Figure 4.5 shows the results of the treatments and dosage effects as analyzed by the ideal function mode of the diamond area function of the instrument. The elastic modulus differences for the Veh treated dogs, though fairly large, are not statistically different $(\mathrm{p}=0.146)$ and the elastic modulus for the $0.2 \mathrm{ALN}$ group were equal $(\mathrm{p}=1.0)$ 


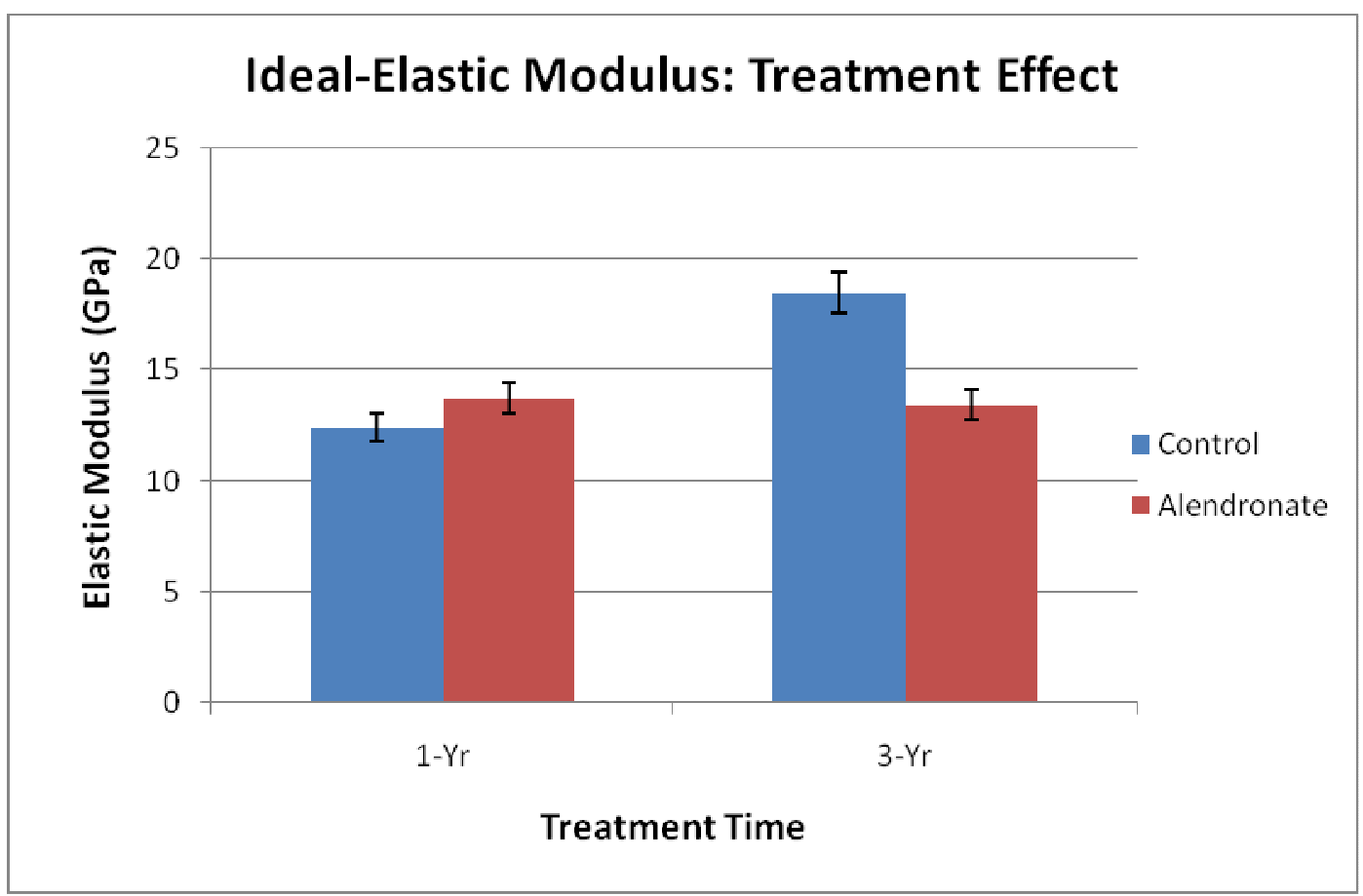

Figure 4.5: Treatment time effect on elastic modulus in beagle dog using ideal function analysis

\subsection{General-Function Elastic Modulus}

As shown in Figure 4.6, difference in treatment for 1 year alendronate medication and the control had a significant effect on the elastic modulus when analyzed with general function method ( $\mathrm{p}$-value $<0.0001$ ), where the elastic modulus of the 1 year alendronate-treated subjects $(16.887 \pm 0.174 \mathrm{GPa})$ is greater than control group $(15.211$ $\pm 0.175 \mathrm{GPa}$ ). The subjects are significantly different within each group (p-value $<$ $0.0001)$ 


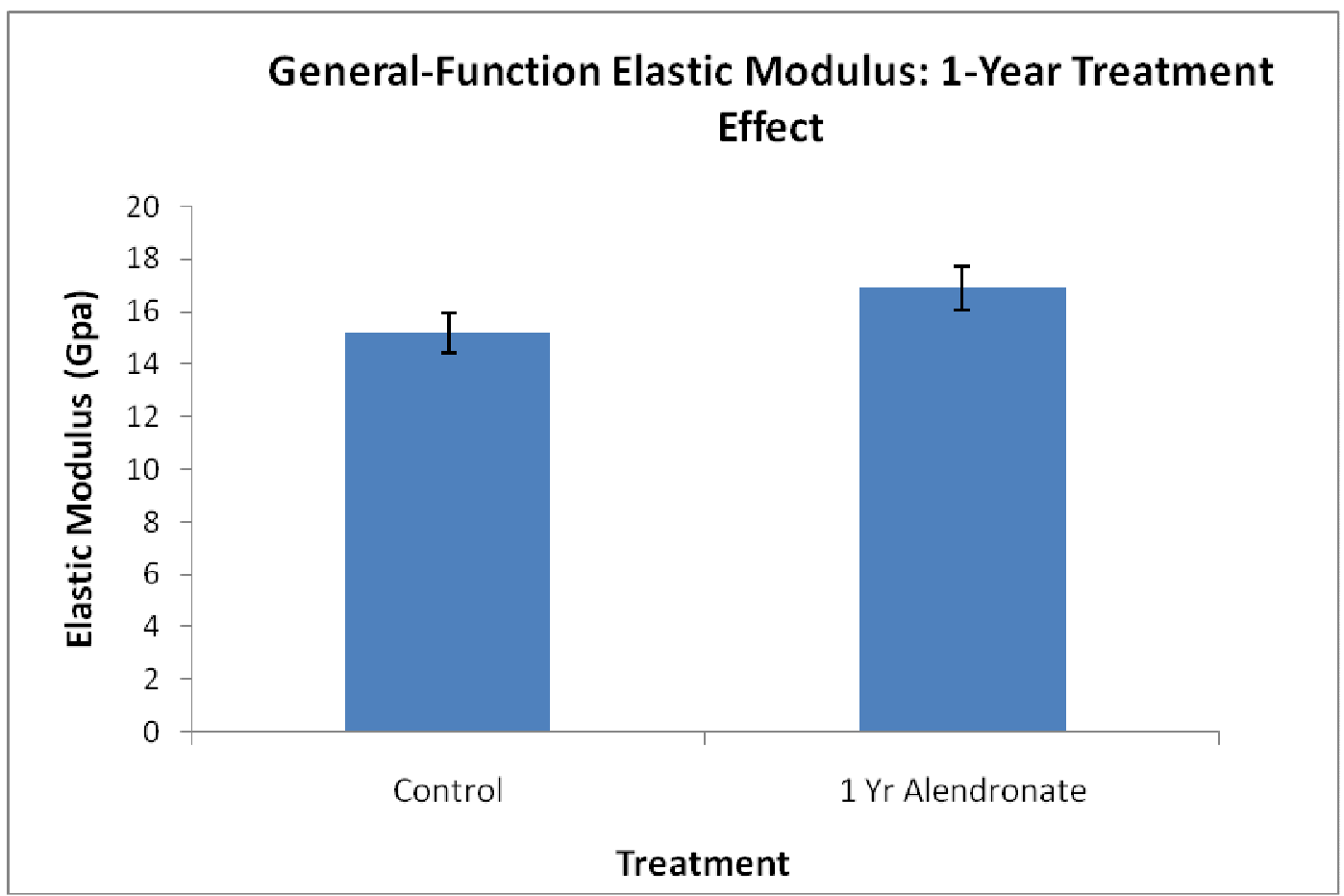

Figure 4.6: 1-year treatment effect on general-function elastic modulus in beagle dogs

When the data was also analyzed using general function (Figure 4.7), differences in the 3-year alendronate dose and the control group indicated a significant effect on the elastic modulus (p-value $<0.0001)$, where the elastic modulus of the control group $(22.289 \pm$ $0.168 \mathrm{GPa})$ is greater than that of the 3 years-treated subjects $(17.086 \pm 0.179 \mathrm{GPa})$ 


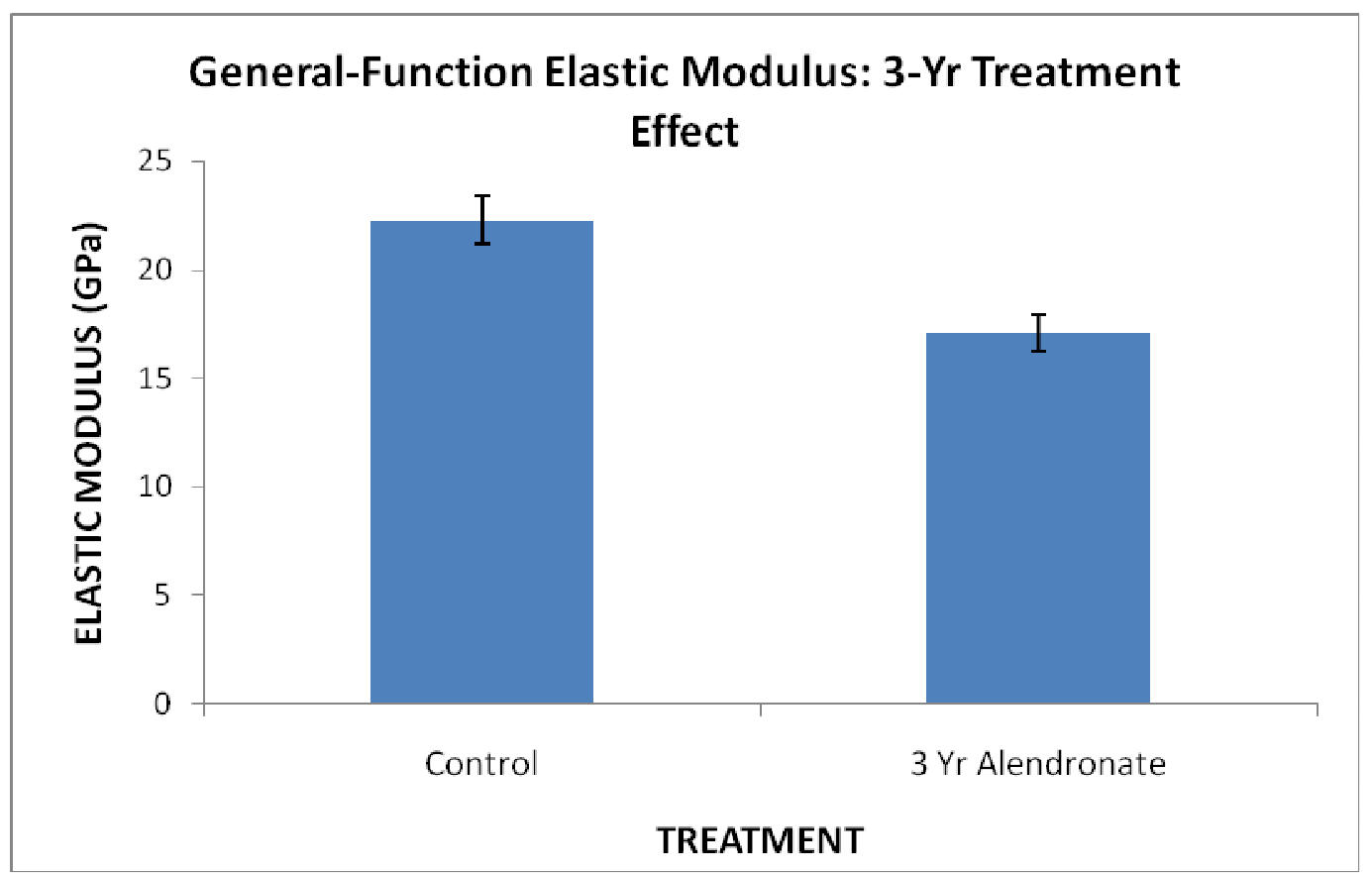

Figure 4.7: 3-year treatment effect on general-function elastic modulus in beagle dog ribs

Figure 4.8 shows the summary of the treatments and dosage effects as analyzed by the general function mode of the diamond area function of the instrument. When compared to their respective group control group, the elastic modulus for the 1-year treatment was higher than that for 3-year treated group, whereas the elastic modulus in 3-year control seems much higher than that of the 1-year. The results for the elastic modulus are shown in Fig 4.8. The elastic modulus differences for the Veh treated dogs were fairly large and statistically different $(\mathrm{p}<0.0001)$, but the elastic modulus for the 0.2 ALN group were equal $(\mathrm{p}=1.0)$ 


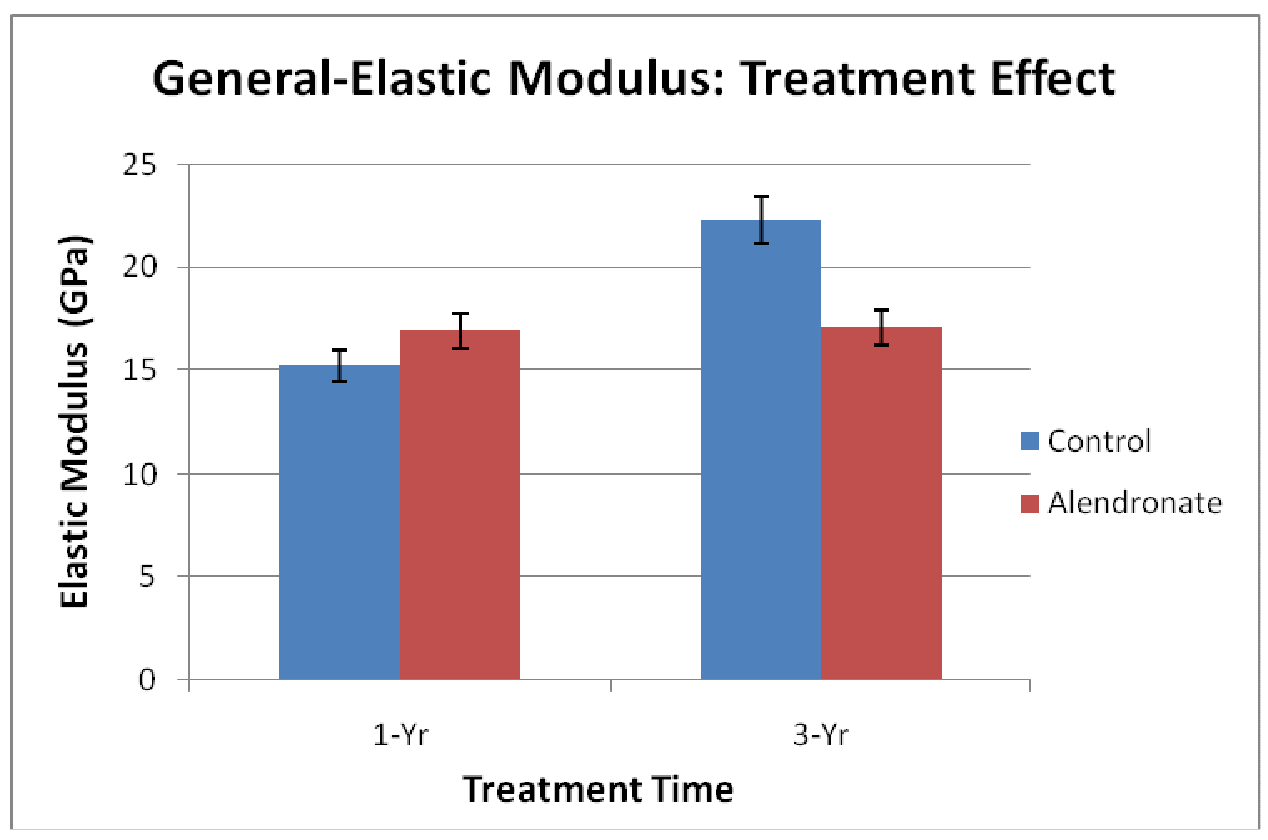

Figure 4.8 Treatment Time effect on elastic modulus in beagle dog using general function analysis

\subsection{Hardness}

A repeated measures ANOVA (SAS V. 9.1, Cary, NC) were used to determine differences with hardness as the dependent variable, and the treatment (control (0) and medicated (1)) as the subject and effects in model. Furthermore, a paired two sample ttest was performed (irrespective of the medication treatment) to determine if there is any difference in the hardness of the samples using the two methods of analysis: Ideal and General function. The result indicates that the hardness obtained from the sample due to ideal analysis (0.470 GPa SD 0.095) was significantly lower than that obtained from the general method (0.658 GPa SD 0.134). Figure 4.9 shows the mean hardness chart from 
these two analysis methods, reflecting the difference $(p$-value $=0)$. See Appendix A: Paired two samples t-test Analysis.

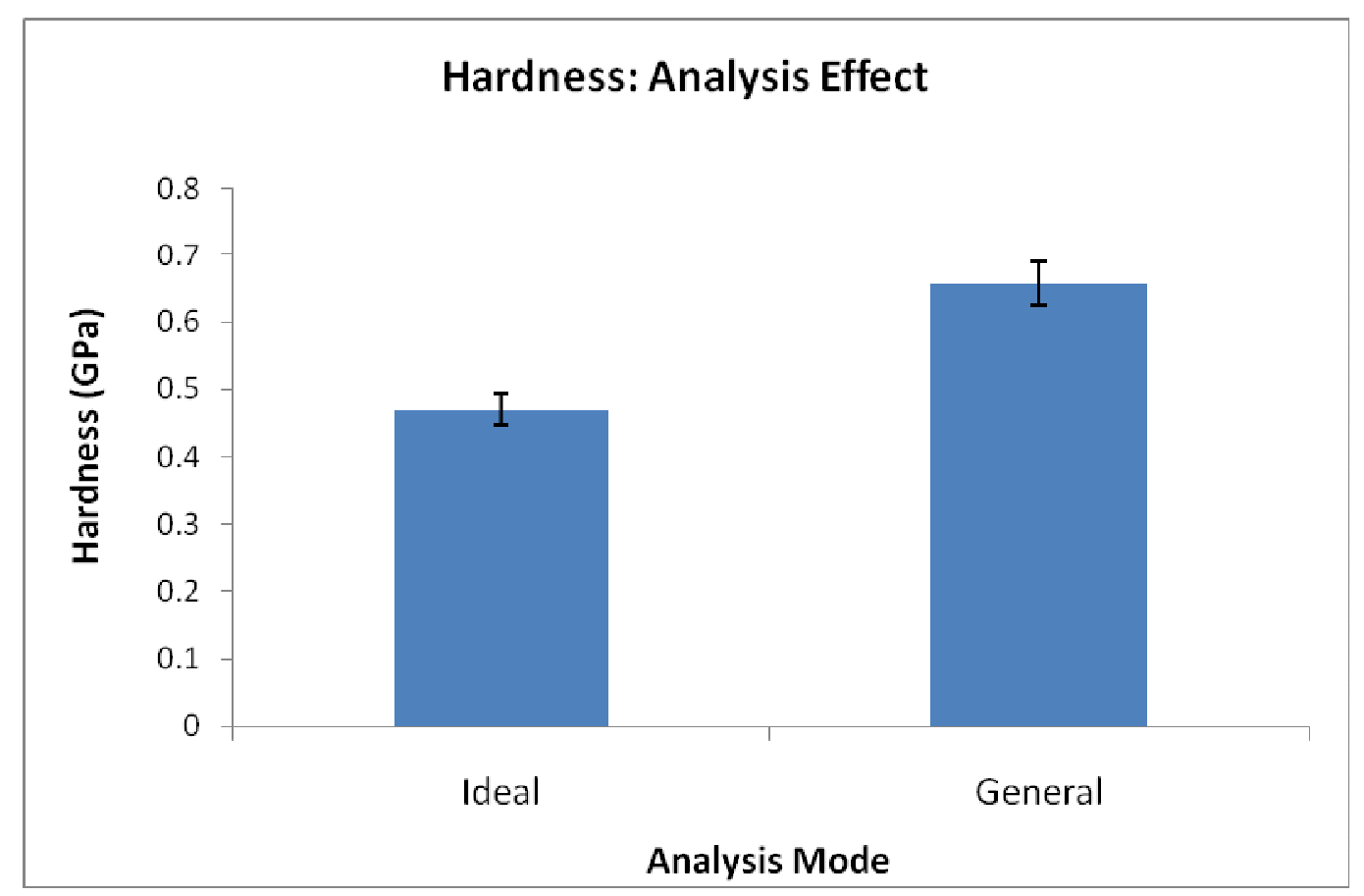

Figure 4.9: Analysis Effect on hardness in Beagle dog ribs.

\subsection{Ideal-Function Hardness}

The ideal function data were grouped into 1 year treatment and 3 years treatment with each having groups of control. There was evidence of significant difference between the hardness values of the 3-year alendronate-treated subjects, and also between the corresponding control group subjects (p-value $<0.0001$ ). Significant difference was evident in distributions of 3-year alendronate treatment and the control group (Figure 4.10) with $\mathrm{p}$-value of $<0.0001$. The hardness of the 3 years alendronate-treated subjects 
$(0.506 \pm 0.0038)$ is significantly lower than that of the control group $(0.560 \pm 0.0037$ $\mathrm{GPa})$.

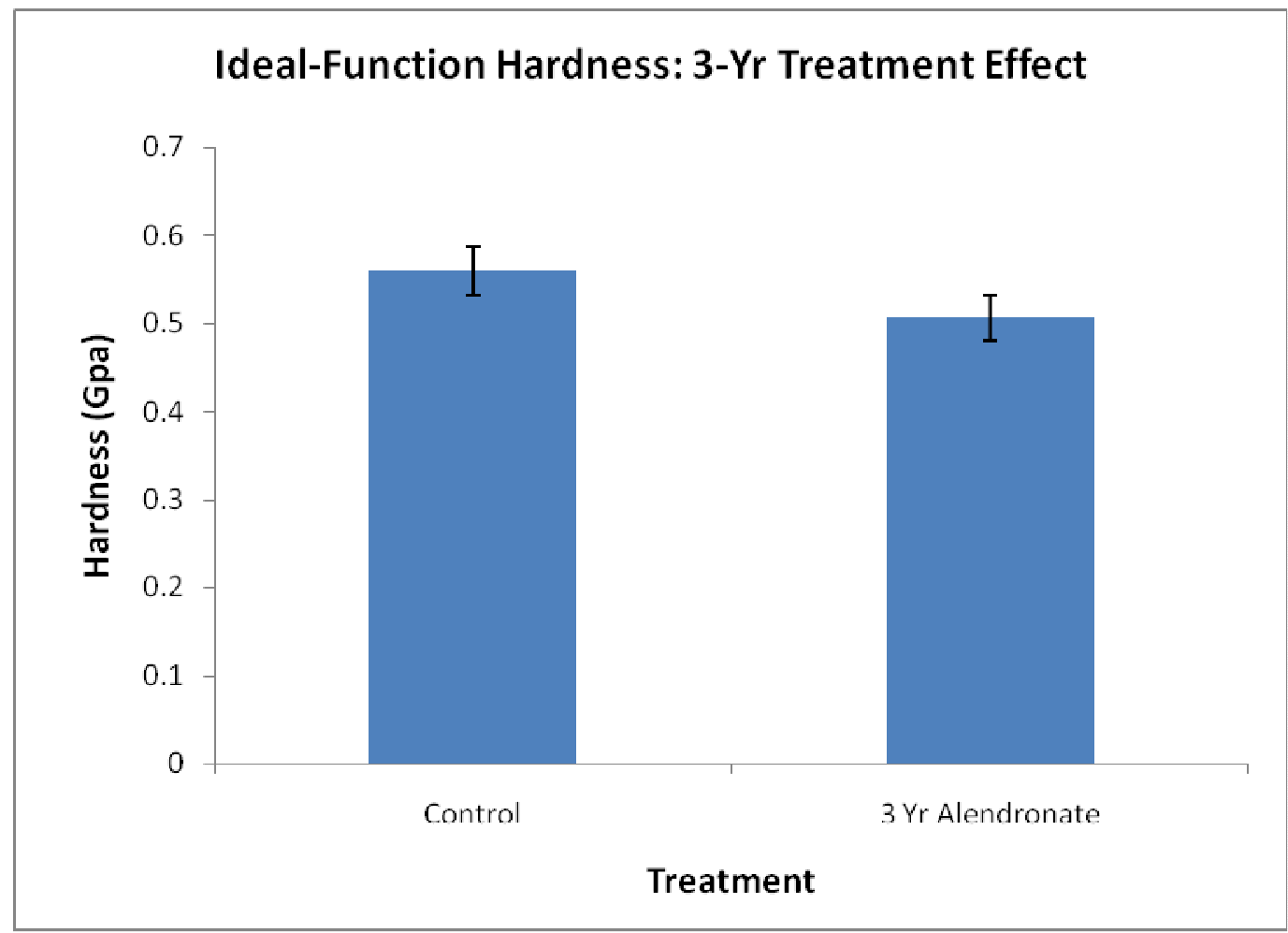

Figure 4.10: 3-year treatment effect on ideal-function hardness in beagle dog ribs.

The hardness of the 1 year alendronate-treated subjects $(0.3950 \pm 0.004 \mathrm{GPa})$ was not significantly lower than that of the control group $(0.405 \pm 0.004 \mathrm{GPa})$, having p-value 0.0894 where $\mathrm{p} \leq 0.05$ indicates significant difference. So, there was not enough evidence of a significant difference in the hardness of these two treatments (Figure 4.11). However, there was significant difference in the hardness values amongst the subjects within each group whether the medicated or the vehicle (both p-values $<0.0001$ ) 


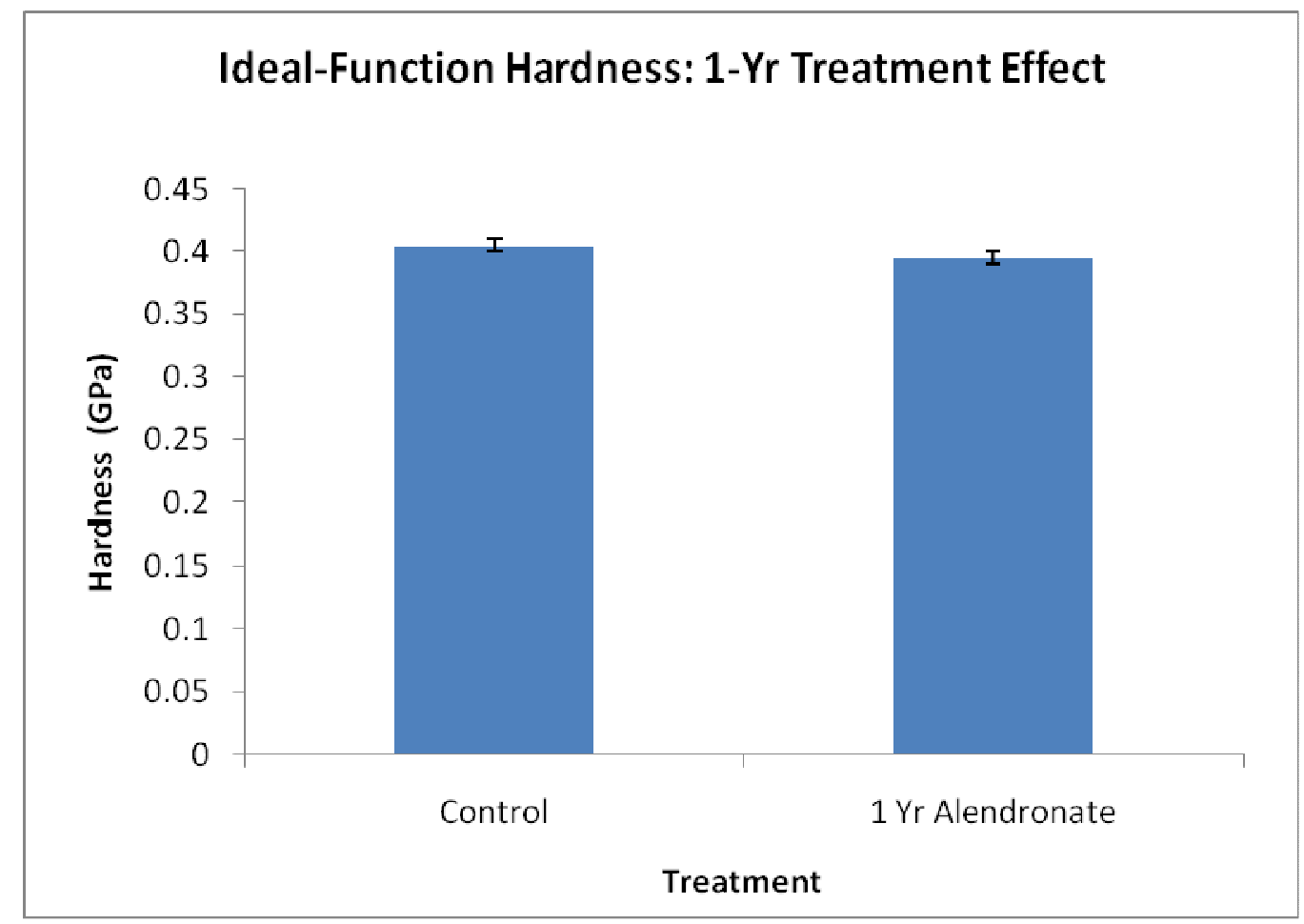

Figure 4.11: 1-year treatment effect on ideal-function hardness in beagle dog ribs.

Figure 4.12 shows the results of the treatments and dosage effects as analyzed by the ideal function mode of the diamond area function of the instrument. The hardness results indicated that the difference for the VEH treated dogs was significant $(p=0.023)$ whereas the differences for the 0.2 ALN group were not $(p=0.140)$. 


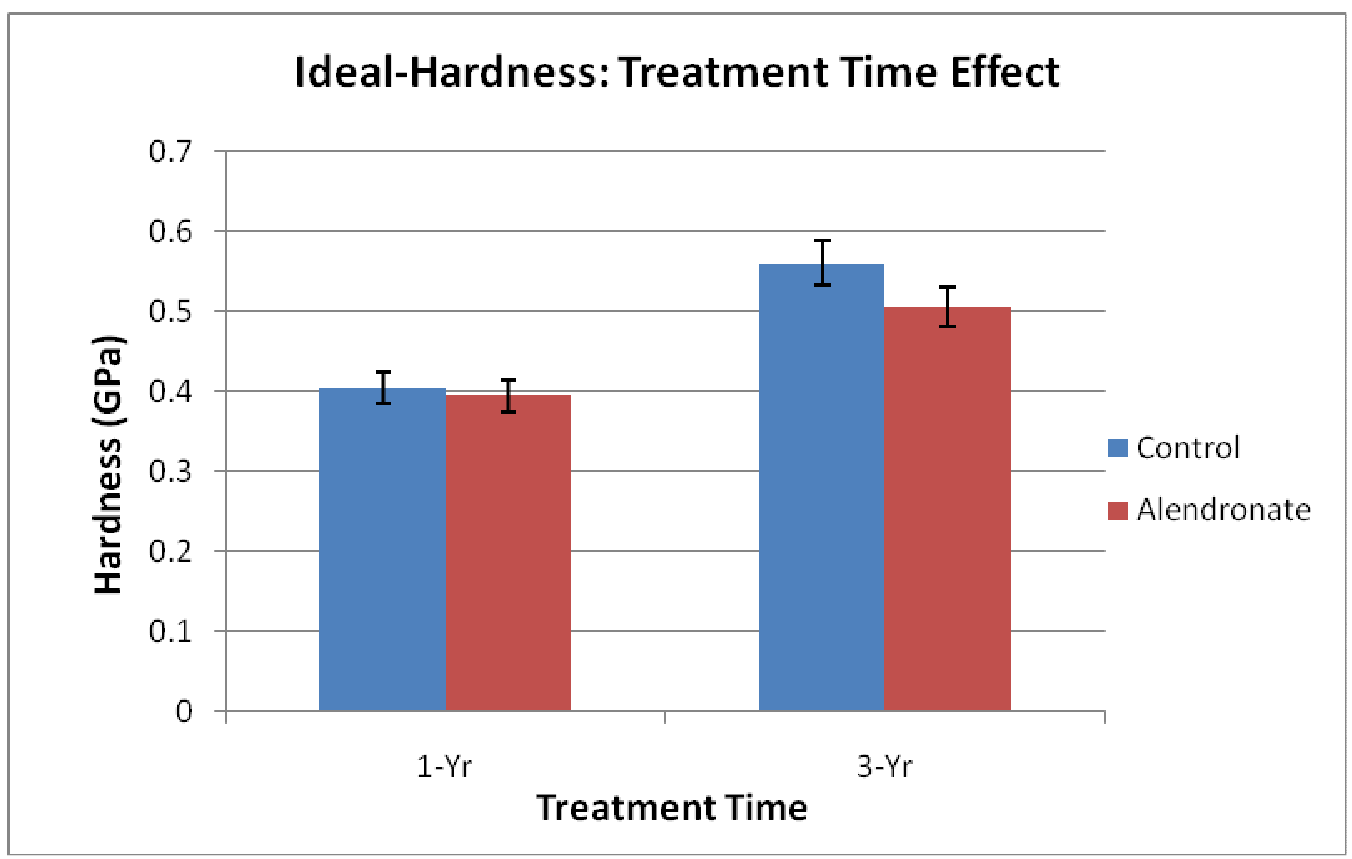

Figure 4.12: Treatment Time on hardness in beagle dog using ideal function analysis

\subsection{General Function Hardness}

From the general function data, hardness was made the dependent variable in the repeated measures ANOVA (SAS V. 9.1, Cary, NC) which were used to determine the differences between subjects in each group of the control and medicated (both 1 year and 3 years alendronate) and also between the two group treatments (control and alendronate-treated). $\mathrm{P} \leq 0.05$ would be an evidence of significant difference in the hardness due to the given treatment effect with the general function analysis method.

The 3 years-treated subjects showed a significantly lower hardness $(0.737 \pm 0.0054 \mathrm{GPa})$ when compared with that of the control group $(0.777 \pm 0.005 \mathrm{GPa})$, Figure 4.13. Within 
each group, there was evidence of significant difference between the hardness values of the subjects $(\mathrm{P}$-value $<0.0001)$

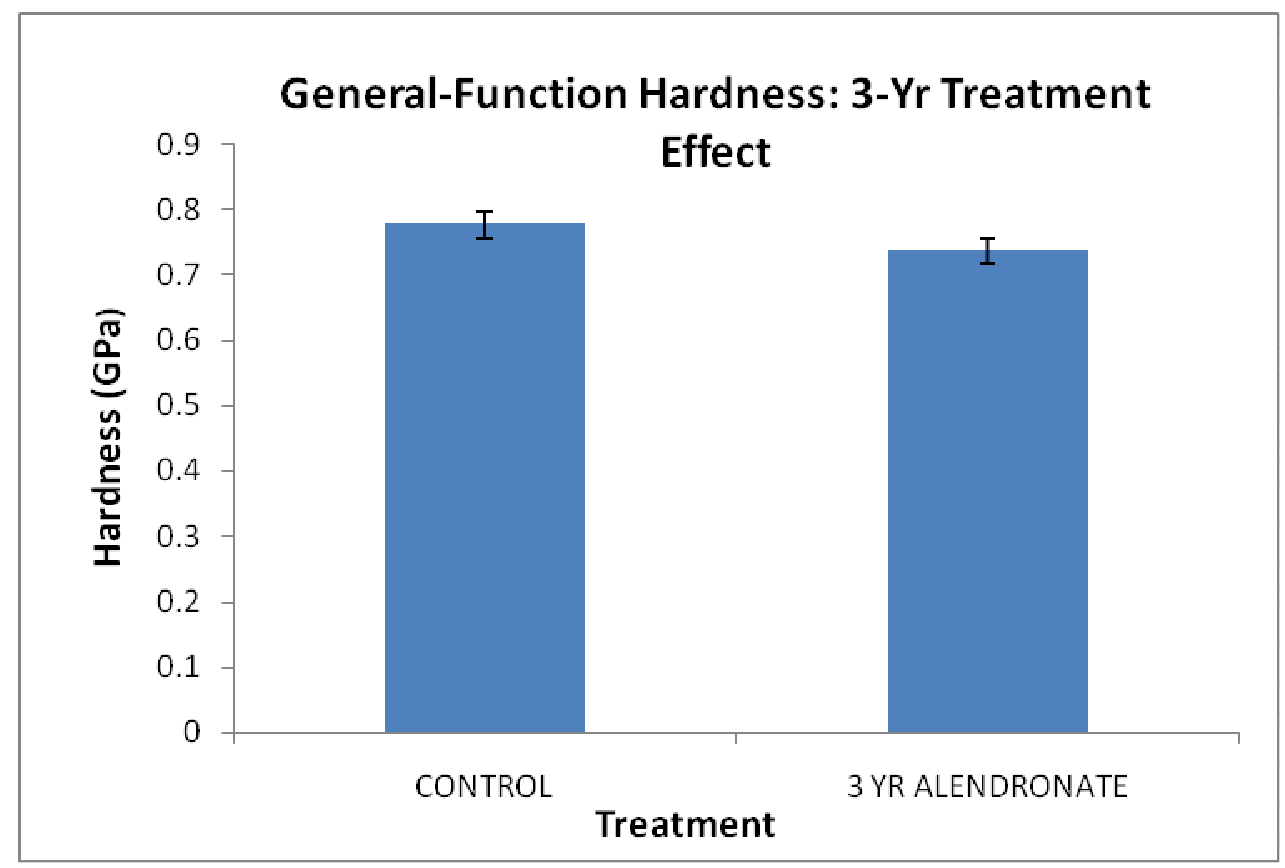

Figure 4.13: 3-year treatment effect on general-function hardness in beagle dog ribs.

The hardness of the 1 year treatment using the same analysis method $(0.555 \pm 0.006 \mathrm{GPa})$ was insignificantly lower than that of the control group $(0.568 \pm 0.006 \mathrm{GPa})$ with 0.104 p-value, while within each group the subjects' hardness were significantly different (pvalue $<0.0001$ ) as shown in Figure 4.14 


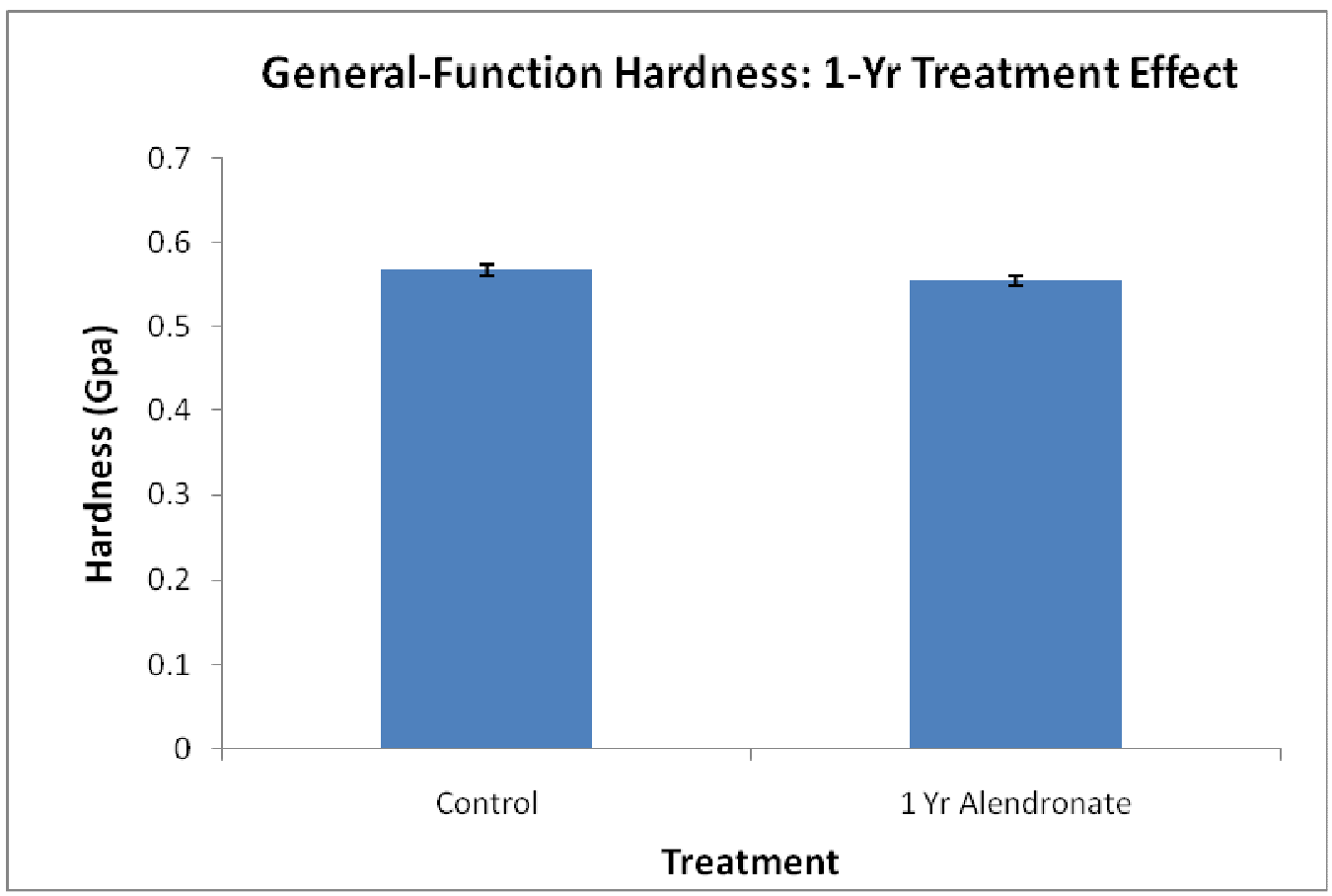

Figure 4.14: 1-year treatment effect on general-function hardness in beagle dog ribs.

Figure 4.15 shows the summary of the treatments and dosage effects on the hardness of the bone sample as analyzed by the general function mode of the diamond area function of the instrument. The hardness of both 1-year and 3-year dosages were higher than that for their control group pairs. The combined 1-Year and 3-Year result indicated there was significant difference in the hardness for both (within) the VEH and ALN treated dogs $(\mathrm{p}<0.0001)$ 


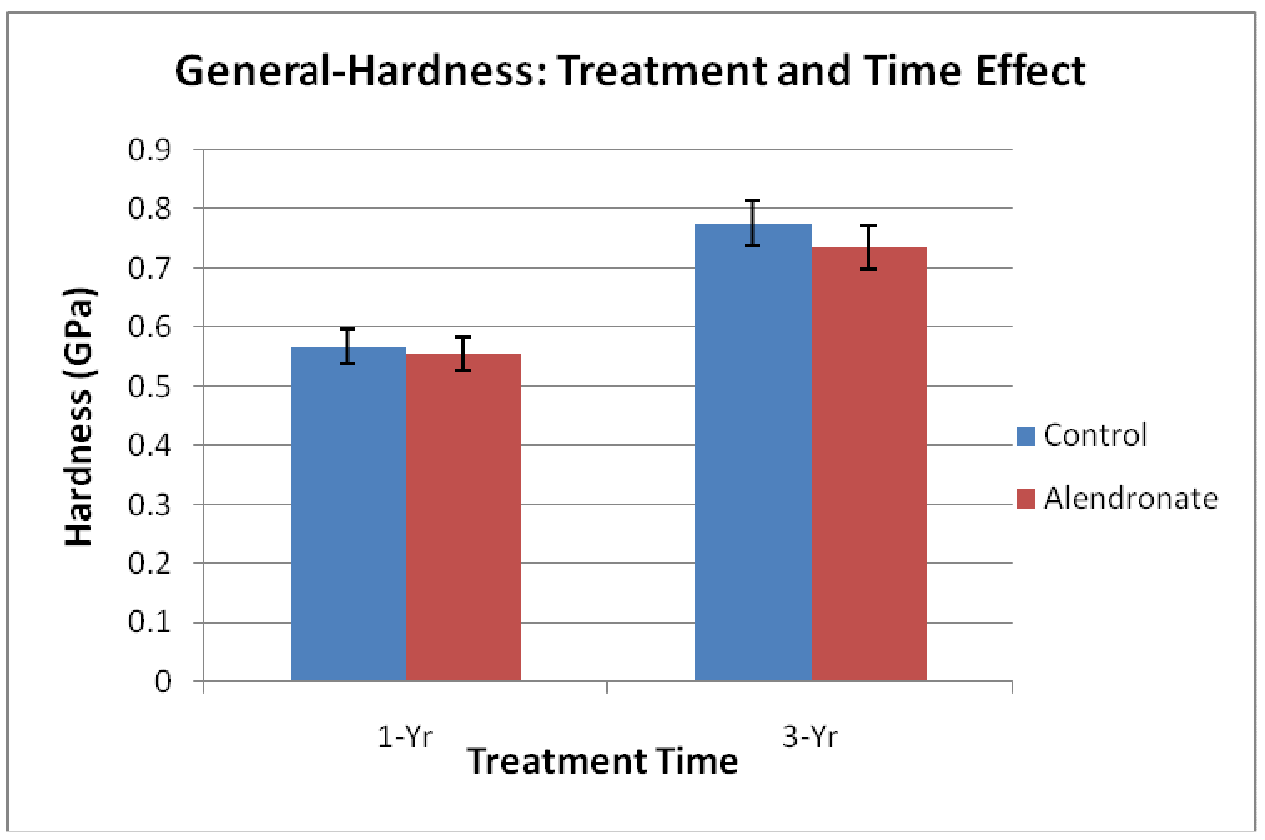

Figure 4.15: Treatment Time effect on hardness in beagle dog using general function analysis

\subsection{Elastic Work}

A repeated measures ANOVA (SAS V. 9.1, Cary, NC) was used to determine the differences in the elastic work between subjects in each group of the control and medicated (both 1 year and 3 years alendronate) and also between the two group treatments (control and alendronate-treated). P-value $\leq 0.05$ would be an evidence of significant difference in the elastic work. The energy properties of the canine ribs were analyzed using the ideal function data (which would yield the same results as general function since the machine frame compliance is not used in determining energy properties).

The elastic work done on the 1year treated subjects $(64.3176 \pm 0.4599 \mathrm{~nJ})$ were significantly lower than that of the control subjects $(72.7549 \pm 0.4640 \mathrm{~nJ})$ having a 
significance of $p \leq 0.0001$. The elastic works on all three subjects within each group were also significantly different from one another $(\mathrm{p} \leq 0.0001)$

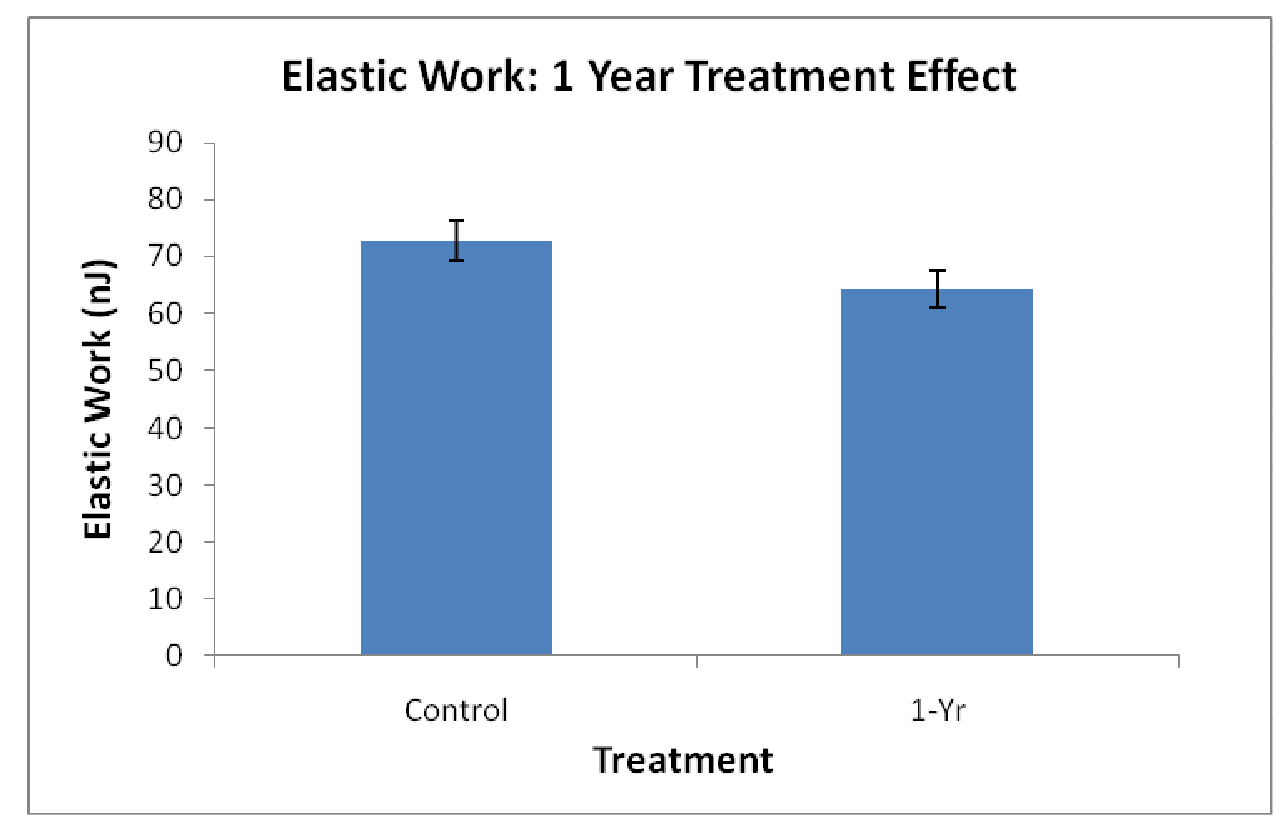

Figure 4.16: 1-year treatment effect on elastic work in beagle dog ribs.

The 3 years treatment group showed a significantly higher elastic work $(76.085 \pm 0.5481$ $\mathrm{nJ})$ when compared to the control treatment group $(58.034 \pm 0.6630 \mathrm{~nJ})$ with significance $p \leq 0.0001$. Likewise, the elastic works of all three subjects within each group were significantly different from one another $(\mathrm{p} \leq 0.0001)$ 


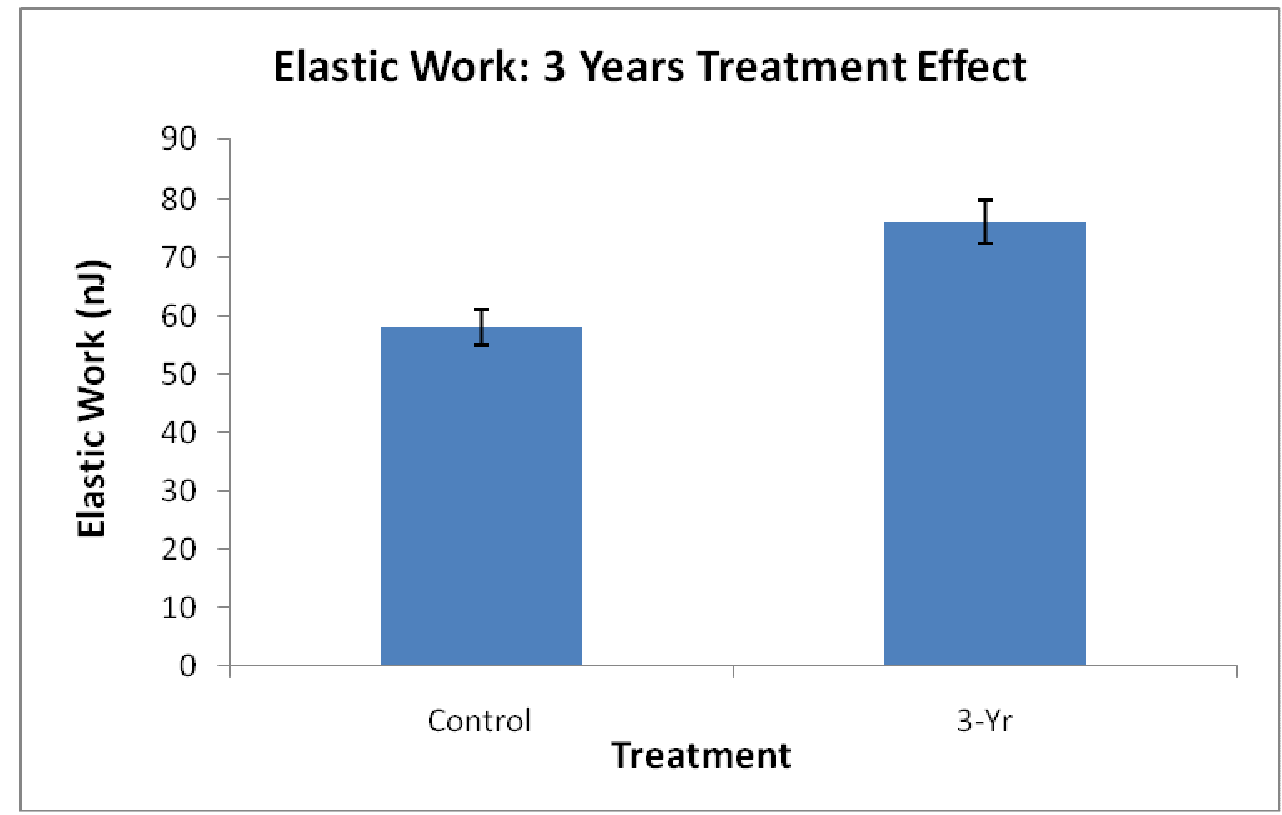

Figure 4.17: 3-year treatment effect on elastic work in beagle dog ribs.

The elastic work of the 3-year alendronate treatment $(76.085 \pm 0.5481 \mathrm{~nJ})$ was significantly higher than that of the 1-year treatment $(64.318 \pm 0.4599 \mathrm{~nJ})$ with the probability, $\mathrm{p} \leq 0.0001$. Unlike the 1 year treatment where the elastic work for alendronate-treated was lower than the control, the 3 year treatment showed a higher elastic work when compared to that of the control. 


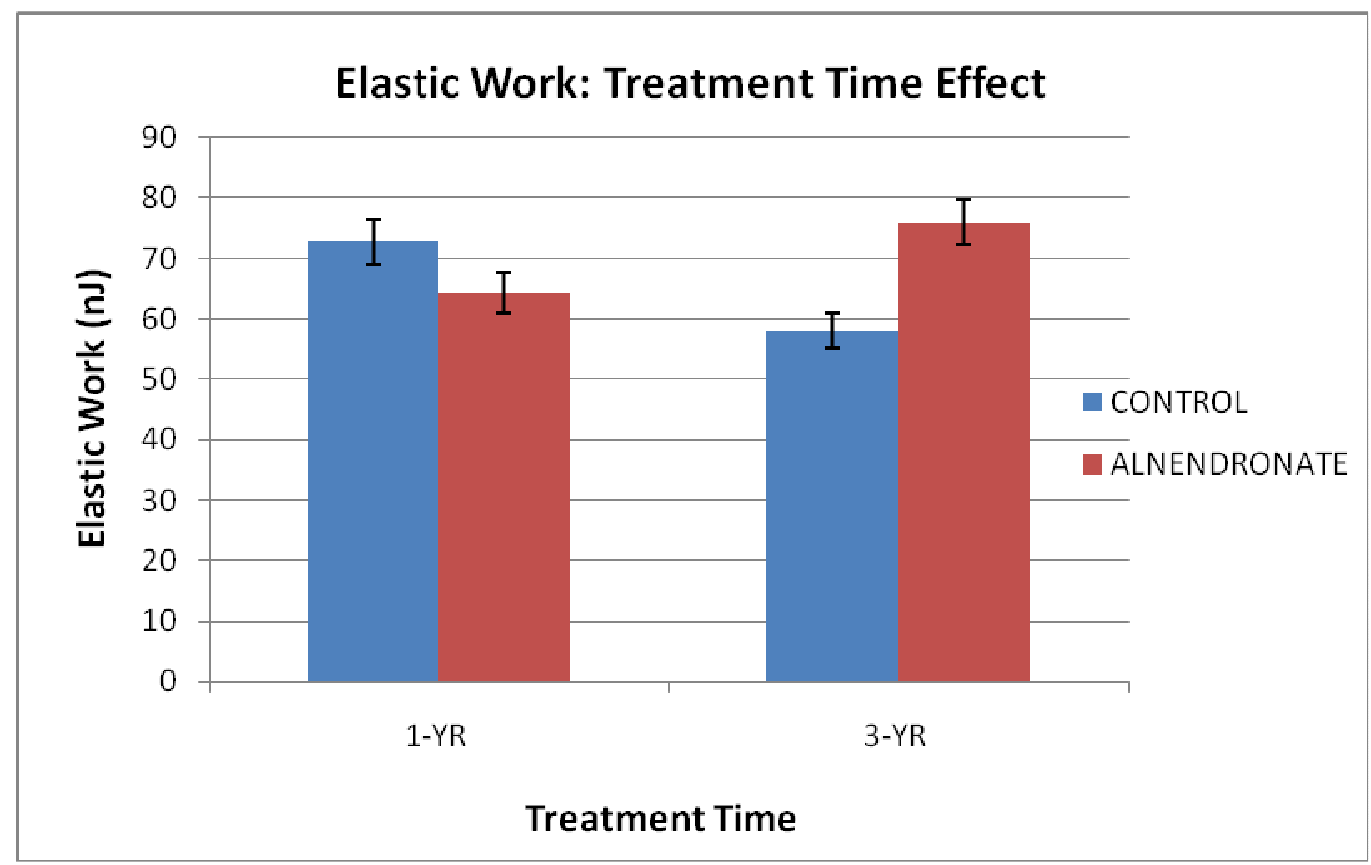

Figure 4.18: Treatment Time effect on elastic work in beagle dog.

\subsection{Plastic Work}

The plastic works for the control group $(301.2 \pm 1.647 \mathrm{~nJ})$ was not significantly different from 1 year treatment group $(303.2 \pm 1.633 \mathrm{~nJ})$, with $\mathrm{P} \leq 0.3899$. However, each of the subjects within each group of treatments (control and treated) was significantly different from one another in their respective groups $(\mathrm{p}<0.0001)$. 


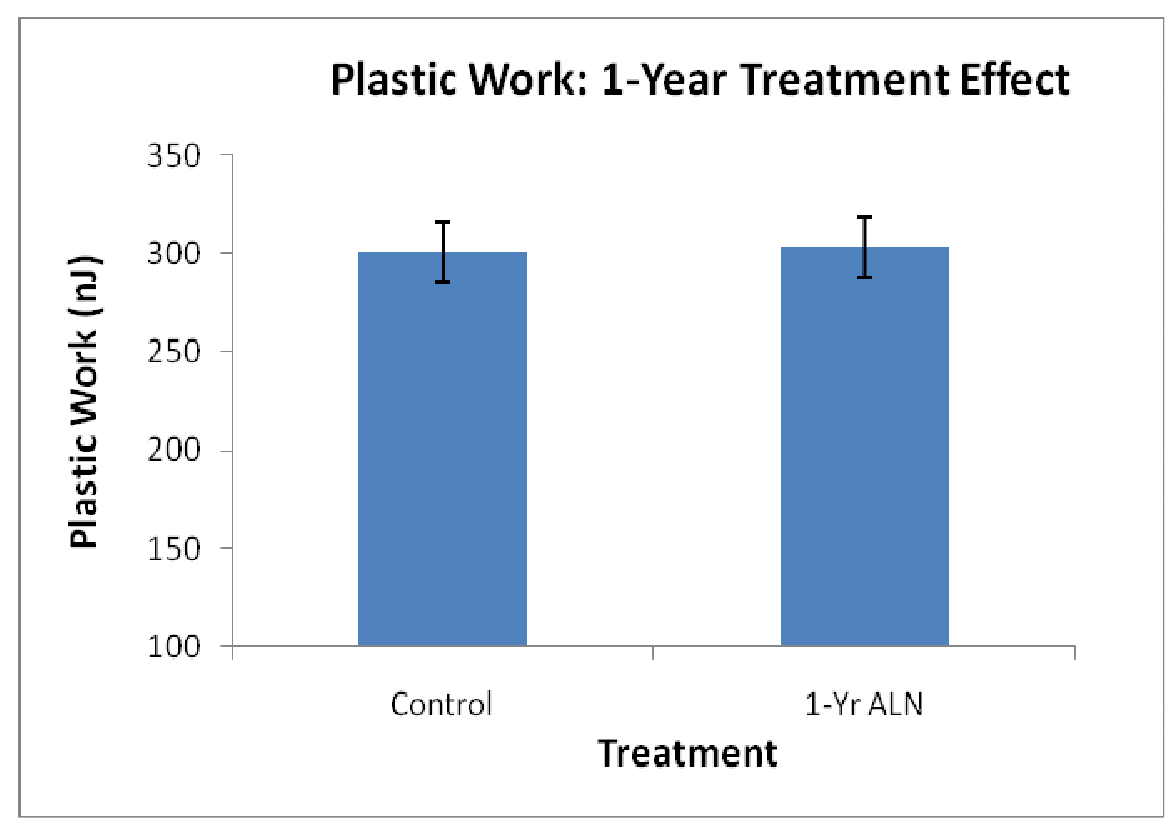

Figure 4.19: 1-year treatment effect on plastic work in beagle dog ribs.

3-Year alendronate treatment showed a significantly higher plastic work (265.81 \pm $1.0494 \mathrm{~nJ})$ over the control treatment $(250.79 \pm 1.2693 \mathrm{~nJ})$ with $\mathrm{p}<0.0001$. All subjects within each group also had significantly different plastic work $(\mathrm{p}<0.0001)$. 


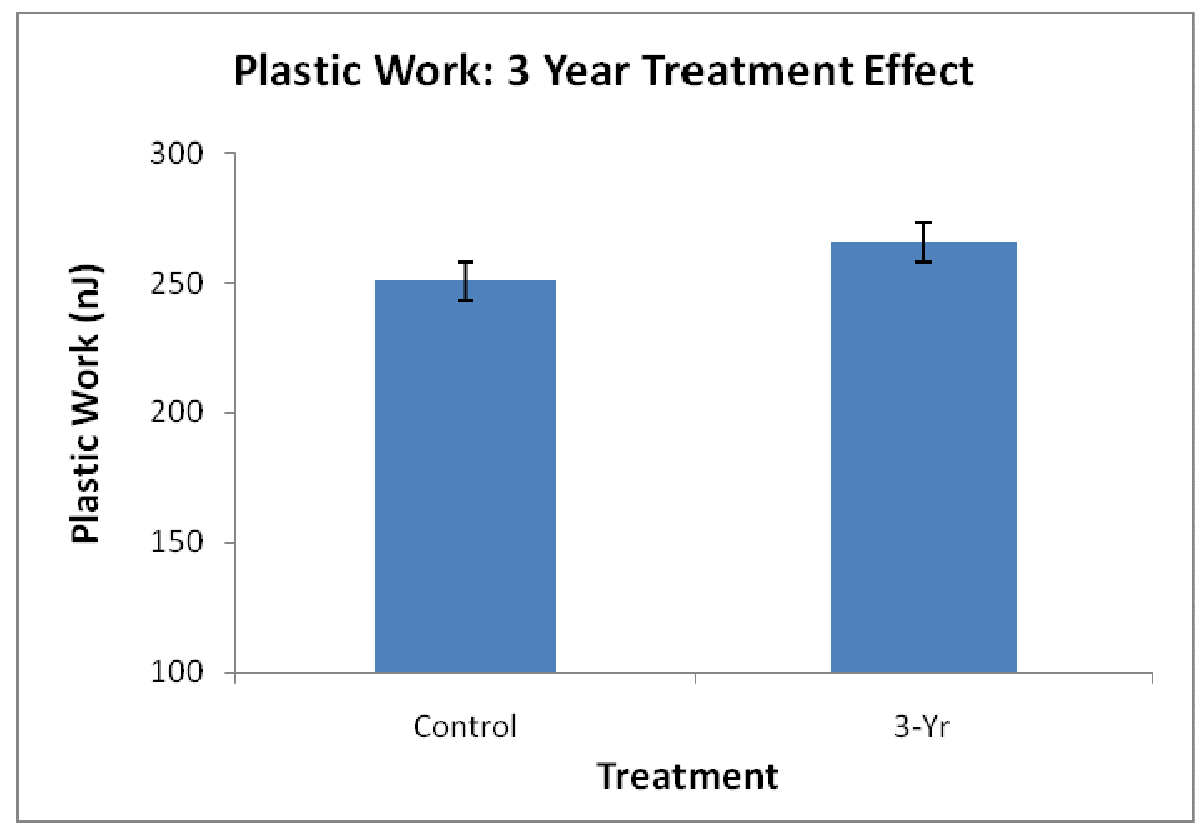

Figure 4.20: 3-year treatment effect on plastic work in beagle dog ribs.

Unlike the elastic work, the plastic work of the 3-year treatment was significantly lower $(265.81 \pm 1.0494 \mathrm{~nJ})$ than that of 1 -year treatment $(303.2 \pm 1.633 \mathrm{~nJ})$. The two control treatments groups were respectively different as their plastic works. 


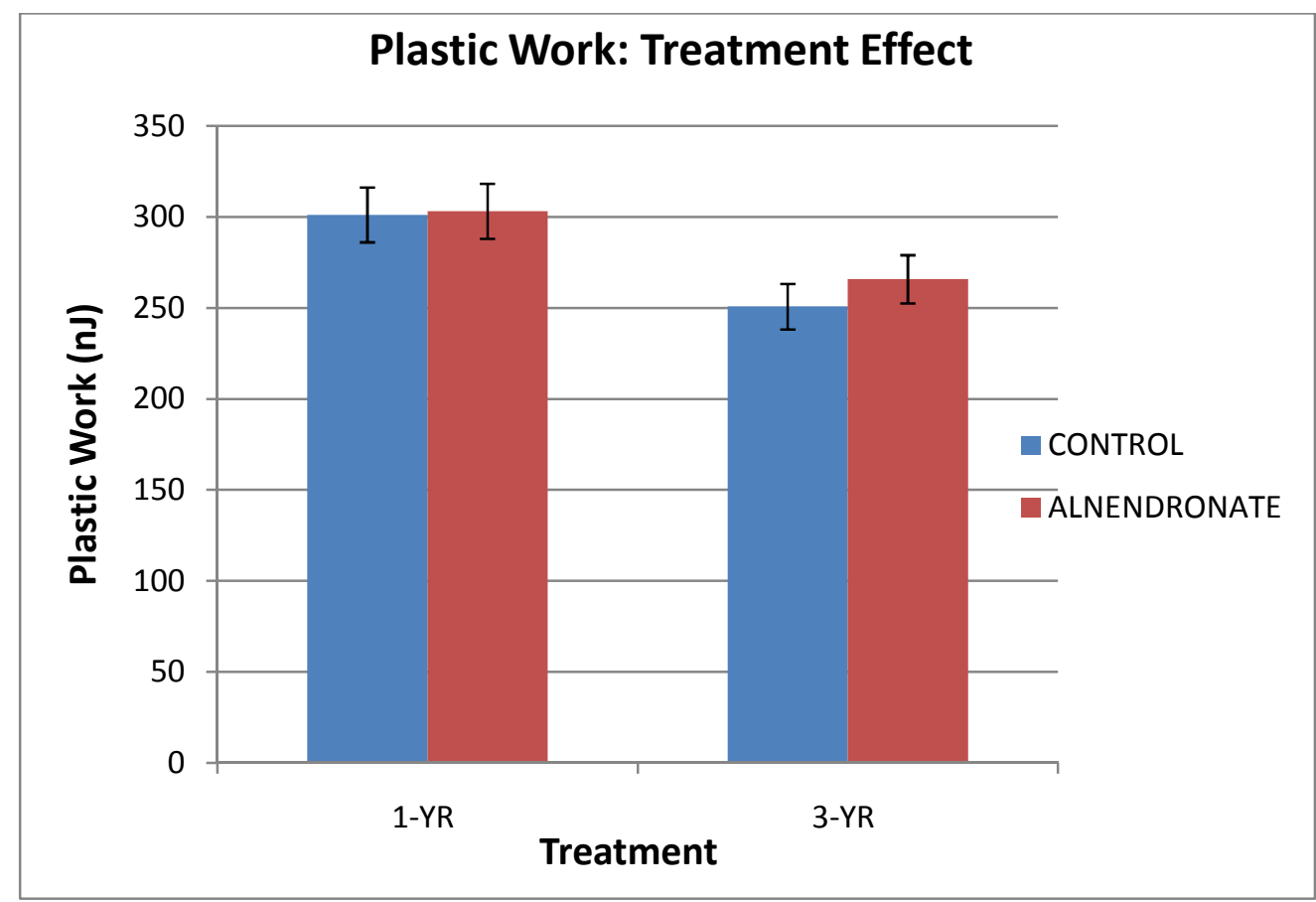

Figure 4.21: Treatment Time effect on plastic work in beagle dog. 


\subsection{Discussion}

The results obtained from the nanoindentation analyses of the alendronate-treated (ALN) beagle clearly reveals the treatment time and analysis methods as they affect the both the hardness and the elastic modulus of the beagle dog ribs. The differences are explained below:

1. All the subjects had significantly different strength and stiffness within each treatment (VEH and $0.2 \mathrm{mg} / \mathrm{kg} \mathrm{ALN})$.

2. The strength and the stiffness were lower in the 3-year alendronate compared to the control.

3. When compared with the vehicle, 1-year alendronate treated beagle dogs had a significantly higher strength, but insignificantly different stiffness.

4. Stiffness at 1 year alendronate treatment did not show any significant difference irrespective of the analysis method.

5. In either of the analysis methods, 3-year treatment indicated an equal strength with 1-year treatment.

6. The plastic work done on 1-year treatment was not different from the control while the elastic work done in the same treatment was significantly lower than the control.

7. Both the plastic and elastic work done of the 3-year treatment was significantly higher than their respective control.

8. Comparing the treatment time, the elastic work after 3 years treatment was higher than 1 year whereas, the reverse was the case with the plastic work 
9. The ideal mode analysis method generated significantly lower stiffness and strength when compared to the general mode. This was because the latter appears to overestimate the area of the indenter tip used for the experiment. Hence the result from the analysis by general function mode was compared with a previous study on beagle dogs and discussed below.

A previous study by Wang et al. had shown that beagle dog vertebrae treated daily for one year had a significantly higher stiffness, but an insignificantly higher strength. The results from that study were not consistent with those obtained from this nanoindentation study. While Wang et al. reported no significant difference in strength, this report showed a significantly higher strength in alendronate treatment over the vehicle (Figure 4.6). Conversely, this report indicated no significant difference in the stiffness, whereas Wang et al. showed that the alendronate-treated had a significantly higher stiffness over the vehicle. According to another author, an 'ideal' biphosphonate dosage for treatment of a bone disease increases bone strength while the brittleness decreases [4]. This statement agrees with the effect of the 1-year alendronate treatment, perhaps not that of the 3-year treatment, though the implied brittleness of the samples was not directly tested.

When compared to 1-year medication, the increase in stiffness after 3-year alendronate treatment (Figures 4.12 and 4.15) corroborated that which was earlier reported from a study on female rats [48]: strength of the alendronate-treated bone is significantly lower than the normal bone; and the stiffness of both the treated and normal bones are not significantly different from each other. This long-term effect of alendronate on the bone 
stiffness also confirmed another finding by Odvina et al which reported a complicated effect of alendronate suppression of bone resorption over time.

In general, elastic work is that which does not go into producing a residual indentation, whereas a plastic work will produce a residual indentation. The elastic work after 3 year of alendronate treatment was higher than the 1 years treatment which indicates that the tissue quality of the 3 year alendronate treatment was probably better than that of the 1 year treatment. The higher plastic work conversely observed in the 1 year treatment over the 3-year treatment further confirmed that 1-year treatment was lower in quality when compared to 3-year treatment. Significant differences in both the strength and stiffness were established between the two modes of data diamond-area-function analyses adopted in this report: general function mode is higher than ideal function mode. The ideal mode analysis seemed to have overestimated the area of the Berkovich indenter tip, which thereby justified the necessity of the calibration of the diamond area function prior the commencement of the experiment.

The fact that the samples after cutting were left unrefrigerated for about 24 hours suggested that the bone properties might possibly have been altered. However, this should have no significant effect on the result (especially comparative), since all samples were tested under this same condition. Furthremore, all the samples, when in use, were out of the freezer for nothing less than 16 hours on the average under a controlled temperature of $23^{\circ} \mathrm{C}$. The longer duration taken for testing on some samples was believed to have caused high range (setback) in the data collected due to the difference in 
the sample moisture content at the start and the end of the indentation schedule. An increase in mechanical properties was observed in some samples as the duration of indentation increased which suggested that as the sample temperature increased from the $-20^{\circ} \mathrm{C}$ (freezer temperature) to ambient temperature $23^{\circ} \mathrm{C}$, the sample strength and stiffness increased. This agrees with the findings of previous studies on effect of moisture on the mechanical properties of bone [8].

From Chapter 2, one of our hypotheses was that tissue-level properties for alendronatetreated (0.2 Alendronate) beagles would increase because of an increased level of mineralization despite a microdamage increase. There were no significant changes in the mechanical strength for the alendronate treated group, but there was a significant increase in the strength of the control (Veh) treated animals (Fig 4.15). Figure 4.8 and Appendix showed that there was generally an increase in the stiffness of both the alendronate and control groups with increase in treatment year. It appeared the dogs used in this study, though skeletally mature, had not yet reached their peak bone mass, which would account for the increases in properties in the control group.

Microdamage is a normal process associated with fatigue loading of bone which can influence bone fragility. Allen et al. reported that alendronate therapy, which is known to be a remodeling suppressant, consequently increased microdamage in ribs after three years treatment [51]. While microdamage does increase, the mineral density and crosssectional areas also increase, which apparently offsets any damaging effects of the microdamage. In the present study, though there appears to be a significant increase in 
the hardness, the change according to Allen et al. did not have negative effect since 0.2 alendronate dosage used for this study was appropriate. Both experimental evidence [51] and computational models of microdamage and remodeling [52] suggest that the greatest effects of microdamage accumulation occurs at one year, which would be consistent with our one-year findings (Fig 4.15).

This study used non-embedded samples, which according to a state-of-art review by Lewis and Nyman, will more accurately reflect the properties of the bone, because the embedding media is known to significantly affect properties [53]. The indentation load in this study was higher than typical nanoindentation studies which are on the order of 30$50 \mathrm{mN}$ and also sample a relatively large volume of material. This is beneficial and will provide a better average value of tissue level properties since the heterogeneity of bone leads to differences within lamellae. 


\subsection{Conclusion and Recommendation}

The trends documented in this study do suggest that $0.2 \mathrm{mg} / \mathrm{kg}$ of alendronate treatment of osteoporosis does not have any long-term negative effect on canine strength, but might increase the stiffness of the bone, reduce the plastic work, and increase the elastic work . The net effect of alendronate treatment appears to be to add bone mass, but not necessarily high quality bone. This effect is analogous to a fracture callous - the woven bone response is of lower quality than lamellar bone, but it is effective in lowering fracture risk by increasing cross-sectional area.

In nanoindentation experiments, different data analysis methods are likely to yield different results. It appears advisable to perform the diamond area function test to establish a general ideal parameter for the instrument (software) use rather than using the default ideal parameter which seemed (from this report) to overestimate the indenter tip contact area. The overestimate contact area consequently and ultimately reduced the elastic moduli obtained.

A weakness of this study was the limited number of dogs used, which would likely account for why we were not able to find statistically significant changes in the strength for the 0.2 ALN group. It appeared the dogs used in this study though skeletally mature, had not yet reached their peak bone mass, which would account for the increases in properties in the control group. In the future, it is advisable to use control samples of the same condition and treatment so as to minimize (if not eliminate) the difference in their properties. 
The sample-holding mechanism of the diamond cutting machine exacted such a high pressure that squeezed some substances out of the bone marrow of some of the samples. This is also believed to have caused some cracks observed on some samples and possibly affected the tissue properties of such squeezed samples. These cracks observed under microscope were avoided as much as possible during indentation scheduling. However, a better mechanism is recommended for holding bone sample of wider range in tissue strength and shape to remove pressure effect on the sample shape and strength.

During one of the indentation schedules, the indenter ran into the marrow space, and while attempting to move to the next position the tip scratched the cortex at every move. This failure to periodically detect the wax-filled surface was due to the depression in the wax-filled spot after polishing and storage. It is probably possible to avoid this surface depression if each sample was tested immediately after polishing rather than storing in freezer and testing later. 


\subsection{REFERENCES}

1. Park, J.B. and R.S. Lakes, Biomaterials : an introduction. 3rd ed. 2007, New York: Springer. xi, $561 \mathrm{p}$.

2. Martin, R.B., Burr, D.B. and Sharkey, N.A., Skeletal Tissue Mechanics. 1989, New York NY: Springer Ver-lag. 392.

3. Gutyon, A.J.H., Textbook of Medical Physiology. 10th ed. 2000, Philadephia, PA: Springer-Verlag.

4. Turner, C.H., Biomechanics of Bone: Determinants of skeletal Fagility and Bone Quality. Osteoporosis International, 2002. 13: p. 97-104.

5. Currey, J.D., Physical characteristics affecting the tensile failure properties of compact bone. J Biomech, 1990. 23(8): p. 837-44.

6. Turner, C.H. and D.B. Burr, Basic biomechanical measurements of bone: $a$ tutorial. Bone, 1993. 14(4): p. 595-608.

7. Roy, M.E., et al., Mechanical and morphological variation of the human lumbar vertebral cortical and trabecular bone. J Biomed Mater Res, 1999. 44(2): p. 1917.

8. Hengsberger, S., Kulik, A., \& Zysset, P. H. , Nanoindentation Discriminates the Elastic Properties of Individual Human Bone Lamellae Under Dry and Physiological Conditions. Bone, 2002. 30 (1): p. 178-184.

9. Rho, J.Y., et al., Variations in the individual thick lamellar properties within osteons by nanoindentation. Bone, 1999. 25(3): p. 295-300.

10. Marieb, N.E., Human Anatomy and Physiology. 3 ed. 1995, Redwood City: The Benjamin/Cummings Publishing Company, Inc. 
11. Burge, R., et al., Incidence and economic burden of osteoporosis-related fractures in the United States, 2005-2025. J Bone Miner Res, 2007. 22(3): p. 465-75.

12. Ammann, P. and R. Rizzoli, Bone strength and its determinants. Osteoporos Int, 2003. 14 Suppl 3: p. S13-8.

13. Li, B., and R. Aspden., Composition and mechanical properties of cancellous bone from the femoral head of patients with osteoporosis or osteoarthritis. J Bone Miner Res. , 1997. 4: p. 641-51.

14. Coats, A.M., Zioupos, P., \& Aspden, R. M. , Material Properties of Subchondral Bone from Patients with Osteoporosis or Osteoarthrithis by Microindentation Testing and Electron Probe Microanalysis. Calcified Tissue International 2003. 73: p. 66-71.

15. Bonjour, J.P., P. Ammann, and R. Rizzoli, Importance of preclinical studies in the development of drugs for treatment of osteoporosis: a review related to the 1998 WHO guidelines. Osteoporos Int, 1999. 9(5): p. 379-93.

16. Oliver, W.C., and G.M. Pharr, An improved tecnique for measuring hardness and elastic modulus using load and displacement sensing indentation experiments $\mathrm{J}$. Material Resources, 1992. 7(6): p. 1564-1583.

17. Fischer-Cripps, A.C., Nanoindentation. Mechanical Engineering. 2002, New York.

18. Rho, J.Y., et al., Microstructural elasticity and regional heterogeneity in human femoral bone of various ages examined by nano-indentation. J Biomech, 2002. 35(2): p. 189-98. 
19. Ko, C.-C., Douglas, W. H., \& Cheng, Y.-S. . Intrinsic Mechanical Competence of Cortical and Trabecular Bone Measured by Nanoindentation and Microindentation Probes. in American Society of Mechanical Engineering:Bioengineering Div. 1995. San Francisco.

20. Leong, P.L., \& Morgan, E. F. , Measurement of Fracture Callus Material Properties via Nanoindentation. Acta Biomater 2008. 4 (5): p. 1569-1575.

21. Zhang, J., Niebur, G. L., \& Ovaert, T. C. , Mechanical property determination of bone through nano- and micro-indentation testing and finite element simulation. Biomechanics, 2008. 41: p. 267-275.

22. Hengsberger, S., Kulik, A., \& Zysset, P., A combine atomic force microscopy and nanoindentation technique to investigate the elastic properties of bone structural units. Cells and Materials, 2001. 1: p. 12-16

23. Zysset, P., Guo, XE., Hoffler, CE., Moore, KE., and Goldein, SA., Elastic Modulus and hardness of cortical and trabecular bone lamellar measured by nanoindentation in human femur. J Biomech, 1999. 32: p. 1005-1012.

24. Franzoso, B. and Z., P.K., Elastic Anisotrophy of Human Cortical Bone Secondary osteons Measured by Nanoindentation. Biomechanical Engineeerring, 2009. 131: p. 021001-1 - 021001-11.

25. NanoTest User Guide. 08/03/2001, Micromaterials Ltd: Wrexham, UK. .

26. Wang, X.Y., Y.J. and Ji, H., A novel scratching approach for measuring agerelated changes in the in situ toughness of bone. biomech, 2007.

27. Gao, S., Qian, L., \& Yu, H. , Anisotropic Wear Resistance of Human Mandible Cortial Bone. Tribol Lett, 2009. 33: p. 73-81. 
28. $\mathrm{Xu}$, J., et al., Atomic force microscopy and nanoindentation characterization of human lamellar bone prepared by microtome sectioning and mechanical polishing technique. J Biomed Mater Res A, 2003. 67(3): p. 719-26.

29. Hansen, J.C., et al., Effect of surface nanoscale topography on elastic modulus of individual osteoblastic cells as determined by atomic force microscopy. $\mathrm{J}$ Biomech, 2007. 40(13): p. 2865-71.

30. Turner, C.H., et al., The elastic properties of trabecular and cortical bone tissues are similar: results from two microscopic measurement techniques. J Biomech, 1999. 32(4): p. 437-41.

31. Wenger, M.P., Horton, M. A., \& Mesquida, P., Nanoscale scraping and dissection of collagen fibril. Nanotechnology, 2008. 19.

32. Evans, G.P., Behiri, J.C., Currey, J.D. and Bonfield, W., J Mater Sci Mater Med, 1990. 1: p. 38.

33. Currey, J.D., ibid, 1988. 21: p. 439.

34. Rho, J.Y. and G.M. Pharr, Effects of drying on the mechanical properties of bovine femur measured by nanoindentation. J Mater Sci Mater Med, 1999. 10(8): p. $485-8$.

35. Townsend, P.R. and R., R.M.,, Buckling studies of single human trabeculae. J Biomech, 1975. 8: p. 199-201.

36. Currey, J.D., The effects of drying and re-wetting on some mechanical properties of cortical bone. J Biomech, 1988. 21(5): p. 439-41.

37. Reilly, D.T., and A.H. Burstein, The elastic and ultimate properties of cortical bone tissue. J Biomech, 1975. 8: p. 393-405. 
38. Fleisch, H., Development of biphosphonates. Breast Cancer Res, 2002. 4(1): p. $30-4$.

39. van Beek, E.R., et al., Differentiating the mechanisms of antiresorptive action of nitrogen containing bisphosphonates. Bone, 2003. 33(5): p. 805-11.

40. Martens, M.G., \& Shaw, H., Maximizing Effectiveness of Biphosphonate Theraphy for Osteoporosis. Southern Medical, 2008. 101(8): p. 824-830.

41. Fleisch, H., Biphosphonate: Meachanisms of action. Endocrine Rev, 1998. 19: p. 80-100.

42. Chabner, D.-E., The Language of Medicine. 2007, St Luis: Saunders Elsevier. 1030.

43. Wang, X., Allen, W.R., Burr D.B. Lavernia, E.J., Jeremic, B. and Fyhrie, D.P., Identification of material parameter based on Mohr-Coulombs failure criterion for biphosphonate treated canine vertebral cnacellous bone. Bone, 2008. 43: p. 775-780.

44. Boivin, G.Y., et al., Alendronate increases bone strength by increasing the mean degree of mineralization of bone tissue in osteoporotic women. Bone, 2000. 27(5): p. 687-94.

45. Chavassieux, P.M., Arlot, M.E., Reda, C., Wei, L., Yates, J., and Meunier, P.J., Histomorphometric Assessment of the Long-term Effects of Alendronate on Bone Quality and Remodelling in Patients with Osteoporosis. Journal of Clinical Investigation, 1997. 100(6): p. 1475-1480.

46. Odvina, C.V., Zerwekh, J.E., Rao, D.S., Maalof, N., Gottschalk, F.A. and Pak, C.Y.C., Severely Suppressed Bone Turnover: A Potential Complication of 
Alendronate Theraphy. Clinical Endocrinology \& Metabolism, 2005. 90(3): p. 1294-1301.

47. Li, J., Mori, S., Kaji, Y., Mashiba, T., Kawanishi, J. and Norimatsu, H., Effect of Biphosphonate (Incadronate) on Fracture Healing of Long bone in rats. Bone, 1999. 14(6): p. 969-79.

48. Kashii, M., et al., Alendronate treatment promotes bone formation with a less anisotropic microstructure during intramembranous ossification in rats. J Bone Miner Metab, 2008. 26(1): p. 24-33.

49. Amanat, N., He, L. H., Swain, M. V., \& Little, D. G. ., The effect of zelodronic acid on the intrinsic material properties of healing bone: An indentation study. Medical Engineering and Physics 2008. 30 p. 843-847.

50. Beake, B., Goodes, S., Jones, S., Gray, A., Harris, A., Pickford, N. and Smith, J., The Nano Test ${ }^{T M}$, in Unit 3, M.M. Ltd, Editor. 2006, Micro Material Ltd: United Kingdom.

51. Allen, M.R., Reinwald, S and Burr, DB., Alendronate Reduces Bone Toughness of Ribs without Significantly Increasing Microdamage Accumulation in Dogs Following 3 Years of Daily Treatment. Calcif Tissue Int, , 2008. 82: p. 354-360.

52. Wang X, E.A., Allen MR, Burr DB, Martin RB, and Hazelwood SJ. , Theoretical analysis of alendronate and risedronate effects on canine vertebral remodeling and microdamage. J Biomech, 2009 42(7): p. 938-44.

53 Lewis, G., and Nyman, JS., Review. The Use of Nanoindentation for Characterizing the Properties of Mineralized Hard Tissues: State-of-the Art Review. Biomed Mater Res B Appl Biomater, 2008 87(1): p. 286-301. 


\section{APPENDIX: BEAGLE DOG STATISTICS}

2ND GEN FUNCTION 3YR ANOVA: ELASTIC MODULUS 1

$15: 21$ Tuesday, August 11, 2009

The Mixed Procedure

Model Information

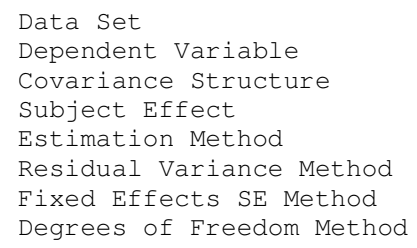

Class Level Information

Class Levels

Values

Treatment

2

01

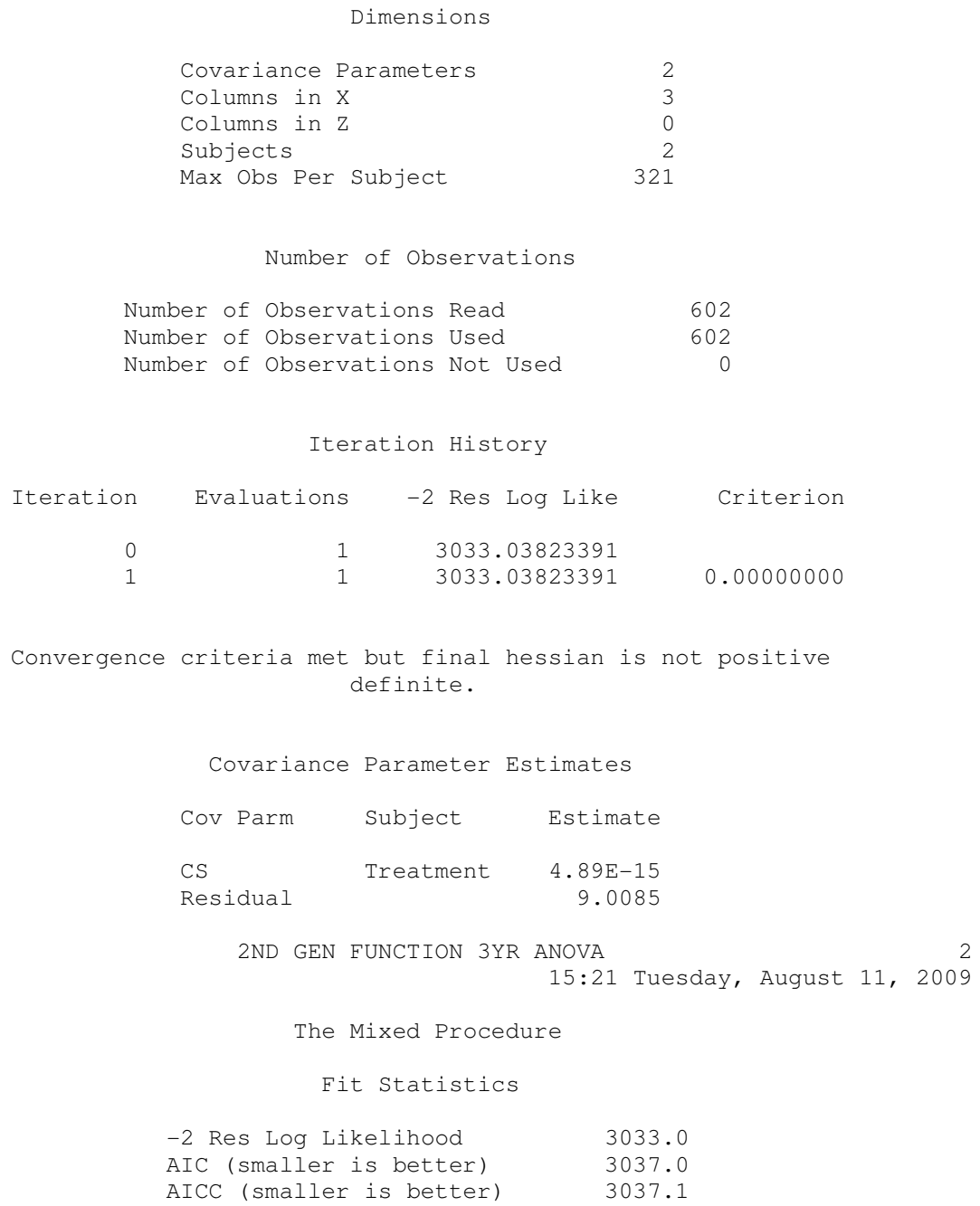


BIC (smaller is better)

3034.4

Null Model Likelihood Ratio Test
DF
Chi-Square
Pr > ChiSq
0.00
1.0000

Type 3 Tests of Fixed Effects

$\begin{array}{lrrrrrr} & \text { Num } & \text { Den } & & \\ \text { Effect } & \text { DF } & \text { DF } & \text { Chi-Square } & \text { F Value } & \text { Pr }>\text { ChiSq } & \text { Pr }>\text { F } \\ \text { Treatment } & 1 & 600 & 450.17 & 450.17 & <.0001<.0001\end{array}$

Least Squares Means

\begin{tabular}{|c|c|c|c|c|c|c|}
\hline & & & Eandard & & & \\
\hline Effect & Treatment & Estimate & Error & $\mathrm{DF}$ & t Value & $\operatorname{Pr}>|t|$ \\
\hline Treatment & 0 & 22.2889 & 0.1675 & 600 & 133.05 & $<.0001$ \\
\hline Treatment & 1 & 17.0864 & 0.1790 & 600 & 95.43 & $<.0001$ \\
\hline
\end{tabular}

Differences of Least Squares Means

\begin{tabular}{|c|c|c|c|c|c|c|c|}
\hline \multirow[b]{2}{*}{ Effect } & \multirow[b]{2}{*}{ Treatment } & \multirow[b]{2}{*}{ _Treatment } & \multicolumn{4}{|c|}{ Standard } & \multirow[b]{2}{*}{$\operatorname{Pr}>|t|$} \\
\hline & & & Estimate & Error & $\mathrm{DF}$ & t Value & \\
\hline \multirow[t]{4}{*}{ Treatment } & 0 & 1 & 5.2025 & 0.2452 & 600 & 21.22 & $<.0001$ \\
\hline & & Differe & es of Least & Squares & Means & & \\
\hline & Effect & Treatment & _Treatment & & djustment & $\mathrm{Adj}$ & $\mathrm{P}$ \\
\hline & Treatment & 0 & 1 & & ukey-Kramer & $<.000$ & 1 \\
\hline
\end{tabular}

\section{ND GEN FUNCTION 3YR ANOVA: HARDNESS}

15:21 Tuesday, August 11, 2009

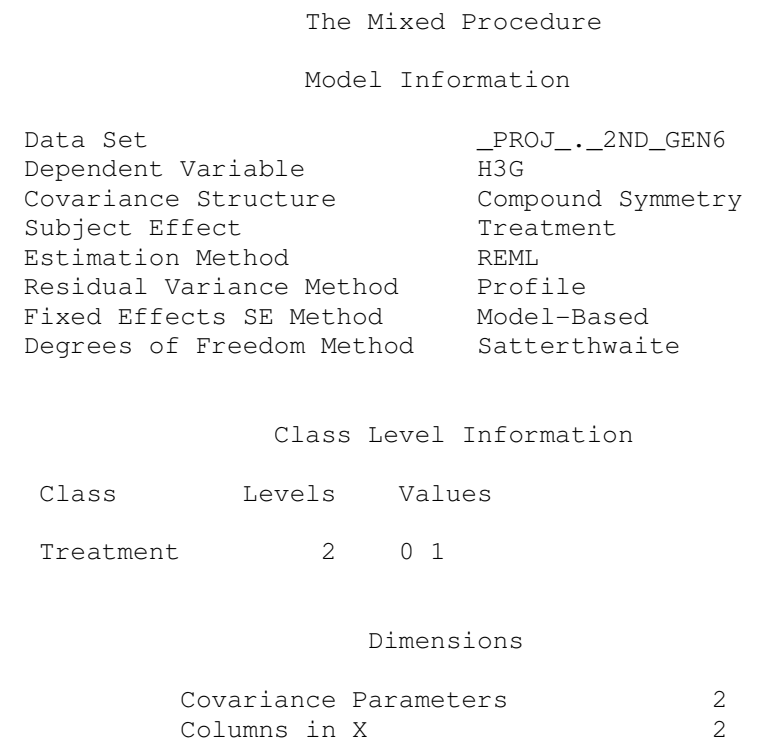


$\begin{array}{ll}\text { Columns in } Z & 0 \\ \text { Subjects } & 2\end{array}$

Max Obs Per Subject $\quad 321$

Number of Observations

Number of Observations Read 602

Number of Observations Used 602

Number of Observations Not Used 0

\begin{tabular}{rrrrr} 
& \multicolumn{2}{c}{ Iteration History } & \\
Iteration & Evaluations & -2 Res Log Like & Criterion \\
0 & 1 & -1180.85581731 & \\
1 & 1 & -1180.85581731 & 0.00000000
\end{tabular}

Convergence criteria met but final hessian is not positive definite.

Covariance Parameter Estimates

$\begin{array}{lll}\text { Cov Parm } & \text { Subject } & \text { Estimate } \\ & \text { Treatment } & 3.74 \mathrm{E}-18 \\ \text { Residual } & & 0.008027\end{array}$

2ND GEN FUNCTION 3YR ANOVA

The Mixed Procedure

Fit Statistics

$\begin{array}{ll}-2 \text { Res Log Likelihood } & -1180.9 \\ \text { AIC (smaller is better) } & -1176.9 \\ \text { AICC (smaller is better) } & -1176.8 \\ \text { BIC (smaller is better) } & -1179.5\end{array}$

Null Model Likelihood Ratio Test
$\mathrm{DF}$
Chi-Square
$\operatorname{Pr}>$ ChiSq
1
0.00
1.0000

Type 3 Tests of Fixed Effects

$\begin{array}{lrrrrrr} & \text { Num } & \text { Den } & & \\ \text { Effect } & \text { DF } & \text { DF } & \text { Chi-Square } & \text { F Value } & \text { Pr }>\text { ChiSq } & \text { Pr }>\text { F } \\ \text { Treatment } & 2 & 600 & 43129.2 & 21564.6 & <.0001<001\end{array}$

Least Squares Means

\begin{tabular}{|c|c|c|c|c|c|c|}
\hline Effect & Treatment & Estimate & $\begin{array}{r}\text { Standard } \\
\text { Error }\end{array}$ & $\mathrm{DF}$ & t Value & $\operatorname{Pr}>|t|$ \\
\hline Treatment & 0 & 0.7769 & 0.005001 & 600 & 155.36 & $<.0001$ \\
\hline Treatment & 1 & 0.7365 & 0.005345 & 600 & 137.81 & $<.0001$ \\
\hline
\end{tabular}

Differences of Least Squares Means

\begin{tabular}{|c|c|c|c|c|c|c|c|}
\hline \multirow[b]{2}{*}{ Effect } & \multirow[b]{2}{*}{ Treatment } & \multirow[b]{2}{*}{-Treatment } & \multicolumn{5}{|c|}{ Standard } \\
\hline & & & Estimate & Error & $\mathrm{DF}$ & t Value & $\operatorname{Pr}>|t|$ \\
\hline Treatment & 0 & 1 & 0.04037 & 0.007319 & 600 & 5.52 & $<.0001$ \\
\hline
\end{tabular}


Differences of Least Squares Means

$\begin{array}{lcccc}\text { Effect } & \text { Treatment } & \text {-Treatment } & \text { Adjustment } & \text { Adj P } \\ \text { Treatment } & 0 & 1 & \text { Tukey-Kramer } & <.0001\end{array}$

\section{ND GEN 1YR ANOVA: ELASTIC MODULUS}

The Mixed Procedure

Model Information

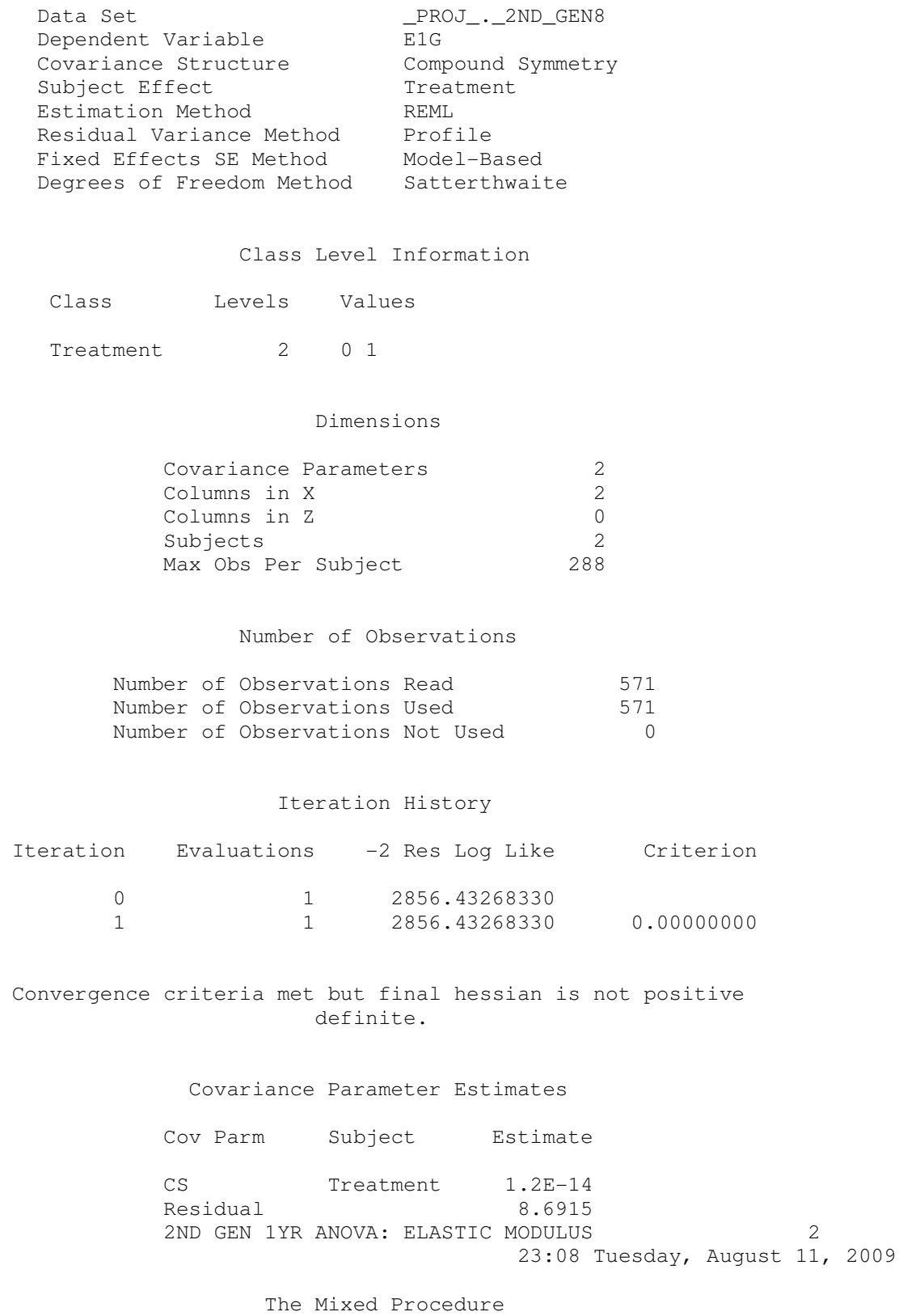




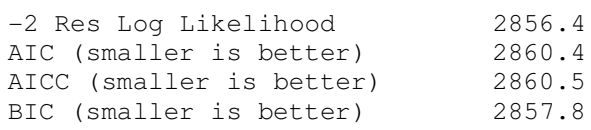

Null Model Likelihood Ratio Test

$\begin{array}{rrr}\text { DF } & \text { Chi-Square } & \text { Pr }>\text { ChiSq } \\ 1 & 0.00 & 1.0000\end{array}$

Solution for Fixed Effects

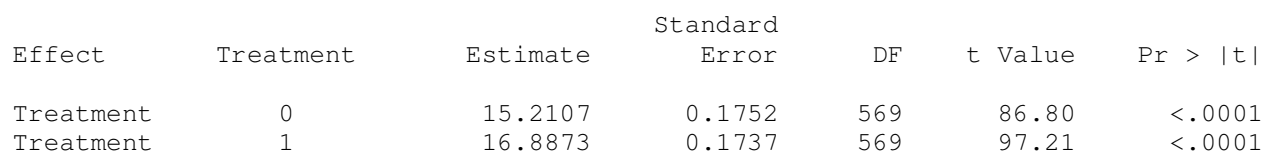

Type 3 Tests of Fixed Effects

$\begin{array}{lrrrrrr} & \text { Num } & \text { Den } & & \\ \text { Effect } & \text { DF } & \text { DF } & \text { Chi-Square } & \text { F Value } & \text { Pr }>\text { ChiSq } & \text { Pr F } \\ \text { Treatment } & 2 & 569 & 16983.2 & 8491.62 & <.0001<.0001\end{array}$

Least Squares Means

\begin{tabular}{|c|c|c|c|c|c|c|}
\hline Effect & Treatment & Estimate & $\begin{array}{l}\text { Eandard } \\
\text { Error }\end{array}$ & $\mathrm{DF}$ & t Value & $\operatorname{Pr}>|t|$ \\
\hline Treatment & 0 & 15.2107 & 0.1752 & 569 & 86.80 & $<.0001$ \\
\hline Treatment & 1 & 16.8873 & 0.1737 & 569 & 97.21 & $<.0001$ \\
\hline
\end{tabular}

Differences of Least Squares Means

\begin{tabular}{|c|c|c|c|c|c|c|c|}
\hline \multirow[b]{2}{*}{ Effect } & \multirow[b]{2}{*}{ Treatment } & \multirow[b]{2}{*}{ _Treatment } & \multicolumn{4}{|c|}{ Standard } & \multirow[b]{2}{*}{$\operatorname{Pr}>\mid t$} \\
\hline & & & Estimate & Error & $\mathrm{DF}$ & t Value & \\
\hline \multirow[t]{4}{*}{ Treatment } & 0 & 1 & -1.6766 & 0.2468 & 569 & -6.79 & $<.0001$ \\
\hline & & Differences & s of Least & Squares & Means & & \\
\hline & Effect & Treatment & _Treatmen & & djustment & $\mathrm{Adj}$ & $\mathrm{P}$ \\
\hline & Treatment & 0 & 1 & & ukey-Kramer & $<.00$ & 1 \\
\hline
\end{tabular}

\section{ND GEN 1YR ANOVA: HARDNESS}

The Mixed Procedure

Model Information

Data set

Dependent Variable

Covariance structure

Subject Effect

Estimation Method

Residual Variance Method

Fixed Effects SE Method

Degrees of Freedom Method

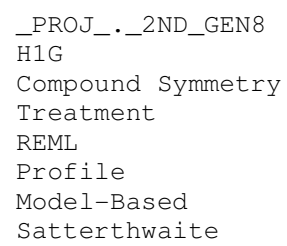


Class Level Information

\begin{tabular}{|c|c|c|}
\hline Class & Levels & Values \\
\hline Treatment & 2 & 01 \\
\hline
\end{tabular}

Dimensions

$\begin{array}{lr}\text { Covariance Parameters } & 2 \\ \text { Columns in X } & 2 \\ \text { Columns in Z } & 0 \\ \text { Subjects } & 2 \\ \text { Max Obs Per Subject } & 288\end{array}$

Number of Observations

Number of Observations Read

Number of Observations Used

Number of Observations Not Used

Iteration History

$\begin{array}{rrrr}\text { Iteration } & \text { Evaluations } & -2 \text { Res Log Like } & \text { Criterion } \\ 0 & 1 & -1071.21098055 & \\ 1 & 1 & -1071.21098055 & 0.00000000\end{array}$

Convergence criteria met but final hessian is not positive definite.

Covariance Parameter Estimates

$\begin{array}{lll}\text { Cov Parm } & \text { Subject } & \text { Estimate } \\ \text { CS } & \text { Treatment } & 1.23 \mathrm{E}-18 \\ \text { Residual } & & 0.008735\end{array}$

2ND GEN 1YR ANOVA: HARDNESS

23:08 Tuesday, August 11, 2009

The Mixed Procedure

Fit Statistics

$\begin{array}{ll}-2 \text { Res Log Likelihood } & -1071.2 \\ \text { AIC (smaller is better) } & -1067.2 \\ \text { AICC (smaller is better) } & -1067.2 \\ \text { BIC (smaller is better) } & -1069.8\end{array}$

Null Model Likelihood Ratio Test
$\mathrm{DF}$
Chi-Square
Pr > ChiSq
1
0.00
1.0000

Effect

Treatment Treatment

Effect
Solution for Fixed Effects

$\begin{array}{cccccc}\text { Treatment } & \text { Estimate } & \begin{array}{c}\text { Standard } \\ \text { Error }\end{array} & \text { DF } & \text { t Value } & \text { Pr }>|t| \\ 0 & 0.5680 & 0.005556 & 569 & 102.24 & <.0001 \\ 1 & 0.5553 & 0.005507 & 569 & 100.83 & <.0001\end{array}$

Type 3 Tests of Fixed Effects

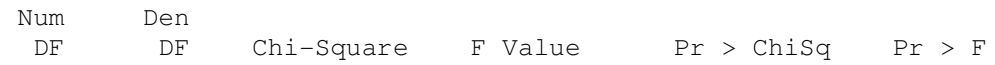




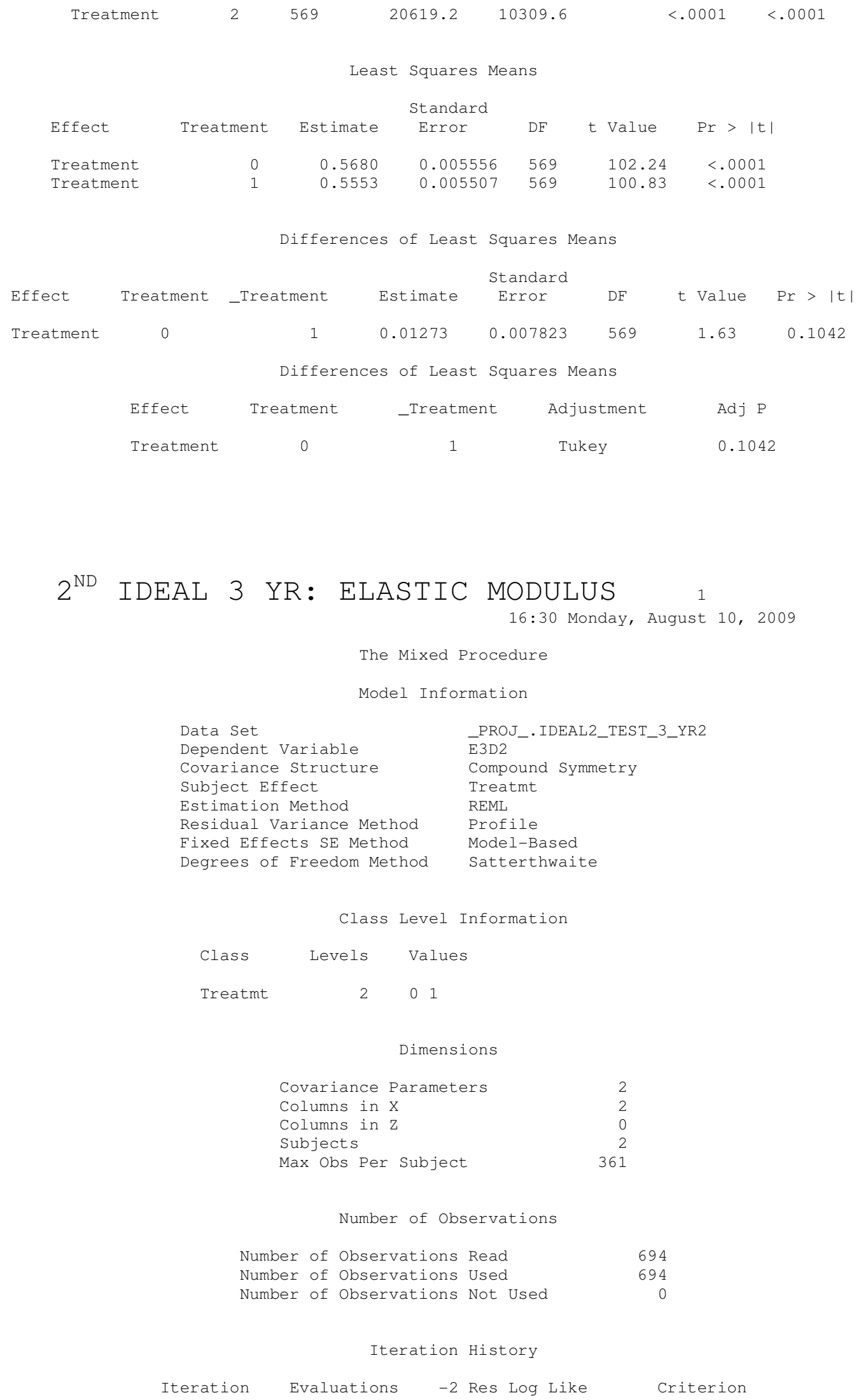




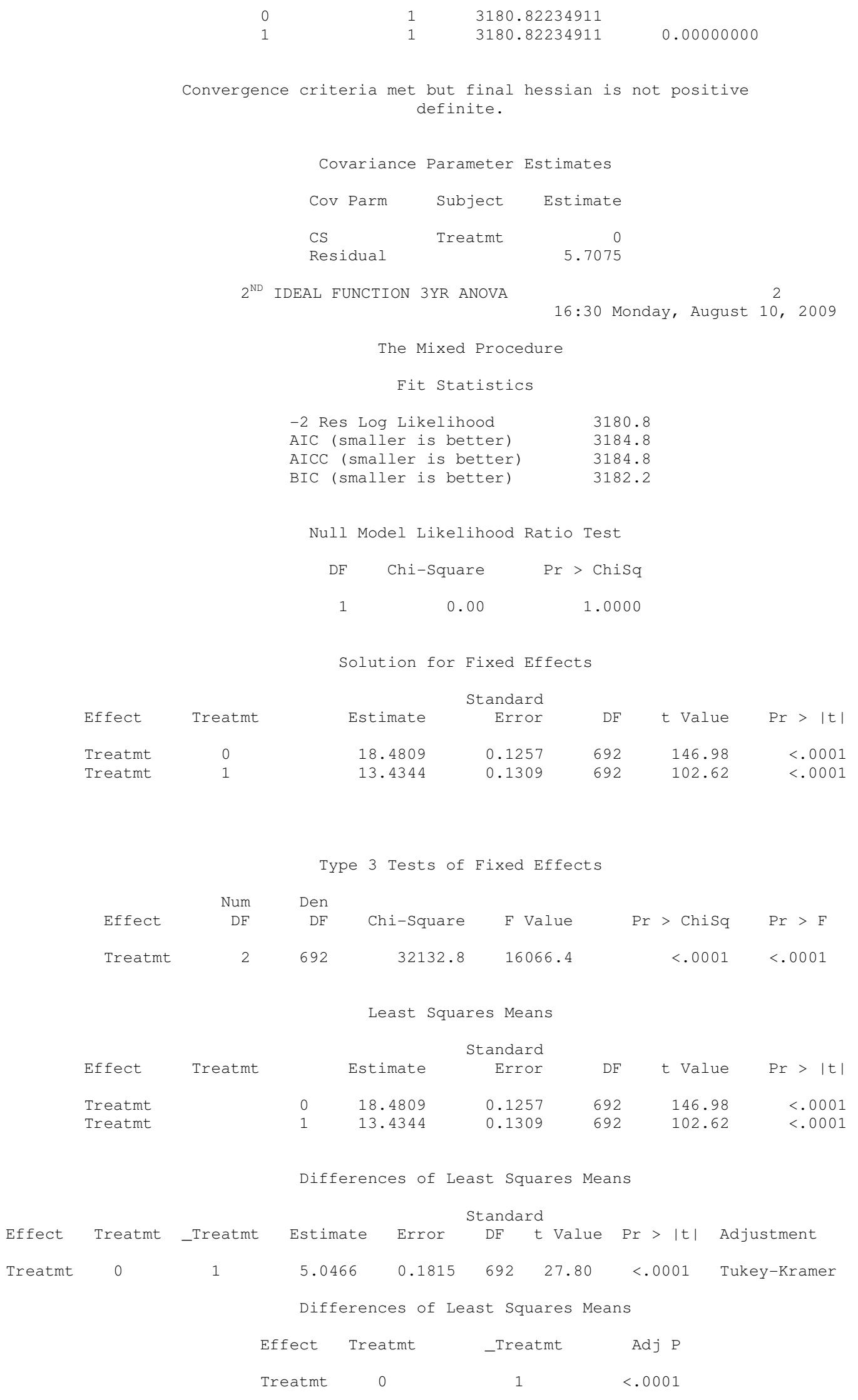


The Mixed Procedure

Model Information

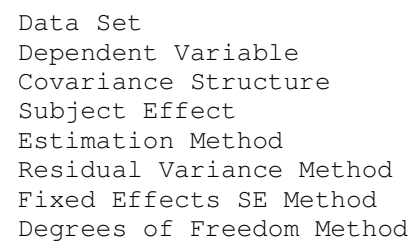

Iteration History

$\begin{array}{rrrrr}\text { Iteration } & \text { Evaluations } & -2 \text { Res Log Like } & \text { Criterion } \\ 0 & 1 & -1715.44962534 & \\ 1 & 1 & -1715.44962534 & 0.00000000\end{array}$

Convergence criteria met but final hessian is not positive definite.

$\begin{array}{lrr}\text { Covariance } & \text { Parameter Estimates } \\ \text { Cov Parm } & \text { Subject } & \text { Estimate } \\ & \text { Treatmt } & 0 \\ \text { CS } & 0.004826\end{array}$

1st GEN FUNCTION 3YR ANOVA

The Mixed Procedure

Fit Statistics

$\begin{array}{ll}-2 \text { Res Log Likelihood } & -1715.4 \\ \text { AIC (smaller is better) } & -1711.4 \\ \text { AICC (smaller is better) } & -1711.4 \\ \text { BIC (smaller is better) } & -1714.1\end{array}$

Null Model Likelihood Ratio Test
DF
Chi-Square
$\mathrm{Pr}>\mathrm{ChiSq}$ 
Solution for Fixed Effects

\begin{tabular}{|c|c|c|c|c|c|c|c|}
\hline Effect & Treatmt & Estimate & $\begin{array}{l}\text { Standard } \\
\text { Error }\end{array}$ & $\mathrm{DF}$ & t Value & $\operatorname{Pr}$ & $>|t|$ \\
\hline Treatmt & 0 & 0.5598 & 0.003656 & 692 & 153.12 & & $<.0001$ \\
\hline Treatmt & 1 & 0.5063 & 0.003807 & 692 & 132.99 & & $<.0001$ \\
\hline
\end{tabular}

Type 3 Tests of Fixed Effects

\begin{tabular}{|c|c|c|c|c|c|c|}
\hline & Num & Den & & & & \\
\hline Effect & $\mathrm{DF}$ & $\mathrm{DF}$ & Chi-Square & F Value & $\operatorname{Pr}>$ ChiSq & $\operatorname{Pr}>F$ \\
\hline Treatmt & 2 & 692 & 41131.6 & 20565.8 & $<.0001$ & $<.0001$ \\
\hline
\end{tabular}

Least Squares Means

\begin{tabular}{|c|c|c|c|c|c|c|}
\hline & & & Standard & & & \\
\hline Effect & Treatmt & Estimate & Error & $\mathrm{DF}$ & t Value & $\operatorname{Pr}>|t|$ \\
\hline Treatmt & 0 & 0.5598 & 0.003656 & 692 & 153.12 & $<.0001$ \\
\hline Treatmt & 1 & 0.5063 & 0.003807 & 692 & 132.99 & $<.0001$ \\
\hline
\end{tabular}

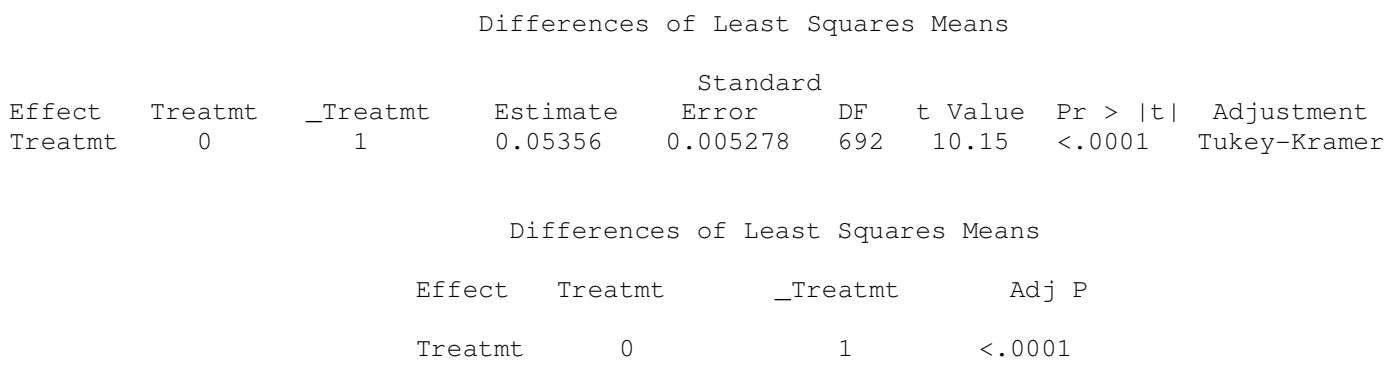

\section{$2^{\text {ND }}$ IDEAL 1YR ANOVA: ELASTIC MODULUS}

The Mixed Procedure

Model Information

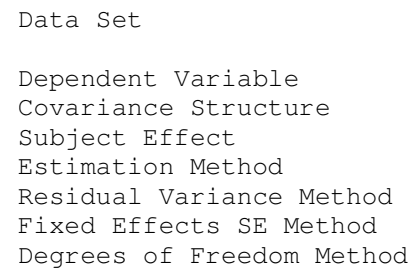

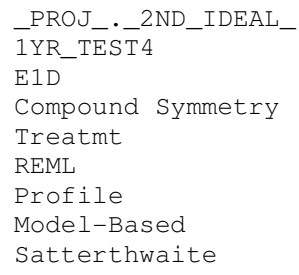


$\begin{array}{lr}\text { Subjects } & 2 \\ \text { Max Obs Per Subject } & 290\end{array}$

Number of Observations

Number of Observations Read 573

Number of Observations Used 573

Number of Observations Not Used 0

Iteration History

$\begin{array}{rrrr}\text { Iteration } & \text { Evaluations } & -2 \text { Res Log Like } & \text { Criterion } \\ 0 & 1 & 2636.97245512 & \\ 1 & 1 & 2636.97245512 & 0.00000000\end{array}$

Convergence criteria met but final hessian is not positive definite.

Covariance Parameter Estimates

$\begin{array}{lrr}\text { Cov Parm } & \text { Subject } & \text { Estimate } \\ \text { CS } & \text { Treatmt } & 6.62 \mathrm{E}-16 \\ \text { Residual } & 5.8152\end{array}$

2ND IDEAL FUNCTION 1YR ANOVA

The Mixed Procedure

Fit Statistics

$\begin{array}{ll}-2 \text { Res Log Likelihood } & 2637.0 \\ \text { AIC (smaller is better) } & 2641.0 \\ \text { AICC (smaller is better) } & 2641.0 \\ \text { BIC (smaller is better) } & 2638.4\end{array}$

Null Model Likelihood Ratio Test
$\mathrm{DF}$
Chi-Square
$\operatorname{Pr}>$ Chisq
1
0.00
1.0000

Solution for Fixed Effects

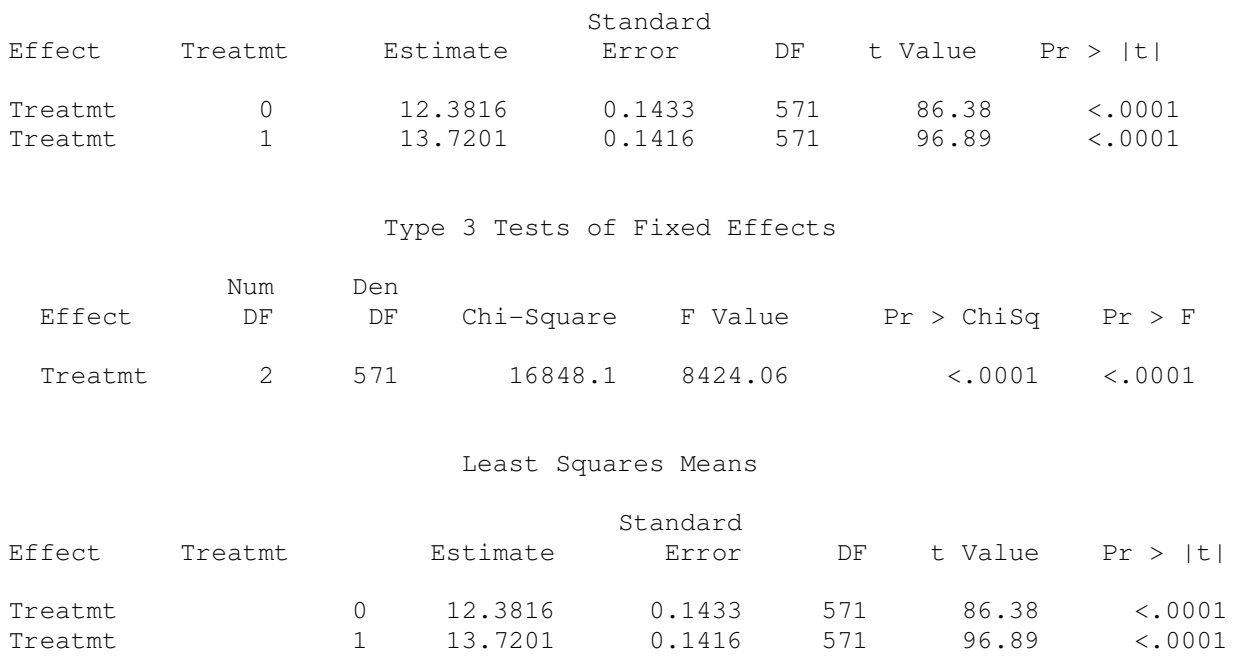

Differences of Least Squares Means

Standard 


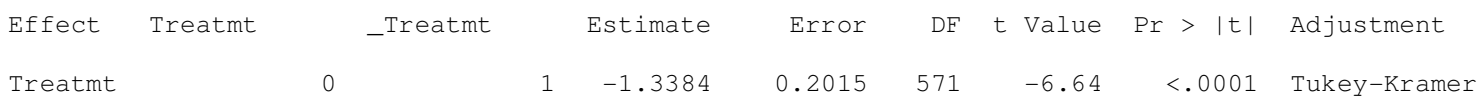

$\begin{array}{cccc}\text { Differences of Least Squares Means } & & \\ & & & \\ \text { Effect } & \text { Treatmt } & \text {-Treatmt } & \text { Adj P } \\ \text { Treatmt } & 0 & 1 & <.0001\end{array}$

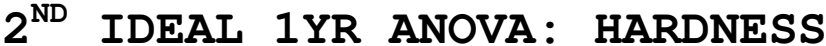

16:30 Monday, August 10, 2009

\author{
The Mixed Procedure \\ Model Information \\ Data set \\ Dependent Variable \\ Covariance Structure \\ Subject Effect \\ Estimation Method \\ Residual Variance Method \\ Fixed Effects SE Method \\ Degrees of Freedom Method \\ Class Level Information \\ Class \\ Levels \\ Treatmt

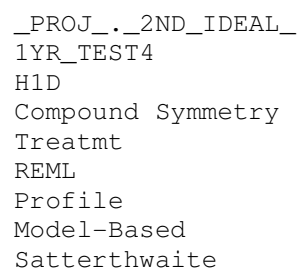

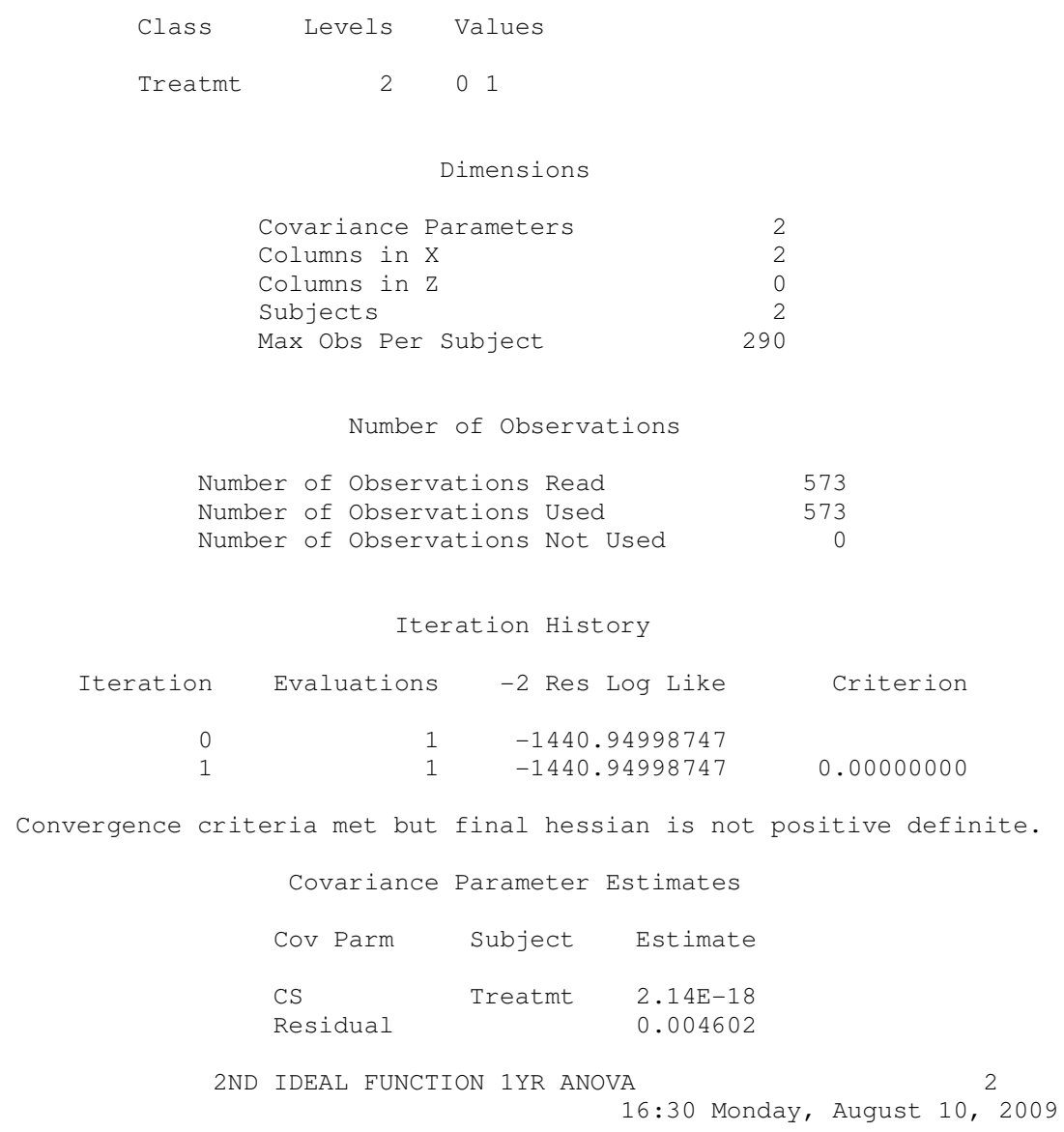


The Mixed Procedure

Fit Statistics

$\begin{array}{ll}-2 \text { Res Log Likelihood } & -1440.9 \\ \text { AIC (smaller is better) } & -1436.9 \\ \text { AICC (smaller is better) } & -1436.9 \\ \text { BIC (smaller is better) } & -1439.6\end{array}$

Null Model Likelihood Ratio Test

$\begin{array}{rrr}\text { DF } & \text { Chi-Square } & \text { Pr }>\text { ChiSq } \\ 1 & 0.00 & 1.0000\end{array}$

Solution for Fixed Effects

\begin{tabular}{|c|c|c|c|c|c|c|c|}
\hline & & & & Standard & & & \\
\hline Effect & Treatmt & & Estimate & Error & $\mathrm{DF}$ & t Value & $\operatorname{Pr}>|t|$ \\
\hline Treatmt & & 0 & 0.4047 & 0.004033 & 571 & 100.35 & $<.0001$ \\
\hline Treatmt & & 1 & 0.3950 & 0.003984 & 571 & 99.16 & $<.0001$ \\
\hline
\end{tabular}

Type 3 Tests of Fixed Effects

$\begin{array}{lrrrrrr} & \text { Num } & \text { Den } & & \\ \text { Effect } & \text { DF } & \text { DF } & \text { Chi-Square } & \text { F Value } & \text { Pr }>\text { ChiSq } & \text { Pr }>\text { F } \\ \text { Treatmt } & 2 & 571 & 19901.3 & 9950.65 & <.0001 & <.0001\end{array}$

Least Squares Means

$\begin{array}{lcccrrr}\text { Effect } & \text { Treatmt } & \text { Estimate } & \begin{array}{c}\text { Standard } \\ \text { Error }\end{array} & \text { DF } & \text { t Value } & \text { Pr }>|t| \\ \text { Treatmt } & 0 & 0.4047 & 0.004033 & 571 & 100.35 & <.0001 \\ \text { Treatmt } & 1 & 0.3950 & 0.003984 & 571 & 99.16 & <.0001\end{array}$

Differences of Least Squares Means

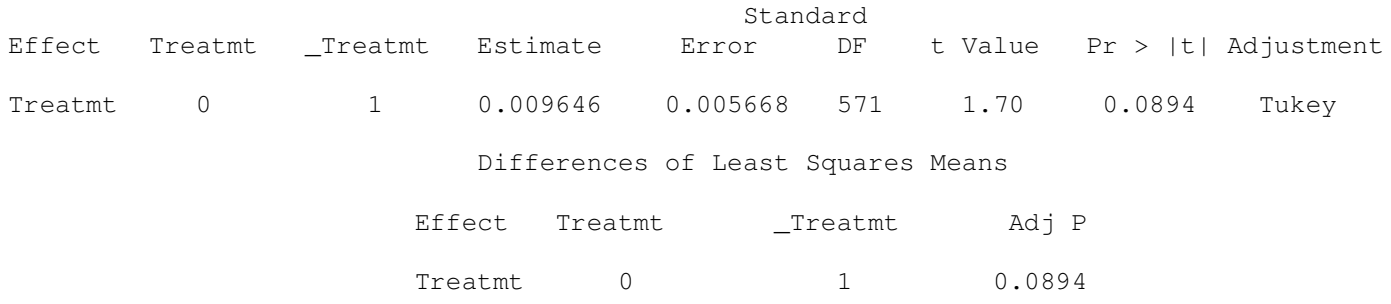

COMBINED GEN FUNCT 1YR-3YR ANOVA: ELASTIC MODULUS 1

21:56 Wednesday, September 9, 2009

The Mixed Procedure

Model Information

Data set

Dependent Variable

Covariance Structure

Subject Effect

Estimation Method
ERROJ_.GEN4
EG
Compound Symmetry
Time
REML 


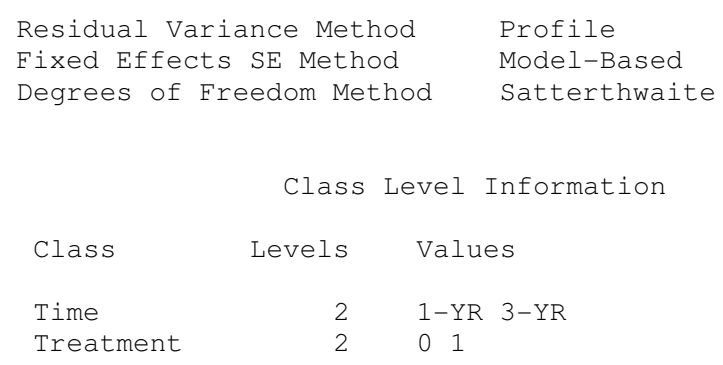

The Mixed Procedure

Fit Statistics

$\begin{array}{ll}-2 \text { Res Log Likelihood } & 5889.7 \\ \text { AIC (smaller is better) } & 5893.7 \\ \text { AICC (smaller is better) } & 5893.7 \\ \text { BIC (smaller is better) } & 5891.0\end{array}$

Null Model Likelihood Ratio Test

$\begin{array}{rrr}\text { DF } & \text { Chi-Square } & \text { Pr }>\text { ChiSq } \\ 1 & 0.00 & 1.0000\end{array}$


Solution for Fixed Effects

\begin{tabular}{|c|c|c|c|c|c|c|c|}
\hline \multirow[b]{2}{*}{ Effect } & \multirow[b]{2}{*}{ Time } & \multirow[b]{2}{*}{ Treatment } & \multicolumn{4}{|c|}{ Standard } & \multirow[b]{2}{*}{$\operatorname{Pr}>|t|$} \\
\hline & & & Estimate & Error & $\mathrm{DF}$ & t Value & \\
\hline Treatment & 0 & & 22.2889 & 0.1661 & 1169 & 134.20 & $<.0001$ \\
\hline Treatment & 1 & & 17.0864 & 0.1775 & 1169 & 96.26 & $<.0001$ \\
\hline Time* Treatment & $1-Y R$ & 0 & -7.0782 & 0.2426 & 1169 & -29.17 & $<.0001$ \\
\hline Time* Treatment & $1-Y R$ & 1 & -0.1991 & 0.2495 & 1169 & -0.80 & 0.4250 \\
\hline Time* Treatment & $3-Y R$ & 0 & 0 & . & . & . & . \\
\hline Time* Treatment & $3-Y R$ & 1 & 0 & . & . & . & . \\
\hline
\end{tabular}

Type 3 Tests of Fixed Effects

\begin{tabular}{|c|c|c|c|c|c|c|c|}
\hline Effect & Num DF & Den DF & Chi-Square & F Value & Pr & $>$ ChiSq & $\operatorname{Pr}>\mathrm{F}$ \\
\hline Treatment & 2 & 1169 & 42427.5 & 21213.8 & & $<.0001$ & $<.0001$ \\
\hline Time*Treatment & 2 & 1169 & 851.67 & 425.84 & & $<.0001$ & $<.0001$ \\
\hline
\end{tabular}

Least Squares Means

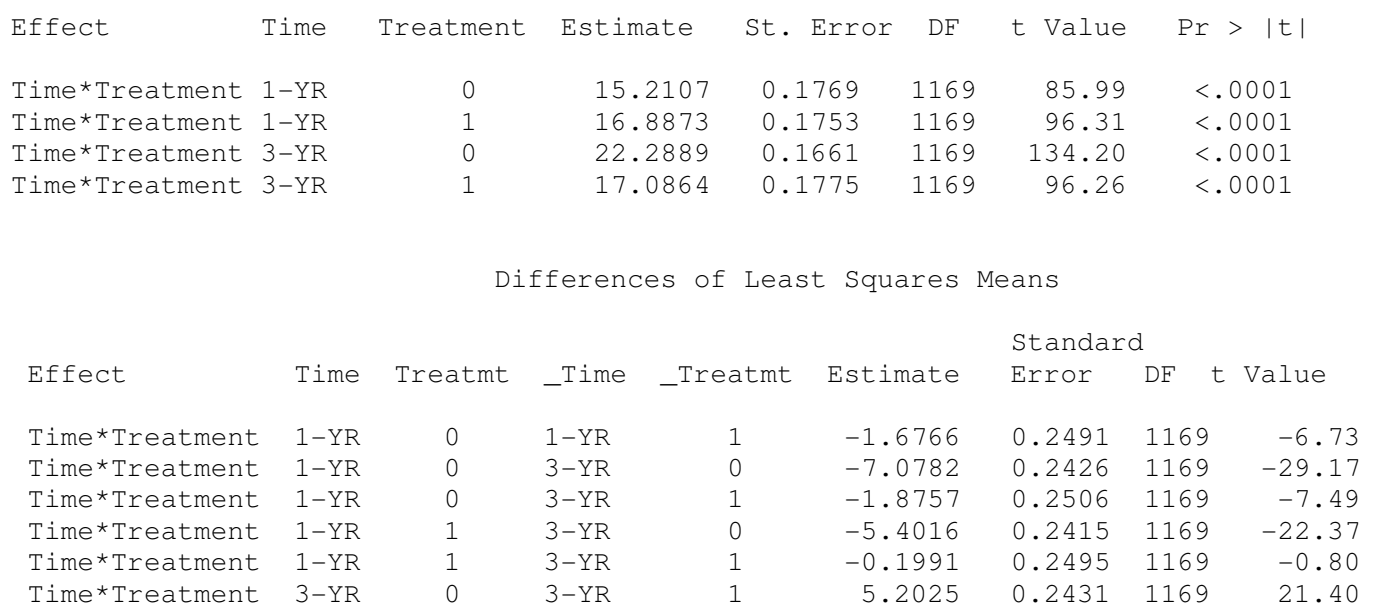

COMBINED GEN FUNCT 1YR-3YR ANOVA: ELASTIC MODULUS 3

21:56 Wednesday, September 9, 2009

The Mixed Procedure

Differences of Least Squares Means

\begin{tabular}{|c|c|c|c|c|c|c|c|}
\hline Effect & Time & Treatmt & _Time & _Treatmt & $\operatorname{Pr}>|t|$ & Adjustment & Adj $P$ \\
\hline Time* Treatment & $1-Y R$ & 0 & $1-Y R$ & 1 & $<.0001$ & Bonferroni & $<.0001$ \\
\hline Time* Treatment & $1-Y R$ & 0 & $3-Y R$ & 0 & $<.0001$ & Bonferroni & $<.0001$ \\
\hline Time* Treatment & $1-Y R$ & 0 & $3-Y R$ & 1 & $<.0001$ & Bonferroni & $<.0001$ \\
\hline Time* Treatment & $1-Y R$ & 1 & $3-Y R$ & 0 & $<.0001$ & Bonferroni & $<.0001$ \\
\hline Time* Treatment & $1-Y R$ & 1 & $3-Y R$ & 1 & 0.4250 & Bonferroni & 1.0000 \\
\hline Time* Treatment & $3-Y R$ & 0 & $3-Y R$ & 1 & $<.0001$ & Bonferroni & $<.0001$ \\
\hline
\end{tabular}

COMBINED GEN FUNCT 1YR-3YR ANOVA: HARDNESS 1 21:56 Wednesday, September 9, 2009

The Mixed Procedure

Model Information 


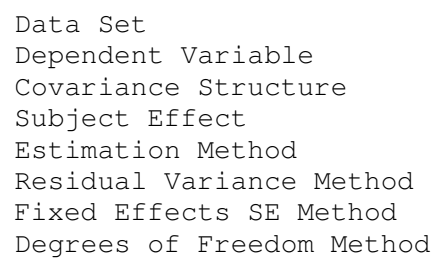

Iteration History

$\begin{array}{rrrr}\text { Iteration } & \text { Evaluations } & -2 \text { Res Log Like } & \text { Criterion } \\ 0 & 1 & -2251.02085669 & \\ 1 & 1 & -2251.02085669 & 0.00000000\end{array}$

Convergence criteria met but final hessian is not positive definite.

$\begin{array}{lcr}\text { Covariance Parameter Estimates } \\ \text { Cov Parm } & \text { Subject } & \text { Estimate } \\ & & \\ \text { CS } & \text { Time } & 1.85 \mathrm{E}-18 \\ \text { Residual } & & 0.008372\end{array}$

COMBINED GEN FUNCT 1YR-3YR ANOVA: HARDNESS

The Mixed Procedure

Fit Statistics

$\begin{array}{ll}-2 \text { Res Log Likelihood } & -2251.0 \\ \text { AIC (smaller is better) } & -2247.0 \\ \text { AICC (smaller is better) } & -2247.0 \\ \text { BIC (smaller is better) } & -2249.6\end{array}$

Null Model Likelihood Ratio Test

DF

$$
\text { Chi-Square }
$$$$
\text { Pr > ChiSq }
$$

1

0.00

1.0000 
Solution for Fixed Effects

\begin{tabular}{|c|c|c|c|c|c|c|c|}
\hline Effect & Time & Treatment & Estimate & $\begin{array}{l}\text { Standard } \\
\text { Error }\end{array}$ & $\mathrm{DF}$ & t Value & $\operatorname{Pr}>\mid t$ \\
\hline Time* Treatment & $1-\mathrm{YR}$ & 0 & 0.5680 & 0.005439 & 1169 & 104.44 & $<.0001$ \\
\hline Time* Treatment & $1-\mathrm{YR}$ & 1 & 0.5553 & 0.005391 & 1169 & 102.99 & $<.0001$ \\
\hline Time* Treatment & $3-Y R$ & 0 & 0.7769 & 0.005107 & 1169 & 152.13 & $<.0001$ \\
\hline Time* Treatment & $3-Y R$ & 1 & 0.7365 & 0.005458 & 1169 & 134.94 & $<.0001$ \\
\hline
\end{tabular}

Type 3 Tests of Fixed Effects

\begin{tabular}{|c|c|c|c|c|c|c|}
\hline & Num & Den & & & & \\
\hline Effect & $\mathrm{DF}$ & $\mathrm{DF}$ & Chi-Square & F Value & $\operatorname{Pr}>$ ChiSq & $\operatorname{Pr}>F$ \\
\hline ime* Treatment & 4 & 1169 & 62867.1 & 15716.8 & $<.0001$ & $<.0001$ \\
\hline
\end{tabular}

Least Squares Means

\begin{tabular}{|c|c|c|c|c|c|c|c|}
\hline Effect & Time & Treatment & Estimate & $\begin{array}{l}\text { Standard } \\
\text { Error }\end{array}$ & $\mathrm{DF}$ & t Value & $\operatorname{Pr}>|t|$ \\
\hline Time*Treatment & $1-\mathrm{YR}$ & 0 & 0.5680 & 0.005439 & 1169 & 104.44 & $<.0001$ \\
\hline Time*Treatment & $1-\mathrm{YR}$ & 1 & 0.5553 & 0.005391 & 1169 & 102.99 & $<.0001$ \\
\hline Time* Treatment & $3-Y R$ & 0 & 0.7769 & 0.005107 & 1169 & 152.13 & $<.0001$ \\
\hline Time*Treatment & $3-Y R$ & 1 & 0.7365 & 0.005458 & 1169 & 134.94 & $<.0001$ \\
\hline
\end{tabular}

Differences of Least Squares Means

\begin{tabular}{|c|c|c|c|c|c|c|c|c|}
\hline \multirow[b]{2}{*}{ Effect } & \multirow[b]{2}{*}{ Time } & \multirow[b]{2}{*}{ Treatmt } & \multirow[b]{2}{*}{ _Time } & \multirow[b]{2}{*}{ _Treatmt } & \multirow[b]{2}{*}{ Estimate } & \multicolumn{3}{|c|}{ Standard } \\
\hline & & & & & & Error & $\mathrm{DF}$ & t Value \\
\hline Time*Treatmt & $1-Y R$ & 0 & $1-Y R$ & 1 & 0.01273 & 0.007658 & 1169 & 1.66 \\
\hline Time*Treatmt & $1-Y R$ & 0 & $3-Y R$ & 0 & -0.2089 & 0.007461 & 1169 & -28.00 \\
\hline Time*Treatmt & $1-Y R$ & 0 & $3-Y R$ & 1 & -0.1685 & 0.007705 & 1169 & -21.87 \\
\hline Time*Treatmt & $1-Y R$ & 1 & $3-Y R$ & 0 & -0.2216 & 0.007426 & 1169 & -29.84 \\
\hline Time*Treatmt & $1-Y R$ & 1 & $3-Y R$ & 1 & -0.1812 & 0.007672 & 1169 & -23.62 \\
\hline Time*Treatmt & $3-Y R$ & 0 & $3-Y R$ & 1 & 0.04037 & 0.007475 & 1169 & 5.40 \\
\hline
\end{tabular}

COMBINED GEN FUNCT 1YR-3YR ANOVA: HARDNESS

21:56 Wednesday, September 9, 2009

The Mixed Procedure

Differences of Least Squares Means

Effect Time Treatment _Time _Treatment Pr $>|t|$ Adjustment Adj P

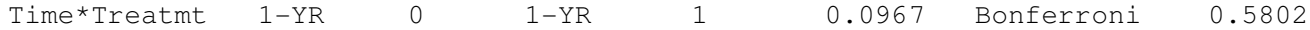

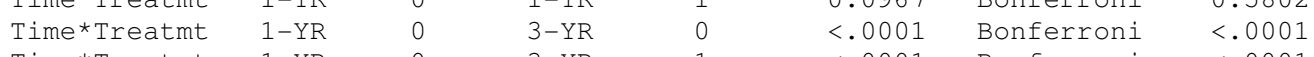

Time*Treatmt 1 -YR 0 3-YR $1 \quad<.0001$ Bonferroni <.0001

Time*Treatment $1-Y R \quad 1 \quad 3-Y R \quad 0 \quad<.0001$ Bonferroni $<.0001$

Time*Treatment 1-YR 1 3-YR $11<$ <.0001 Bonferroni <.0001

Time*Treatment 3-YR $0 \quad 3-Y R \quad 1 \quad<.0001$ Bonferroni $<001$

COMBINED IDEAL FUNCT 1YR-3YR ANOVA: ELASTIC MODULUS

1

21:56 Wednesday, September 9, 2009

The Mixed Procedure

Model Information 


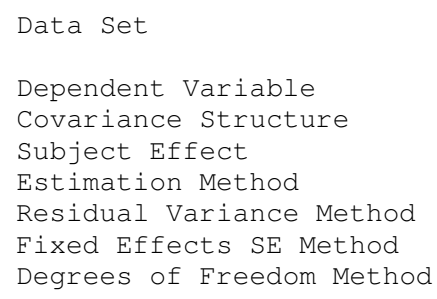

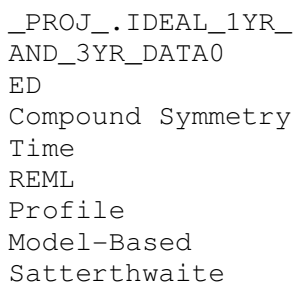

Class Level Information

\begin{tabular}{|c|c|c|}
\hline Class & Levels & Values \\
\hline Treatmt & 2 & 01 \\
\hline Time & 2 & 1-YR 3-YR \\
\hline
\end{tabular}

Dimensions

$\begin{array}{lr}\text { Covariance Parameters } & 2 \\ \text { Columns in X } & 6 \\ \text { Columns in Z } & 0 \\ \text { Subjects } & 2 \\ \text { Max Obs Per Subject } & 659\end{array}$

Number of Observations

Number of Observations Read 1232

Number of Observations Used 1232

Number of Observations Not Used 0

Iteration History

$\begin{array}{rrrr}\text { Iteration } & \text { Evaluations } & -2 \text { Res Log Like } & \text { Criterion } \\ 0 & 1 & 5677.92499952 & \\ 1 & 1 & 5677.92499952 & 0.00000000\end{array}$

Convergence criteria met but final hessian is not positive definite.

Covariance Parameter Estimates

$\begin{array}{lrr}\text { Cov Parm } & \text { Subject } & \text { Estimate } \\ \text { CS } & \text { Time } & 0 \\ \text { Residual } & & 5.8543\end{array}$

COMBINED IDEAL FUNCT 1YR-3YR ANOVA: ELASTIC MODULUS 2 21:56 Wednesday, September 9, 2009

The Mixed Procedure

Fit Statistics

$\begin{array}{ll}-2 \text { Res Log Likelihood } & 5677.9 \\ \text { AIC (smaller is better) } & 5681.9 \\ \text { AICC (smaller is better) } & 5681.9 \\ \text { BIC (smaller is better) } & 5679.3\end{array}$

Null Model Likelihood Ratio Test

$\mathrm{DF}$

Chi-Square

Pr > ChiSq 
Solution for Fixed Effects

\begin{tabular}{|c|c|c|c|c|c|c|c|}
\hline \multirow[b]{2}{*}{ Effect } & \multirow[b]{2}{*}{ Time } & \multicolumn{6}{|c|}{ Standard } \\
\hline & & Treatmt & Estimate & Error & $\mathrm{DF}$ & t Value & $\operatorname{Pr}>|t|$ \\
\hline Treatmt & & 0 & 8.7734 & 0.1340 & 1228 & 140.09 & $<.0001$ \\
\hline Treatmt & & 1 & 13.8974 & 0.1326 & 1228 & 104.81 & $<.0001$ \\
\hline Treatmt*Time & $1-Y R$ & 0 & -6.3917 & 0.1966 & 1228 & -32.51 & $<.0001$ \\
\hline Treatmt*Time & $3-Y R$ & 0 & 0 & . & . & & . \\
\hline Treatmt*Time & $1-Y R$ & 1 & -0.1774 & 0.1943 & 1228 & -0.91 & 0.3616 \\
\hline Treatmt*Time & $3-Y R$ & 1 & 0 & & & & \\
\hline
\end{tabular}

Type 3 Tests of Fixed Effects

$\begin{array}{lcclccc} & \text { Num } & \text { Den } & & & \\ \text { Effect } & \text { DF } & \text { DF } & \text { Chi-Square } & \text { F Value } & \text { Pr }>\text { ChiSq } & \text { Pr }>\text { F } \\ \text { Treatmt } & 2 & 1228 & 45311.7 & 22655.9 & <.0001 & <.0001 \\ \text { Treatmt*Time } & 2 & 1228 & 1058.00 & 529.00 & <.0001 & <.0001\end{array}$

Least Squares Means

$\begin{array}{lcccccrc}\text { Effect } & \text { Time } & \text { Treatmt } & \text { Estimate } & \begin{array}{l}\text { Standard } \\ \text { Error }\end{array} & \text { DF } & \text { t Value } & \text { Pr }>|t| \\ & & & & & & & \\ \text { Treatmt*Time } & \text { 1-YR } & 0 & 12.3816 & 0.1438 & 1228 & 86.09 & <.0001 \\ \text { Treatmt*Time } & \text { 3-YR } & 0 & 18.7734 & 0.1340 & 1228 & 140.09 & <.0001 \\ \text { Treatmt*Time } & \text { 1-YR } & 1 & 13.7201 & 0.1421 & 1228 & 96.56 & <.0001 \\ \text { Treatmt*Time } & \text { 3-YR } & 1 & 13.8974 & 0.1326 & 1228 & 104.81 & <.0001\end{array}$

Differences of Least Squares Means

\begin{tabular}{lcrrrrrrr} 
& \multicolumn{1}{c}{} & \multicolumn{7}{c}{ Standard } \\
Effect & Time & Treatmt & _Time & _Treatmt & Estimate & Error & DF & t Value \\
Treatmt*Time & 1-YR & 0 & 3-YR & 0 & -6.3917 & 0.1966 & 1228 & -32.51 \\
Treatmt*Time & 1-YR & 0 & 1-YR & 1 & -1.3384 & 0.2022 & 1228 & -6.62 \\
Treatmt*Time & 1-YR & 0 & 3-YR & 1 & -1.5158 & 0.1956 & 1228 & -7.75 \\
Treatmt*Time & 3-YR & 0 & 1-YR & 1 & 5.0533 & 0.1953 & 1228 & 25.87 \\
Treatmt*Time & 3-YR & 0 & 3-YR & 1 & 4.8760 & 0.1885 & 1228 & 25.86 \\
Treatmt*Time & 1-YR & 1 & 3-YR & 1 & -0.1774 & 0.1943 & 1228 & -0.91
\end{tabular}

$\begin{aligned} & \text { COMBINED IDEAL FUNCT 1YR-3YR ANOVA: ELASTIC MODULUS } 3 \\ & 21: 56 \text { Wednesday, September 9, } 2009\end{aligned}$

The Mixed Procedure

Differences of Least Squares Means

$\begin{array}{lcrccccc}\text { Effect } & \text { Time } & \text { Treatmt } & \text { Time } & \text { _Treatmt } & \text { Pr }>|t| & \text { Adjustment } & \text { Adj P } \\ & & & & & & & \\ \text { Treatmt*Time } & \text { 1-YR } & 0 & \text { 3-YR } & 0 & <.0001 & \text { Bonferroni } & <.0001 \\ \text { Treatmt*Time } & \text { 1-YR } & 0 & \text { 1-YR } & 1 & <.0001 & \text { Bonferroni } & <.0001 \\ \text { Treatmt*Time } & \text { 1-YR } & 0 & \text { 3-YR } & 1 & <.0001 & \text { Bonferroni } & <.0001 \\ \text { Treatmt*Time } & \text { 3-YR } & 0 & \text { 1-YR } & 1 & <.0001 & \text { Bonferroni } & <.0001 \\ \text { Treatmt*Time } & \text { 3-YR } & 0 & \text { 3-YR } & 1 & <.0001 & \text { Bonferroni } & <.0001 \\ \text { Treatmt*Time } & \text { 1-YR } & 1 & \text { 3-YR } & 1 & 0.3616 & \text { Bonferroni } & 1.0000\end{array}$

COMBINED IDEAL FUNCT 1YR-3YR ANOVA: HARDNESS 1

21:56 Wednesday, September 9, 2009

The Mixed Procedure 
Model Information

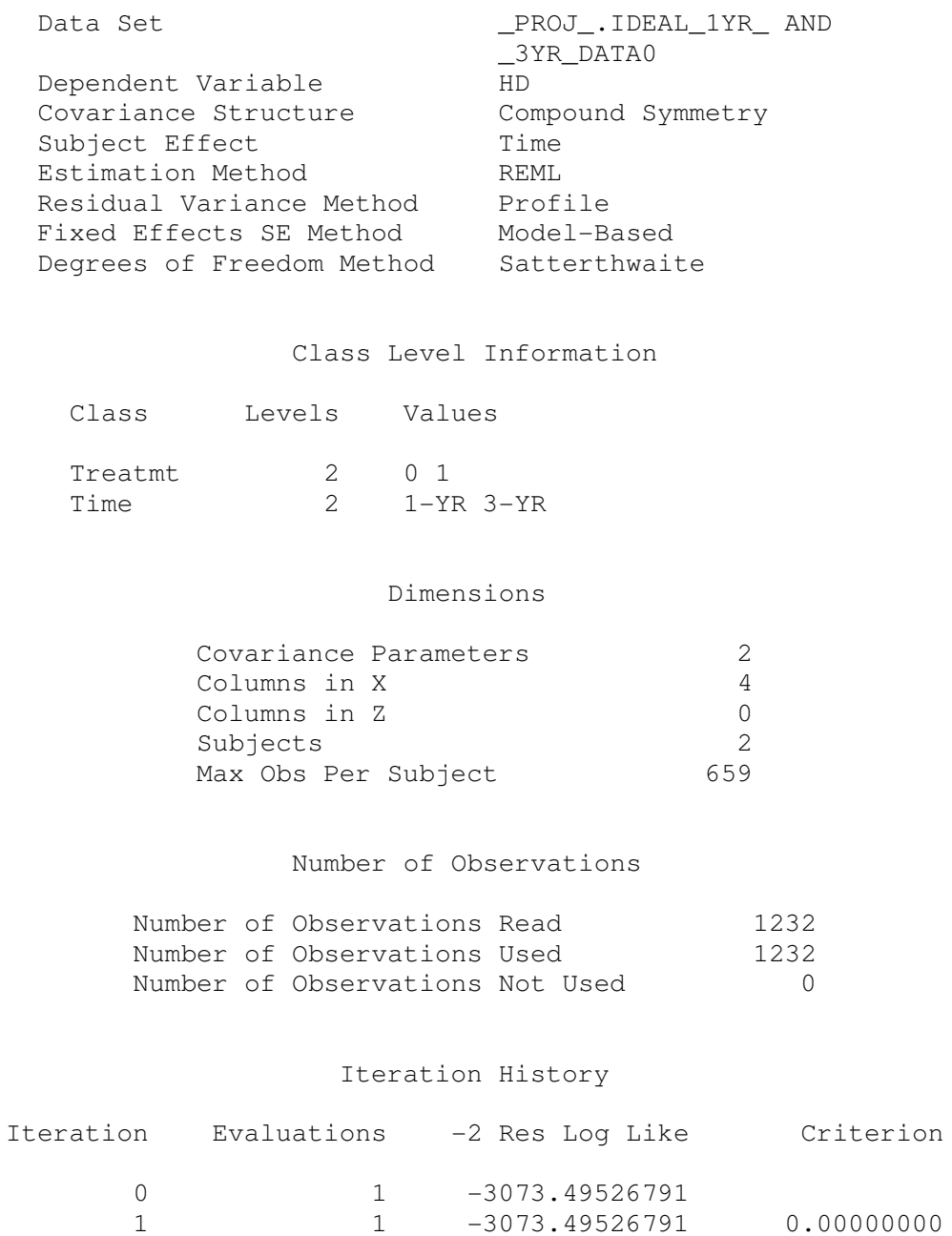


DF

1
Chi-Square

0.00

Pr > ChiSq

1.0000

Solution for Fixed Effects

\begin{tabular}{|c|c|c|c|c|c|c|c|}
\hline & & & & Standard & & & \\
\hline Effect & Time & Treatmt & Estimate & Error & $\mathrm{DF}$ & t Value & $\operatorname{Pr}>|t|$ \\
\hline Treatmt* Time & $1-Y R$ & 0 & 0.4047 & 0.004077 & 1228 & 99.25 & $<.0001$ \\
\hline Treatmt*Time & $3-Y R$ & 0 & 0.5498 & 0.003799 & 1228 & 144.74 & $<.0001$ \\
\hline Treatmt*Time & $1-Y R$ & 1 & 0.3950 & 0.004027 & 1228 & 98.08 & $<.0001$ \\
\hline Treatmt*Time & $3-Y R$ & 1 & 0.5063 & 0.003758 & 1228 & 134.71 & $<.0001$ \\
\hline
\end{tabular}

Type 3 Tests of Fixed Effects

$\begin{array}{llccccc}\text { Effect } & \begin{array}{l}\text { Num } \\ \text { DF }\end{array} & \begin{array}{l}\text { Den } \\ \text { DF }\end{array} & \text { Chi-Square } & \text { F Value } & \text { Pr }>\text { ChiSq } & \text { Pr }>\text { F } \\ \text { Treatmt*Time } & 4 & 1228 & 58564.9 & 14641.2 & <.0001 & <.0001\end{array}$

Least Squares Means

\begin{tabular}{|c|c|c|c|c|c|c|c|}
\hline \multirow[b]{2}{*}{ Effect } & \multirow[b]{2}{*}{ Time } & \multicolumn{6}{|c|}{ Standard } \\
\hline & & Treatmt & Estimate & Error & $\mathrm{DF}$ & t Value & $\operatorname{Pr}>|t|$ \\
\hline Treatmt*Time & $1-Y R$ & 0 & 0.4047 & 0.004077 & 1228 & 99.25 & $<.0001$ \\
\hline Treatmt* Time & $3-Y R$ & 0 & 0.5498 & 0.003799 & 1228 & 144.74 & $<.0001$ \\
\hline Treatmt*Time & $1-\mathrm{YR}$ & 1 & 0.3950 & 0.004027 & 1228 & 98.08 & $<.0001$ \\
\hline Treatmt*Time & $3-Y R$ & 1 & 0.5063 & 0.003758 & 1228 & 134.71 & $<.0001$ \\
\hline
\end{tabular}

Differences of Least Squares Means

\begin{tabular}{|c|c|c|c|c|c|c|c|c|}
\hline Effect & Time & Treatmt & _Time & _Treatmt & Estimate & $\begin{array}{c}\text { Standard } \\
\text { Error }\end{array}$ & $\mathrm{DF}$ & t Value \\
\hline Treatmt*Time & $1-Y R$ & 0 & $3-Y R$ & 0 & -0.1451 & 0.005572 & 1228 & -26.05 \\
\hline Treatmt*Time & $1-Y R$ & 0 & $1-\mathrm{YR}$ & 1 & 0.009646 & 0.005731 & 1228 & 1.68 \\
\hline Treatmt*Time & $1-Y R$ & 0 & $3-Y R$ & 1 & -0.1016 & 0.005545 & 1228 & $-18 \cdot 33$ \\
\hline Treatmt*Time & $3-Y R$ & 0 & $1-Y R$ & 1 & 0.1548 & 0.005536 & 1228 & 27.96 \\
\hline Treatmt*Time & $3-Y R$ & 0 & $3-Y R$ & 1 & 0.04351 & 0.005344 & 1228 & 8.14 \\
\hline Treatmt*Time & $1-Y R$ & 1 & $3-Y R$ & 1 & -0.1113 & 0.005509 & 1228 & -20.20 \\
\hline
\end{tabular}

COMBINED IDEAL FUNCT 1YR-3YR ANOVA: HARDNESS 3

21:56 Wednesday, September 9, 2009

The Mixed Procedure

Differences of Least Squares Means

\begin{tabular}{|c|c|c|c|c|c|c|c|}
\hline Effect & Time & Treatmt & _Time & _Treatmt & $\operatorname{Pr}>|t|$ & Adjustment & $\operatorname{Adj} P$ \\
\hline Treatmt*Time & $1-Y R$ & 0 & $3-Y R$ & 0 & $<.0001$ & Bonferroni & $<.0001$ \\
\hline Treatmt*Time & $1-Y R$ & 0 & $1-Y R$ & 1 & 0.0926 & Bonferroni & 0.5555 \\
\hline Treatmt*Time & $1-Y R$ & 0 & $3-Y R$ & 1 & $<.0001$ & Bonferroni & $<.0001$ \\
\hline Treatmt*Time & $3-Y R$ & 0 & $1-Y R$ & 1 & $<.0001$ & Bonferroni & $<.0001$ \\
\hline Treatmt*Time & $3-Y R$ & 0 & $3-Y R$ & 1 & $<.0001$ & Bonferroni & $<.0001$ \\
\hline Treatmt* Time & $1-Y R$ & 1 & $3-Y R$ & 1 & $<.0001$ & Bonferroni & $<.0001$ \\
\hline
\end{tabular}

ENERGY 1YR ANOVA: PLASTIC WORK 
The Mixed Procedure

Model Information

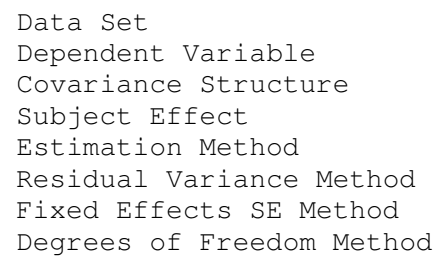

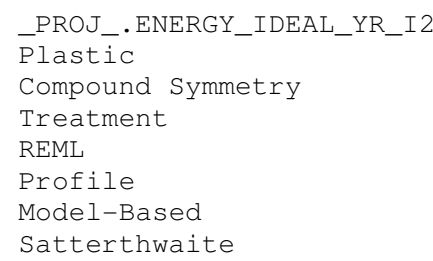

The Mixed Procedure

Fit Statistics

$\begin{array}{ll}-2 \text { Res Log Likelihood } & 5406.2 \\ \text { AIC (smaller is better) } & 5410.2 \\ \text { AICC (smaller is better) } & 5410.3 \\ \text { BIC (smaller is better) } & 5407.6\end{array}$

Null Model Likelihood Ratio Test

$\mathrm{DF}$

Chi-Square

Pr > ChiSq 


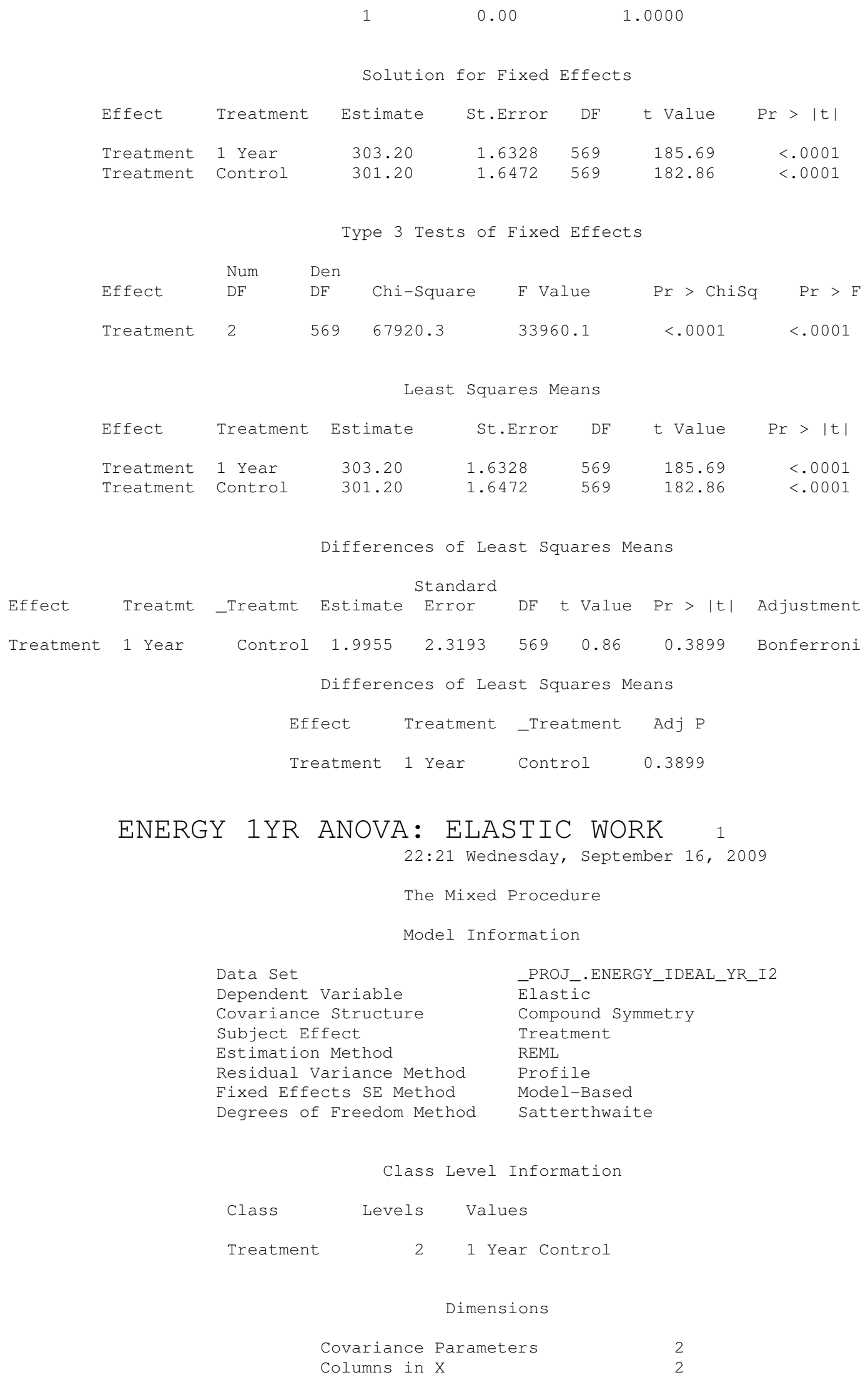


$\begin{array}{lr}\text { Columns in Z } & 0 \\ \text { Subjects } & 2 \\ \text { Max Obs Per Subject } & 288\end{array}$

Number of Observations

Number of Observations Read 571

Number of Observations Not Used

Iteration History

$\begin{array}{rrrr}\text { Iteration } & \text { Evaluations } & -2 \text { Res Log Like } & \text { Criterion } \\ 0 & 1 & 3964.38202143 & \\ 1 & 1 & 3964.38202143 & 0.00000000\end{array}$

Convergence criteria met.

Covariance Parameter Estimates

Cov Parm Subject Estimate

CS Treatment 0

Residual 60.9180

ENERGY 1YR ANOVA: ELASTIC WORK

2

22:21 Wednesday, September 16, 2009

The Mixed Procedure

Fit Statistics

$\begin{array}{ll}-2 \text { Res Log Likelihood } & 3964.4 \\ \text { AIC (smaller is better) } & 3968.4 \\ \text { AICC (smaller is better) } & 3968.4 \\ \text { BIC (smaller is better) } & 3965.8\end{array}$

Null Model Likelihood Ratio Test

$\begin{array}{rrr}\text { DF } & \text { Chi-Square } & \text { Pr }>\text { Chisq } \\ 1 & 0.00 & 1.0000\end{array}$

Solution for Fixed Effects

$\begin{array}{lcccccc}\text { Effect } & \text { Treatment } & \text { Estimate } & \text { St.Error } & \text { DF } & t \text { Value } & \text { Pr }>\text { I } \mid \\ \text { Treatment } & \text { 1 Year } & 64.3176 & 0.4599 & 569 & 139.85 & <.0001 \\ \text { Treatment } & \text { Control } & 72.7549 & 0.4640 & 569 & 156.81 & <.0001\end{array}$

Type 3 Tests of Fixed Effects

$\begin{array}{lcccccr}\text { Effect } & \text { Num } & \text { Den } & & & \\ & \text { DF } & \text { DF } & \text { Chi-Square } & \text { F Value } & \text { Pr }>\text { ChiSq } & \text { Pr }>\text { F } \\ \text { Treatment } & 2 & 569 & 44147.6 & 22073.8 & <.0001 & <.0001\end{array}$

Effect

Standard

Treatment

1 Year $\quad 64.3176$

$0.4599 \quad 569$

t Value

$\operatorname{Pr}>|t|$

$<.0001$ 


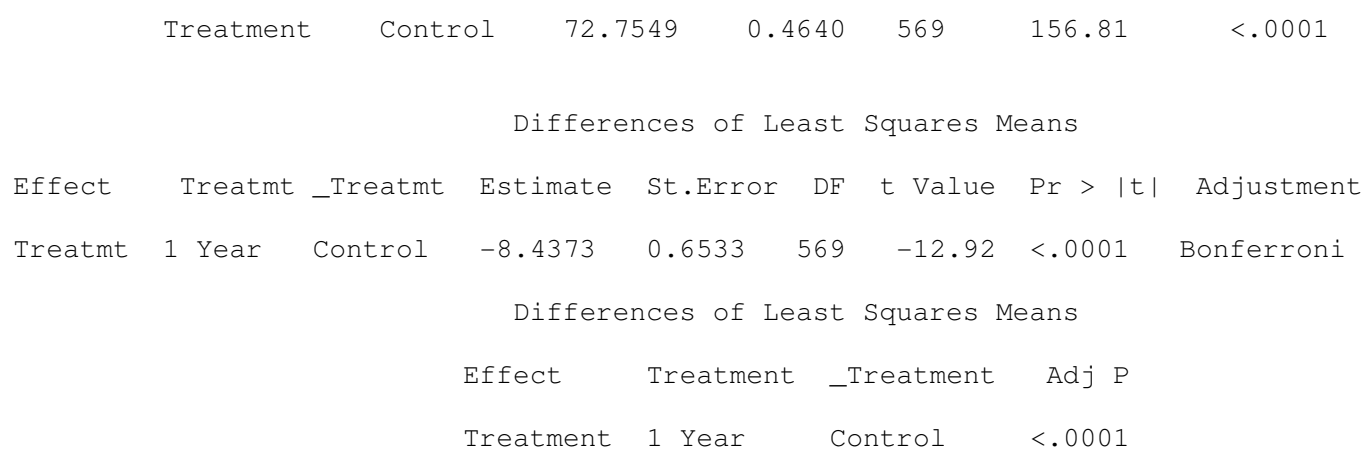

\section{ENERGY 3YR ANOVA: PLASTIC WORK I}

22:21 Wednesday, September 16, 2009

The Mixed Procedure

Model Information

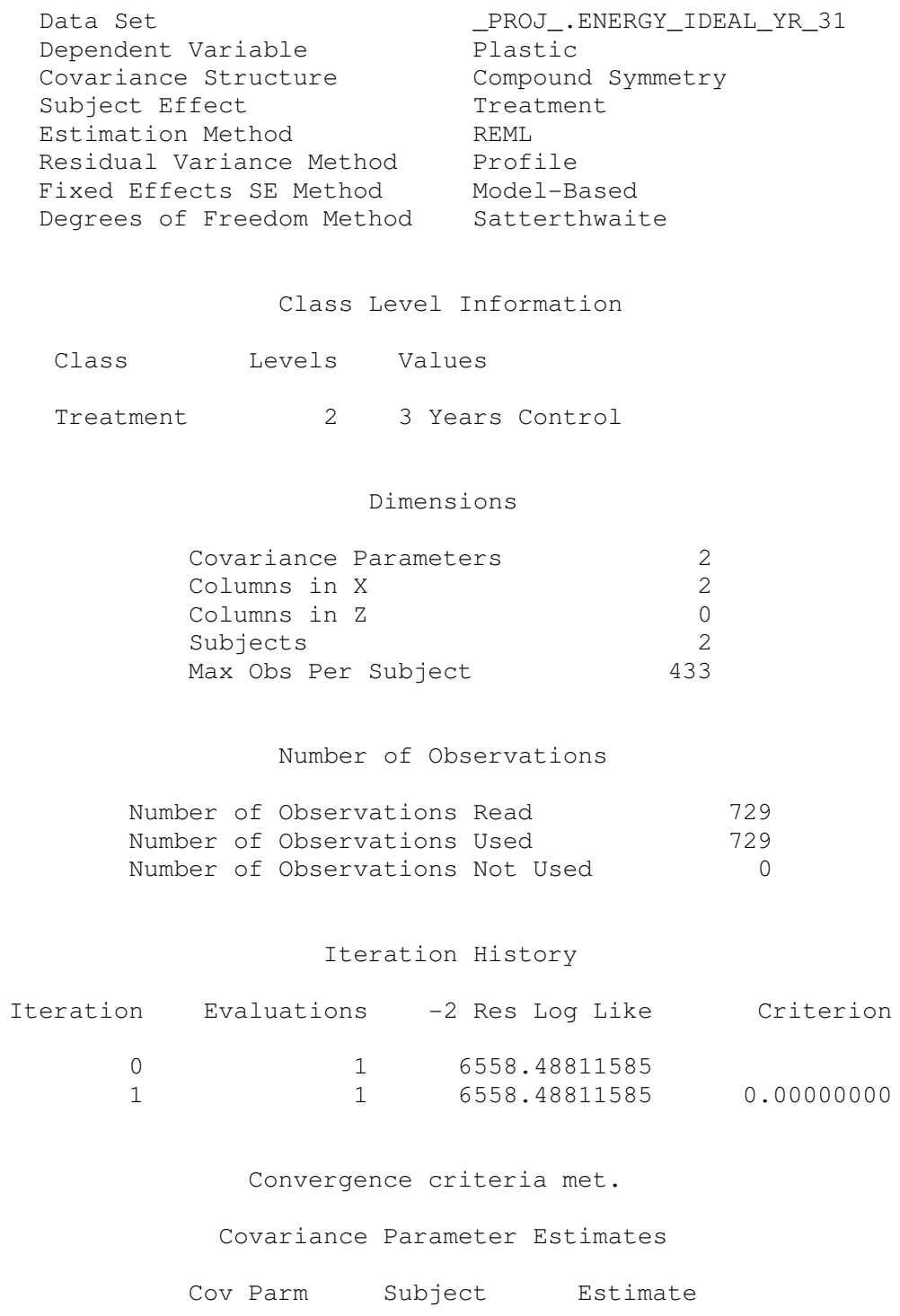




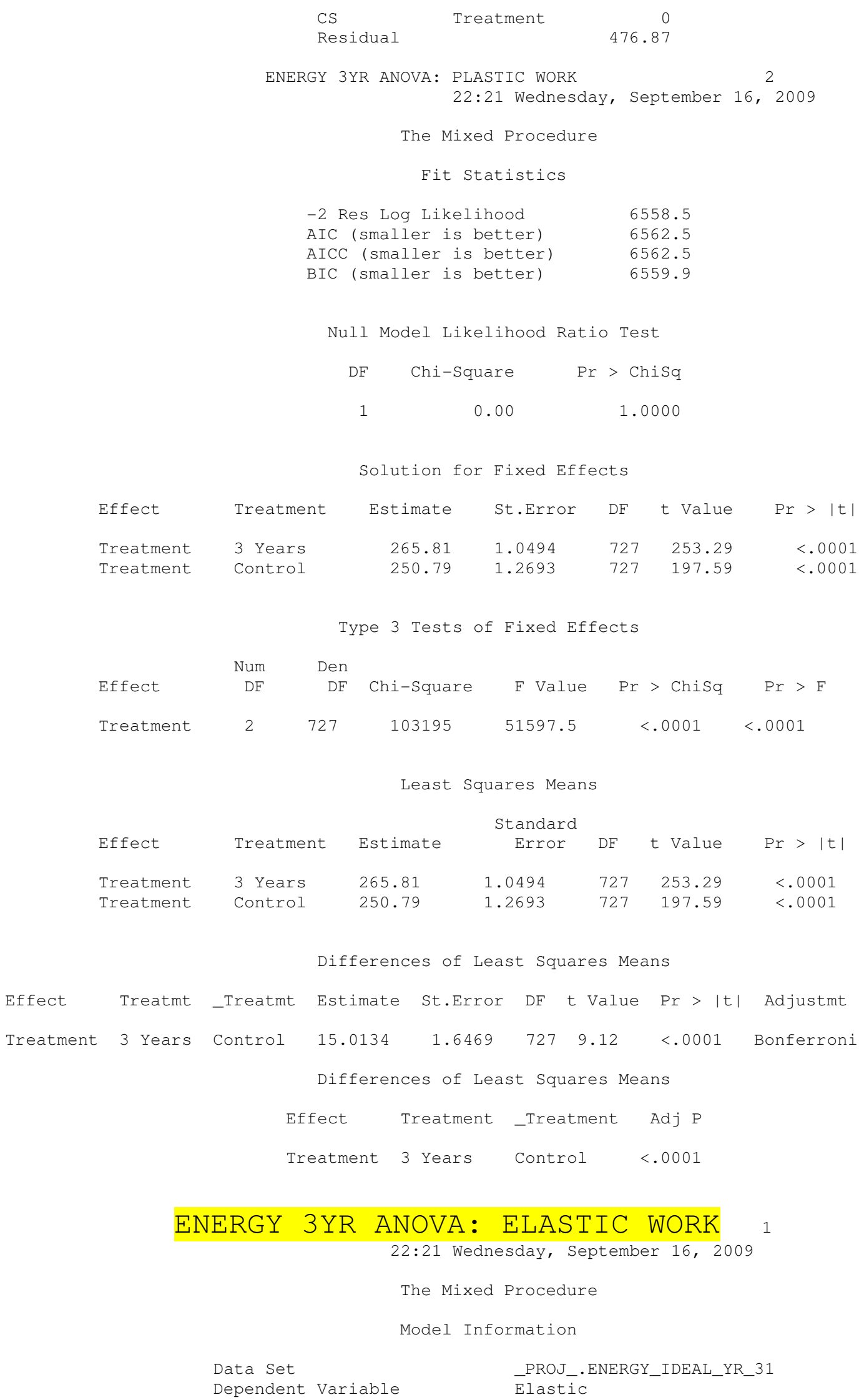




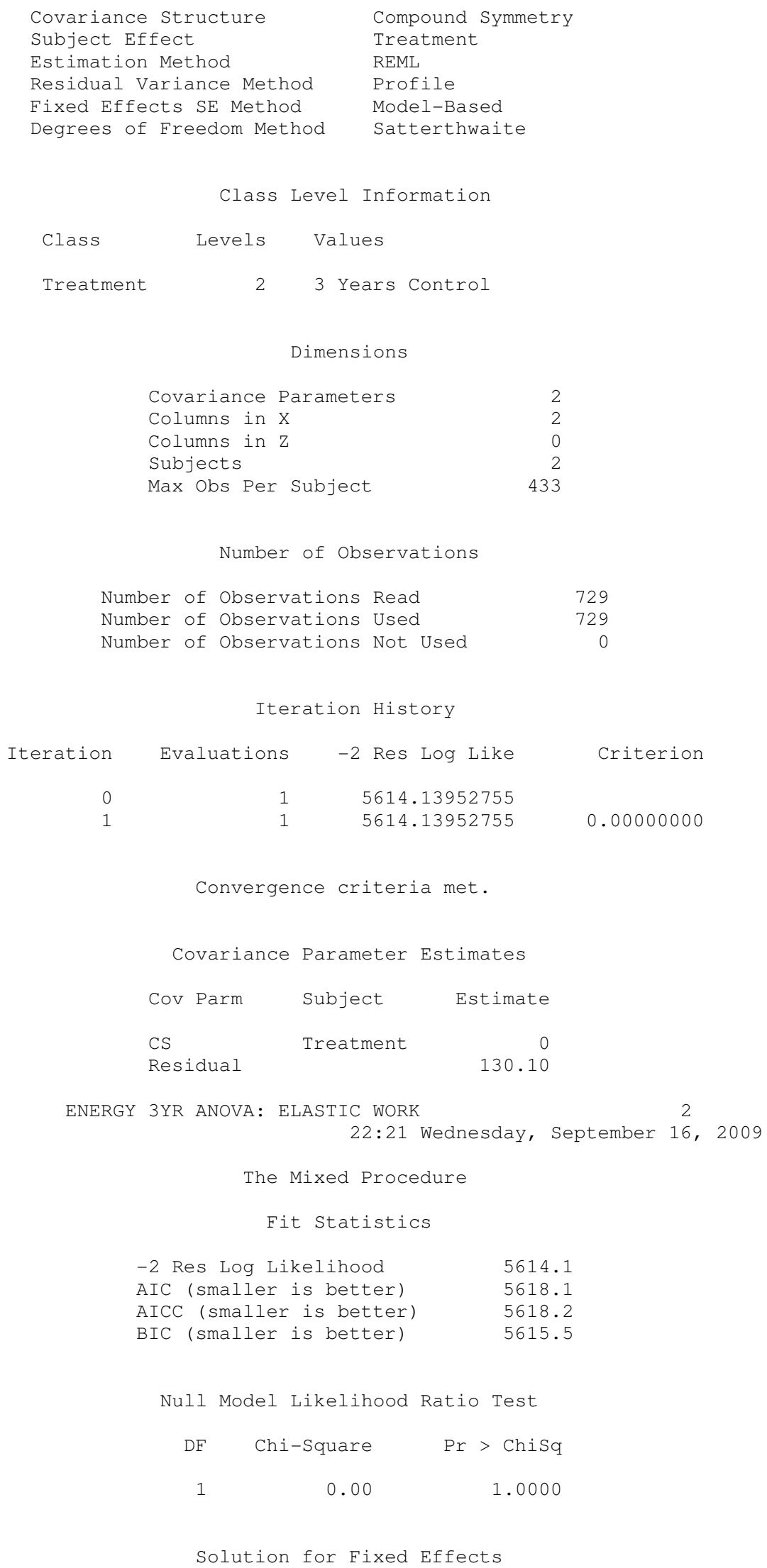

ENERGY 3YR ANOVA: ELASTIC WORK

The Mixed Procedure

Fit Statistics

$\begin{array}{ll}-2 \text { Res Log Likelihood } & 5614.1 \\ \text { AIC (smaller is better) } & 5618.1 \\ \text { AICC (smaller is better) } & 5618.2 \\ \text { BIC (smaller is better) } & 5615.5\end{array}$

Null Model Likelihood Ratio Test 


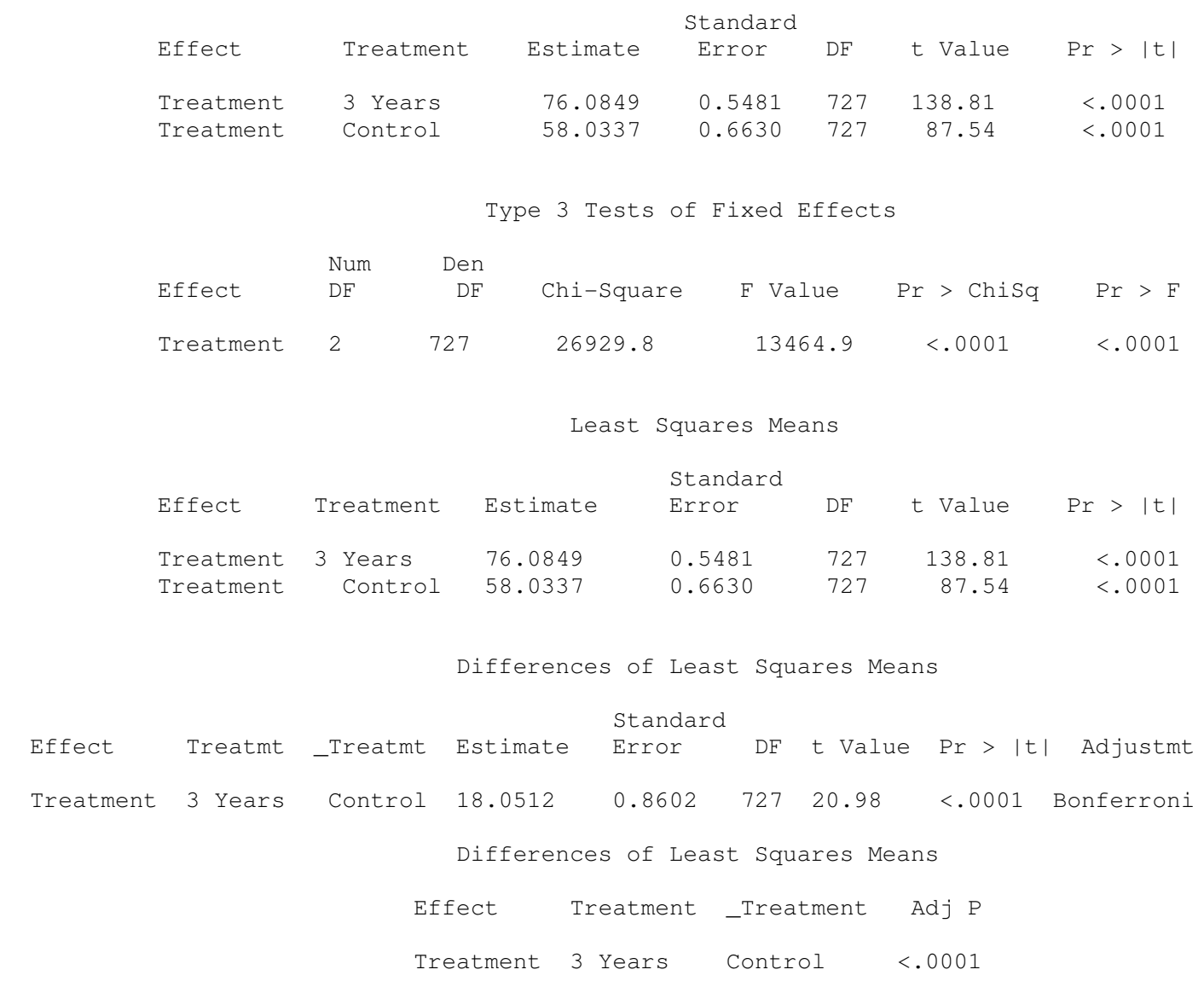

ENERGY COMBINED 1YR AND 3YR ANOVA: PLASTIC WORK 1

22:57 Monday, September 14, 2009

The Mixed Procedure

Model Information

$\begin{array}{ll}\text { Data Set } & \text { _PROJ_.IMPORTED4 } \\ \text { Dependent Variable } & \text { Plastic_Work } \\ \text { Covariance Structure } & \text { Compound Symmetry } \\ \text { Subject Effect } & \text { Time } \\ \text { Estimation Method } & \text { REML } \\ \text { Residual Variance Method } & \text { Profile } \\ \text { Fixed Effects SE Method } & \text { Model-Based } \\ \text { Degrees of Freedom Method } & \text { Satterthwaite }\end{array}$

Class Level Information

\begin{tabular}{lrc} 
Class & Levels & Values \\
Time & 2 & 1-YR 3-YR \\
Treatment & 2 & ALENDRO CONTROL \\
& & \\
& \multicolumn{3}{c}{ Dimensions } \\
& \multicolumn{3}{c}{2} \\
Covariance Parameters & 4 \\
Columns in X & 0 \\
Columns in Z & 2 \\
Subjects & 729 \\
Max Obs Per Subject
\end{tabular}


Number of Observations

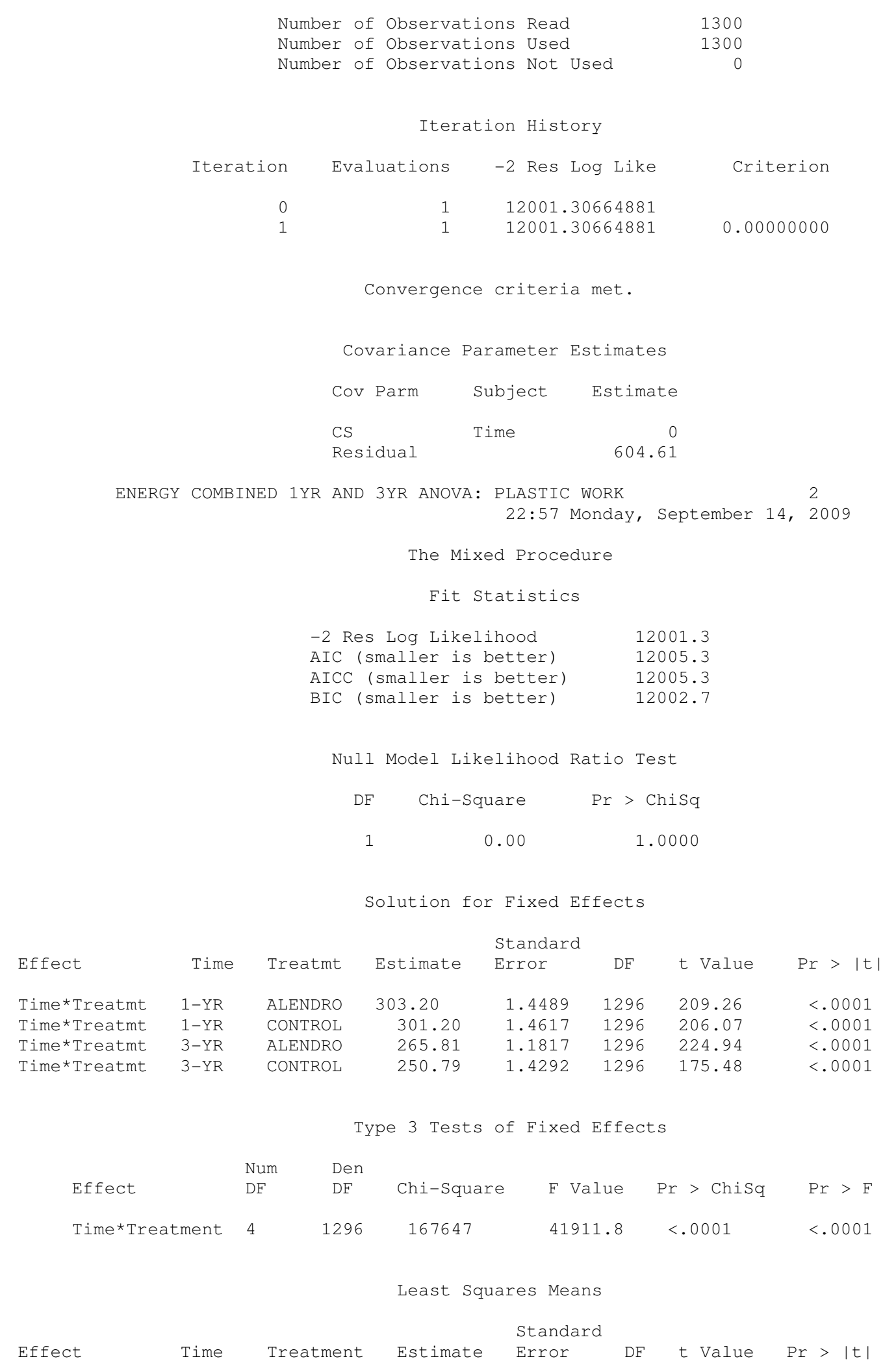




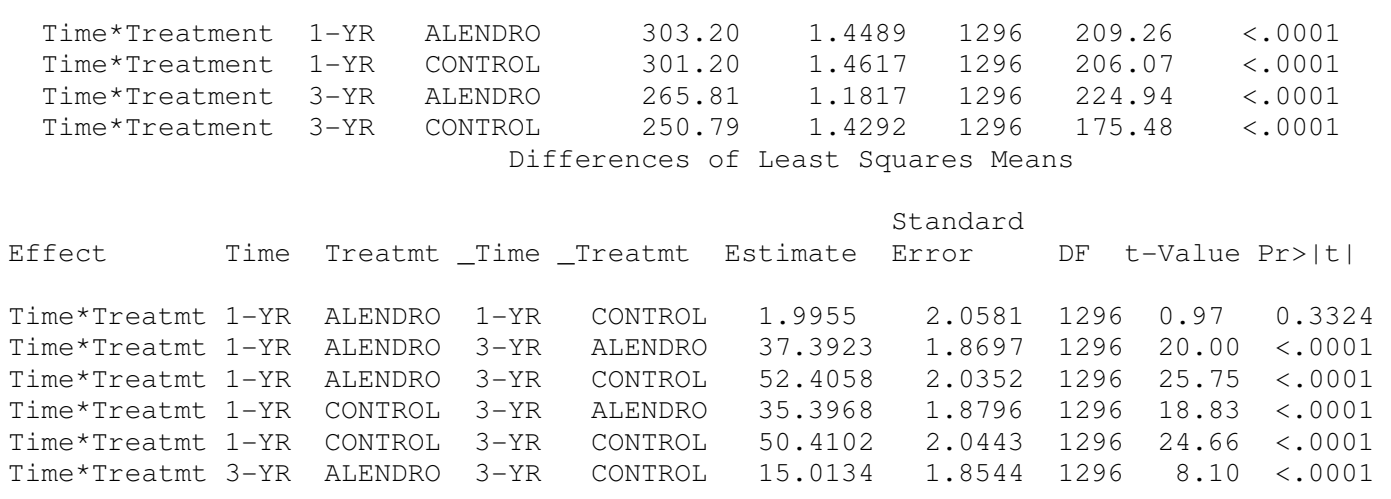

Differences of Least Squares Means

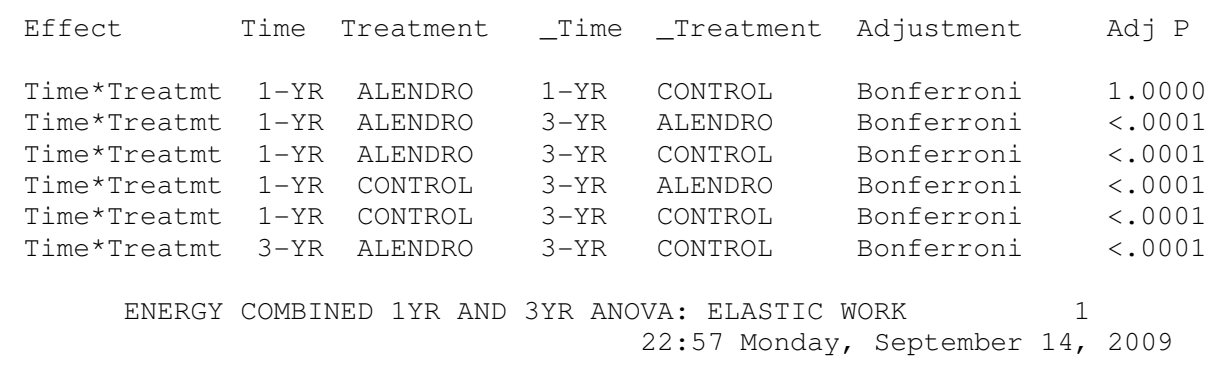

The Mixed Procedure

Model Information

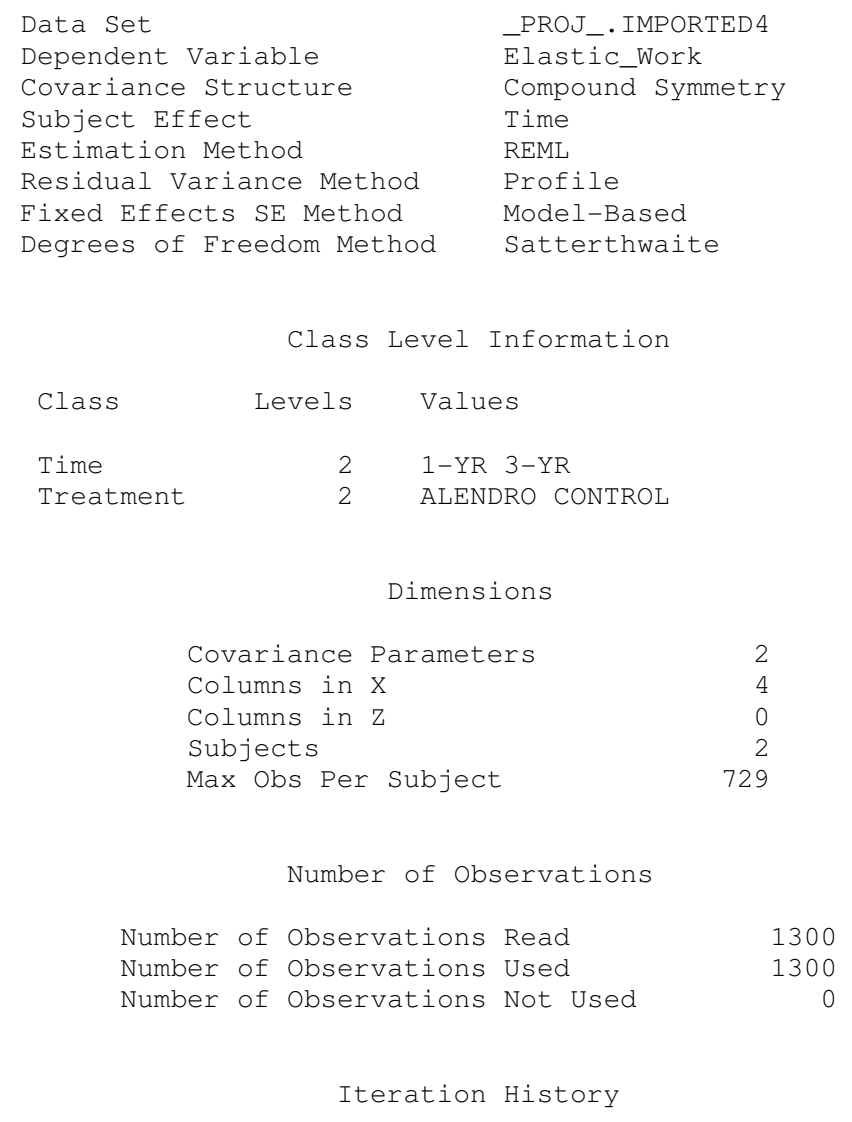




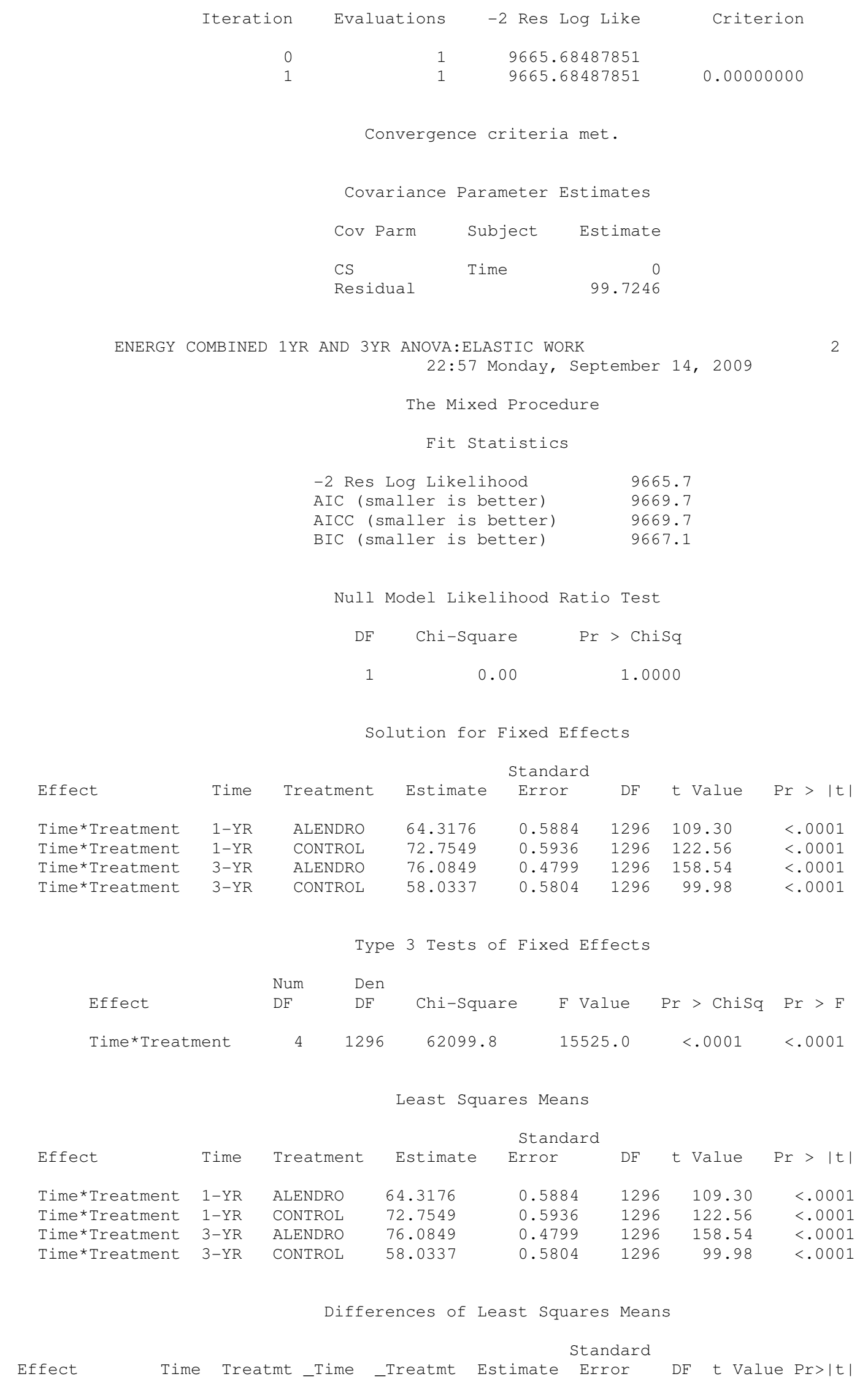


Time*Treatmt 1-YR ALENDRO 1-YR

Time*Treatmt 1-YR ALENDRO 3-YR

Time*Treatmt 1-YR ALENDRO 3-YR

Time*Treatmt 1-YR CONTROL 3-YR

Time* Treatmt 1-YR CONTROL 3-YR

Time* Treatmt 3-YR ALENDRO 3-YR
CONTROL

ALENDRO

CONTROL

ALENDRO

CONTROL

CONTROL

$\begin{array}{rlrr}-8.4373 & 0.8359 & 1296 & -10.09<.0001 \\ -11.7673 & 0.7593 & 1296 & -15.50<.0001 \\ 6.2840 & 0.8265 & 1296 & 7.60<.0001 \\ -3.3299 & 0.7633 & 1296 & -4.36<.0001 \\ 14.7213 & 0.8302 & 1296 & 17.73<.0001 \\ 18.0512 & 0.7531 & 1296 & 23.97<.0001\end{array}$

$23.97<.0001$

\begin{tabular}{|c|c|c|c|c|c|c|}
\hline Effect & Time & Treatment & _Time & _Treatment & Adjustment & $\operatorname{Adj} P$ \\
\hline Time*Treatment & $1-\mathrm{YR}$ & ALENDRO & $1-Y R$ & CONTROL & Bonferroni & $<.0001$ \\
\hline Time*Treatment & $1-Y R$ & ALENDRO & $3-Y R$ & ALENDRO & Bonferroni & $<.0001$ \\
\hline Time*Treatment & $1-Y R$ & ALENDRO & $3-Y R$ & CONTROL & Bonferroni & $<.0001$ \\
\hline Time* Treatment & $1-Y R$ & CONTROL & $3-Y R$ & ALENDRO & Bonferroni & $<.0001$ \\
\hline Time*Treatment & $1-Y R$ & CONTROL & $3-Y R$ & CONTROL & Bonferroni & $<.0001$ \\
\hline Time*Treatment & $3-Y R$ & ALENDRO & $3-Y R$ & CONTROL & Bonferroni & $<.0001$ \\
\hline
\end{tabular}

t-Test: Paired Two Sample for Ideal and General Function Analysis Means: HARDNESS

\begin{tabular}{|c|c|c|c|}
\hline & $I D E A L \quad(A)$ & GEN & $(B)$ \\
\hline Mean & 0.47002884 & & 0.65767811 \\
\hline Variance & 0.00940966 & & 0.01768277 \\
\hline Observations & 1225 & & 1225 \\
\hline Pearson Correlation & 0.99999331 & & \\
\hline Hypothesized Mean Difference & 0 & & \\
\hline$d f$ & 1224 & & \\
\hline t stat & -182.56074 & & \\
\hline $\mathrm{P}(\mathrm{T}<=\mathrm{t})$ one-tail & 0 & & \\
\hline t Critical one-tail & 1.64609949 & & \\
\hline$P(T<=t)$ two-tail & 0 & & \\
\hline t Critical two-tail & 1.96190395 & & \\
\hline
\end{tabular}

t-Test: Paired Two Sample for Ideal and General Function Analysis Means: ELASTIC MODULUS

\begin{tabular}{lcc}
\hline & IDEAL $\quad(A)$ & GEN $(B)$ \\
\hline Mean & 14.5064063 & 17.8026358
\end{tabular}




$\begin{array}{lrr}\text { Variance } & 10.6777039 & 15.9837107 \\ \text { Observations } & 1225 & 1225 \\ \text { Pearson Correlation } & 0.999974 & 0 \\ \text { Hypothesized Mean Difference } & 1224 & 0 \\ \text { df } & -157.87564 \\ t \text { Stat } & 1.64609949 \\ \text { P (T<=t) one-tail } & 0 \\ t \text { Critical one-tail } & 1.96190395 \\ \text { P (T<=t) two-tail } & 0 \\ t \text { Critical two-tail } & \end{array}$


